\title{
Cretaceous theropods from India: A' review of specimens described by Huene and Matley (1933)
}

\author{
Fernando E. NOVAS ${ }^{1,3}$, Federico L. AGNOLIN ${ }^{1}$ and Saswati BANDYOPADHYAY ${ }^{2}$
}

\begin{abstract}
Museo Argentino de Ciencias Naturales «B. Rivadavia», Av. A. Gallardo 470, (1405) Buenos Aires, Argentina fernovas@yahoo.com.ar 2Geological Studies Unit, Indian Statistical Institute, 203 Barrackpore Trunk Road,

Kolkata 700 035, India. saswati@isical.ac.in "Researcher of CONICET.
\end{abstract}

\begin{abstract}
The Late Cretaceous (Maastrichtian) Lameta Formation of central India has yielded dissociated elements of a variety of predatory dinosaurs, most of them coming from a quarry named the "Carnosaur bed." The materials were described by Huene and Matley nearly 70 years ago. They recognized nine theropod species, which they sorted out into the theropod subgroups "Carnosauria" and "Coelurosauria». Huene and Matley also described a considerable amount of theropod hindlimb bones (e.g., femora, tibiae, metatarsals, and pedal phalanges) that they cotuld not refer to any of these species, but vaguely interpreted as corresponding to "allosaurid" or "coelurosaurid" theropods. We reviewed the available collection of Cretaceous theropods from Bara Simla housed at the Geological Survey of India, Kolkata, arriving to the following conclusions. 1) Indosuchus and Indosaurus are abelisaurids, as recognized by previous authors, but available information is not enough to judge whether they are synonyms; 2 ) Laevisuchus indicus is a small abelisauroid, related to Noascurus and Masiakasaurus on the basis of their peculiar cervical vertebrae; 3) the controversial taxa "Compsosuchus», "Dryptosauroides", "Ornithomimoides", and «ubbulpuria» are represented by isolated vertebrae corresponding to different portions of the neck and tail, and also exhibit abelisauroid features; 4) hindlimb bones originally referred to as "allosaurid" and "coelurosaurian" also exhibit abelisauroid characters, and bones of large size are tentatively referred to as corresponding to Indosuchus or Indosaurus, whereas some pedal bones of smaller size may belong to Laevisuchus; 5 ) two kinds of abelisaurid feet are apparent: one in which the phalanges of digit III and IV are robust, and another type in which the phalanges of digit IV are transversely narrow and dorsoventrally deep. This review demonstrates that all of the theropod elements discovered at the "Carnosaur bed" belong to a single theropod clade, the Abelisauroidea.
\end{abstract}

Key words: Theropods, Abelisaurids, Lameta Formation, Cretaceous, India.

The only available comprehensive contribution on Cretaceous theropod dinosaurs from India is that of Frederich von Huene and Charles Matley published in 1933. Their descriptions were based on a large, but mixed assemblage of isolated bones collected from a single fossiliferous spot the "Carnosaur bed") within the Late Cretaceous Lameta Group, extensively exposed in the Provinces of Madhya Pradesh, Grujat, and Maharashtra in NW India (Fig. 1; Matley, 1921; Chatterjee, 1978; Chatterjee \& Rudra, 1996). Within this multispecies bone association, Huene and Matley (1933) recognized the following nine species of Cretaceous predatory dinosaurs: Indosuchus raptorius and Indosaurus matleyi, both coined on the basis of incomplete basicrania, and Compsosuchus solus, Laevisuchus indicus, Jubbulpuria tenuis, Coeluroides largus, Dryptosauroides grandis, Ornithomimoides mobilis, and Ornithomimoides (?) barasimlensis, coined on the basis of isolated vertebrae corresponding to different positions in the vertem bral column.

These authors sorted out the Indian theropods into Carnosauria and Coelurosauria, the main two lineages Huene had previously recognized within predatory dinosaurs (e.g., Huene 1914, 1920). Indosuchus and Indosaurus were considered to be members of the carnosaurian family Allosauridae mainly on the basis of their large size and primitive features resembling the Jurassic Allosaurus, while the remaining seven species were gathered within the Coelurosauria on the basis of their smaller size and more slender proportions. Compsosuchus was related to the Jurassic Compsognathus, whereas Laevisuchus, Jubbulpuria, Coeluroides, and Dryptosauroides were assembled within the "Coeluridae", a group that in Huene's concept also included, among others, the Jurassic Ornitholestes hermanni and Coelurus agilis (see for example, Huene, 1956). In addition, Ornithomimoides mobilis and 


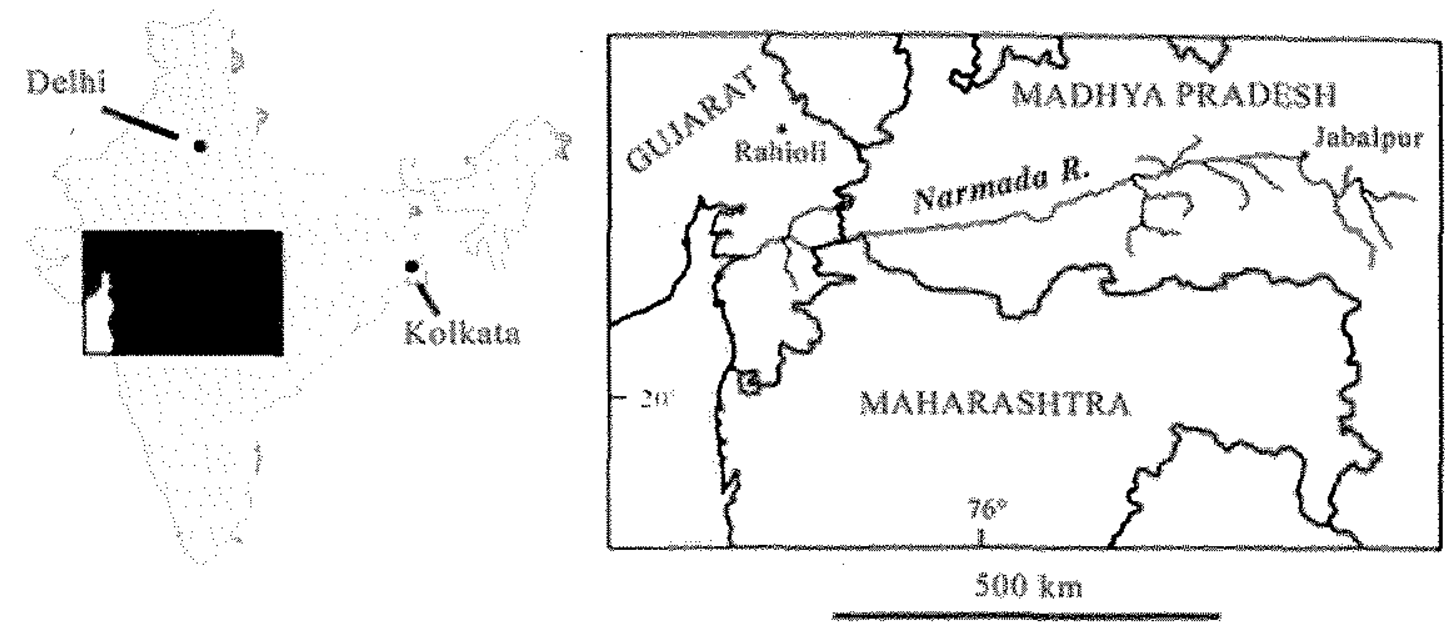

Fig. 1. Map of India showing the Late Cretaceous (Maastrichtian) fossil site at Jabalpur.

Ornithomimoides (?) barasimlensis were referred by Huene and Matley (1933) and later by Huene (1956) to the Ornithomimidae. But, most of the bones collected from the "Carnosaur bed" (e.g., several skull elements, teeth, vertebrae, hemapophyses, and pelvic and hindlimb bones) could not be referred to any of the species listed above, and thus they were considered by Huene and Matley either as Allosauridae, Carnosauria or Coelurosauria of indeterminable relationships.

Subsequent taxonomic interpretations of the Indian theropods were seriously obstructed by the mixed condition of the numerous, diverse elements recovered from the "Carnosaur bed". Sorting out these skeletal elements into discrete specimens transformed into an impossible task, a problem that Huene and Matley and many other researchers (including us) were unable to resolve. Moreover, original specimens were not described again in later studies (e.g., Romer, 1956; Walker, 1964; Chatterjee, 1978; Molnar, 1990; Molnar et al., 1990; Norman, 1990) mainly because they were misplaced at the collections of the Geological Survey of India, thus further delaying the elucidation of the phylogenetic relationships of the Indian theropods.

A turning point in the understanding on the systematic affinities of these dinosaurs, at least for Indosaurus matleyi and Indosuchus raptorius, was reached after Abelisaurus comahuensis and Carnotaurus sastrei were described from Late Cretaceous beds of Patagonia. Abelisaurus was described as a representative of a new clade of theropod dinosaurs, the Abelisauridae (Bonaparte \& Novas, 1985, Bonaparte et al., 1990), to which new members were subsequently added (e.g.,
Xenotarsosaurus bonapartei, Ilokelesia aguadagrandensis, Majungatholus atopus, Aucasaurus garridoi; Martínez et al.1987, Bonaparte, 1991b; Novas, 1997; Sampson et al., 1998; Coria \& Salgado 1998; Coria et al., 2002). Bonaparte and Novas (1985) pointed out some resemblances shared by Abelisaurus with the Indian taxa Indosuchus and Indosaurus, although more precise systematic statements were later expressed by Bonaparte (1986, 1991b) and Bonaparte et al. (1990). These authors considered both Indosuchus raptorius and Indosaurus matleyi as probable members of Abelisauridae, an interpretation that has gained wide acceptance since then (e.g., Molnar, 1990; Chatterjee \& Rudra, 1996, Sampson et al., 1998; Lamanna et al., 2002). In particular, Molnar (1990) identified several characters shared by the Indian "carnosaurs" and the Patagonian abelisaurids, thus substantiating the original suspicion of Bonaparte and Novas (1985). Consistent progress was produced with the discovery by $\mathrm{S}$. Chatterjee and assistants of a large sample of bones of at least seven abelisaurid specimens referred to as Indosuchus raptorius (Chatterjee \& Rudra, 1996), thus affording more data about the anatomy and taxonomy of this Indian taxon.

However, no major progress was made with regard to the Indian theropod postcranial material. In two previous papers (Novas \& Bandyopadhyay, 1999, 2001), we studied the theropod pedal unguals of the Indian collection, recognizing their abelisaurid nature. This prompted some comprehensive ideas about the systematics of the Indian theropods as a whole. Probably the most relevant interpretations of our 
survey were that Laevisuchus is an abelisauroid diagnosable on the basis of its cervical vertebrae, and that the controversial taxa Compsosuchus, Dryptosauroides, Ornithomimoides, and Jubbulpuria are based on isolated vertebrae corresponding to different portions of the neck and tail, which also exhibit abelisauroid features. Through this "taxonomic purification", the phylogenetic relationships of the Indian theropods can be addressed in a clearer context. In agreement with our interpretations, Carrano et al. (2002) recognized derived features uniting Laevisuchus with other small sized abelisauroids (Noasauridae).

But the "Carnosaur bed" also yielded the remains of Lametasaurus indicus, originally described by Charles Matley (1923) as an armoured ornithischian (i.e., a stegosaur) and consequently restudied by Huene and Matley (1933) in their section on ornithischian dinosaurs. However, Lametasaurus was reinterpreted by Chakravarti (1935) as a member of the Theropoda, and more recently, Wilson et al. (2003) found evidence supporting that Lametasaurus indicus is an abelisaurid theropod. Thus, the "Carnosaur bed" yielded remains of three nominated taxa of large abelisauroids: Indosuchus, Indosaurus and Lametasaurus.

Our current knowledge of Gondwanan abelisauroids, based on associated specimens from Argentina (Abelisaurus, Carnotaurus, Aucasaurus, Ilokelesia, Noasaurus, Velocisaurus, Ligabueino), Madagascar (Majungatholus, Masiakasaurus), and the new theropod material from India (Indosuchus raptorius and Rajasaurus narmadensis; Chatterjee \& Rudra, 1996; Wilson et al., 2003), invites a review of the theropod specimens first described by Huene and Matley in 1933. The aim of the present paper is to offer more information and some new illustrations of such old specimens, comparing them with other abelisaurs with the aim to test previous interpretations.

\section{MATERIALS AND METHODS}

Abbreviations: ANINH, American Museum of Natural History, New York; FMNH PR, Field Museum of Natural History, Chicago; GSI, Geological Survey of India, Kolkata; ISI, Indian Statistical Institute, Kolkata; MACN-CH, Museo Argentino de Ciencias Naturales "Bernardino Rivadavia", Paleontología de Vertebrados (Colección Chubut), Buenos Aires; MCA, Museo "Carlos Ameghino", Cipoletti; UNPSJB-PY, Universidad Nacional de la Patagonia "S. J. Bosco", Comodoro Rivadavia, Chubut; MPM, Museo $\mathrm{P}_{\mathrm{a}-}$ dre Manuel Molina, Río Gallegos, Santa Cruz.
Our primary goal is to recognize the presence of abelisauroid features in the available GSI theropod collection, and secondarily to identify, if possible, derived characters distinctive of the Indian forms. To carry on this task, we have studied most of the bones belonging to the GSI that were described and illustrated by Huene and Matley (1933), as well as bones referred to Indosuchus raptorius housed at the AMNH (see the Appendix for a complete list of theropod specimens considered in the present paper). Available theropod materials are re-described below according to major anatomical regions (e.g., skull and jaw, vertebral column, and hindlimb bones), labeling each specimen (mostly individual bones) under current anatomical terminology. However, for the sake of clarity, some of the specimens are re-described keeping their original generic and specific names (e.g., Indosuchus raptorius, Indosaurus matleyi, Compsosuchus solus, Laevisuchus indicus, Jubbulpuria tenuis, Coeluroides largus, Dryptosauroides grandis, Ornithomimoides mobilis, and Ornithomimoides (?) barasimlensis). Several other bones that were vaguely referred by Huene and Matley (1993) as pertaining to «allosaurids" or "coelurosaurids" are also reviewed. The reason for this categorization is because the above mentioned impossibility in identifying discrete individuals represented by more than a single bone. We follow recent papers (e.g., Bonaparte, 1991b; Novas, 1992; Carrano et al., 2002; Wilson et al., 2003) in considering Abelisauroidea as the node including Abelísauridae plus Noasauridae.

\section{SPECIMEN STUDY}

\section{Theropod taxa based on skull bones}

Two theropod taxa fall within this category: Indosuchus raptorius and Indosaurus matleyi (Huene, 1932; Huene \& Matley, 1933).

Indosuchus raptorius. This taxon was coined on the basis of three basicrania belonging to a large theropod (GSI K20/350, GSI K27/685, and GSI K27/690). From these specimens, GSI $\mathrm{K} 27 / 685$ was designated as lectotype of Indosuchus raptorius by Chatterjee (1978). Since these specimens are currently lost or misplaced in the GSI collections, our available data source is restricted to the information originally offered by Huene and Matley (1933). Skull roofs and basicrania referred to as. Indosuchus exhibit interesting resemblances with abelisaurid theropods in the fronto-lacrimal suture, the la. crimal bone, the parietal crest, the parasphenoid, and the orbitosphenoid (Fig. 2). In specimen GSI 

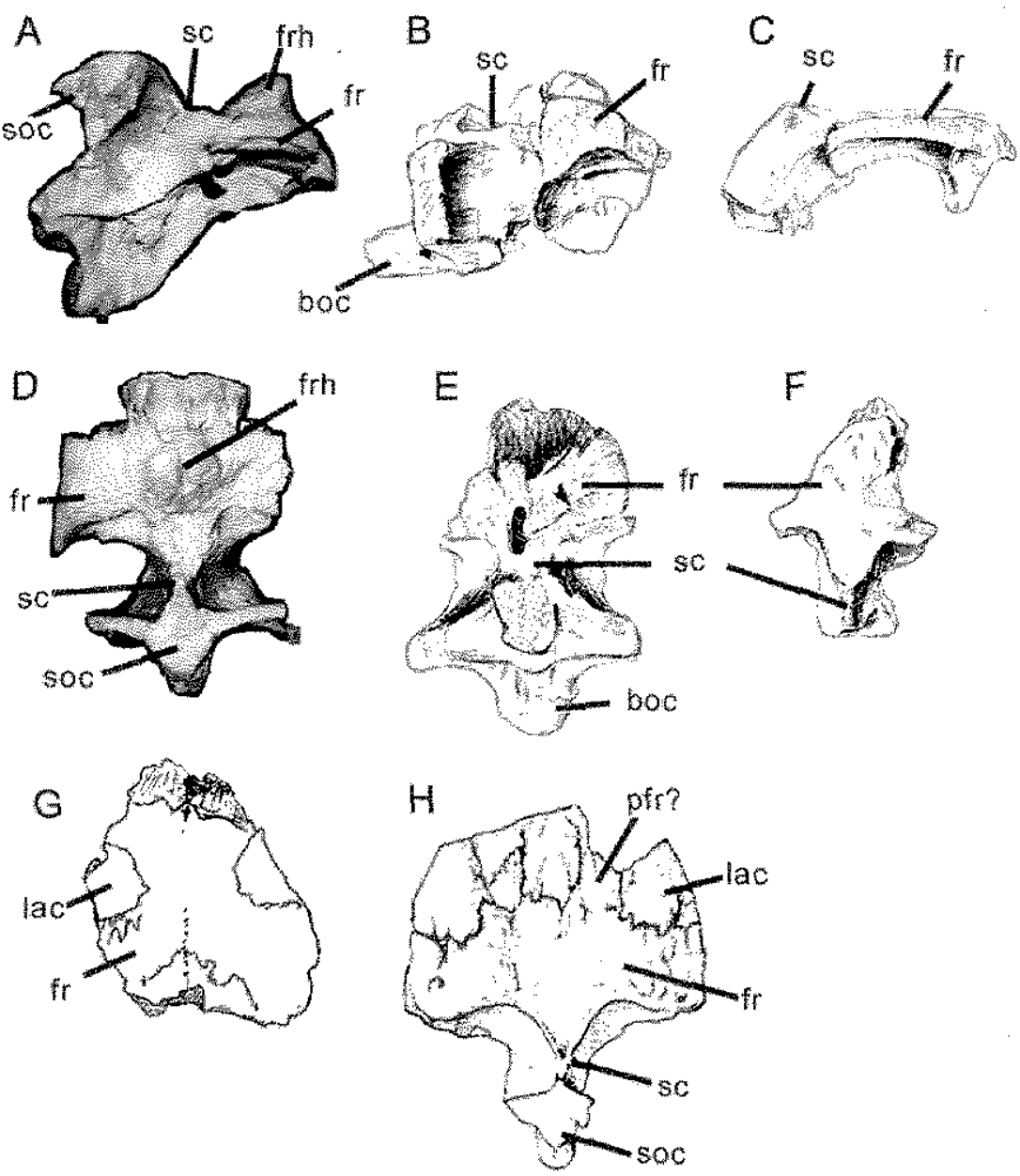

Fig. 2. Basicrania of different abelisaurid theropods, in lateral (A-C), and dorsal (D-H) views. A, D, Majungatholus aiopus (from Sampson et al., 1998); B, E, Indosaurus matleyi (K27/565) (from Huene \& Matley, 1933); C, F, Indosuchus raptorius (K 27/685) (from Huene \& Matley, 1933); G, Indosuchus raptorius (K20/350) (from Huene \& Matley, 1933); and H, Abelisaurus comahuensis (modified, from Bonaparte \& Novas, 1985). Not to scale. Abbreviations: boc basioccipital; fr, frontal; frh, frontal horn; lac, lacrimal; prf, prefrontal; sc, sagital crest; soc, supraoccipital.

K20/350 the suture between frontal and lacrimal (mislabeled as "prefrontal" in the original description) closely matches that of Abelisaurus comahuensis, especially in the subquadrangular outline of the suture and the sharp "peg" of the lacrimal medially projecting into a "socket" in the frontal (Fig. 2G, H). Moreover, the fronto-lacrimal suture constitutes a wide groove behind the lacrimal, a condition that is also seen in Abelisaurus comahuensis. Lacrimals widely exposed in dorsal view is a condition that specimen GSI K27/350 shares with Abelisaurus comahuensis and Majungatholus atopus (Sampson et al., 1998), except for Carnotaurus (MACN-CH 894) in which the lacrimals are transversely narrow. The narrow parietal crest of Indosuchus, repeatedly used in support of tyrannosaurid affinities of the Indian taxon (e.g., Chatterjee, 1978; Walker 1964), is also present in the abelisaurids Abelisaurus, Majungatholus and Carnotaurus. This set of features strengths allocation of GSI K20/350 to the Abelisauridae, thus dismissing previous suggestions of ankylosaur affinities for such specimen (Walker, 
1964). Abelisaurid traits are present in the sagital parietal crest of specimen GSI K27/685: in dorsal view, the rostral half of this crest has a cup-shaped contour, being transversely narrow towards the rear (Fig. 2F). This condition is only documented in abelisaurids among Theropoda (e.g., Carnotaurus sastrei, Abelisaurus comahuensis, Majungatholus atopus). Notable for specimen GSI $\mathrm{K} 27 / 685$ is the presence of an inter-orbital wall (presumably made up by the parasphenoid bone), which is vertically hanging below the mid-frontal suture (Fig. 3C). Such inter-orbital wall, also seen in specimen GSI K27/565 of Indosaurus matleyi (Figs. 2B, 3B) is almost identical to that of abelisaurids Abelisaurus comahuensis (Bonaparte \& Novas, 1985), Carnotaurus sastrei (MACN.CH 894), and Majungatholus atopus (Sampson et al., 1998). Moreover, in GSI K27/685 the cranial half of the parasphenold ends in a diamond-shaped structure (eventually the orbitosphenoid; Currie \& Zhao, 1993), which bears a double-foramen for the exit of the olfactory nerve. Ossified parasphenoids tightly fused to the skull roof and with a double exit for nerve I, are features not exclusive for Abelisauridae, since they are present also in Ceratosaurus (Madsen \& Welles, 2000), Acrocanthosaurus (Stovall \& Langston, 1950), and some tyrannosaurids (Russell, 1970). Albeit such conditions for the parasphenoid and orbitosphenoid may be not synapomorphic for Abelisauridae, at least their presence in the Indian basicrania is congruent with other abelisaurid features.

Some differences among the Indian basicrania and other abelisaurid taxa are discernable on the basis of the figures given by Huene and Matley (1933). For example, in specimen GSI K20/350 the fronto-nasal suture appears to be rostrally placed with respect to the lacrimals (Fig. $2 \mathrm{G}$ ), in contrast to the remaining abelisaurids in which such suture is more caudally placed, approximately at level of the rostrolateral notch of the frontals for articulation with the lacrimals. GSI K20/350 also exhibits on its caudal half a median suture between both frontals, as well as a clear frontoparietal suture. The presence of visible dorsal sutures in GSI K20/350 is in agreement with the lack of fusion with the parasphenoidal bone, thus exposing the ventral furrow for the olfactory canal (Huene \& Matley, 1933). Both frontals and parasphenoid are completely fused in Abelisaurus comahuensis and Carnotaurus sastrei, as well as in specimens GSI K27/685 of Indosuchus raptorius and GSI K27/565 of Indosaurus matleyi. Presumably the lack of ossification among the skull roof and braincase bones may be due to ontogenetic development, with no systematic significance, but the other differences may constitute autapomorphic features of Indosuchus raptorius.

Indosaurus matleyi. This species was founded by Huene on the basis of a single piece of skull, catalogued with the number GSI K27/565. Chatterjee (1978) later declared this specimen to be the holotype of Indosaurus matleyi. The specimen consists of the posterior part of the skull, the dorsal surface of which is partially damaged and includes the right frontal bone, the temporal region, and the area for articulation with the postorbital (Fig. 2B, E). In dorsal view the frontal is subtriangular, with an anterolateral notch for articulation with the lacrimal. The dorsal surface is slightly rugose, although not to the degree seen in Abelisaurus (Bonaparte \& Novas, 1985). In lateral view (Fig. 2B) the articular surface for the postorbital and lacrimal bones is rugose, being dorsoventrally deep in the postorbital portion (reaching $5 \mathrm{~cm}$ thick), and becoming shallower rostrally (nearly $3 \mathrm{~cm}$ thick). The posterior surface of the frontal is high, except for the surface bounding the supratemporal fossa, which is excavated. Both dorsal and posterior surfaces of the frontal are separated by a sharp border. An interorbital wall, vertically hanging below the mid-frontal suture and presumably made up by the parasphenoid, is a character that Indoscurus matleyi (GSI K27/565) shares with Indosuchus raptorius (GSI K27/685) and other abelisaurids (see above; Fig. 3).

Bonaparte and Novas (1985) found similarities between Abelisaurus comahuensis and Indosaurus matleyi based on the broad interorbital region, and Molnar (1990) noted that this Indian taxon resembles Carnotaurus sastrei in the massive frontals and supraoccipital and markedly elevated sagittal crests of the parietals. Later, Bonaparte (1991b) pointed out that the supratemporal openings of Indosaurus are anteroposteriorly short, resembling Abelisaurus and Carnotaurus. The above mentioned authors obviously concluded that Indosaurus is a member of Abelisauridae, an interpretation also followed by Chatterjee and Rudra (1996).

Indosuchus and Indosaurus shows some distinctions with respect to other abelisaurids. The Indian taxa lack, at least, the prominent central dome on frontal bones autapomorphic of Majungatholus atopus, or the paired frontal horns that characterize the Patagonian Carnotaurus. In this regard, the morphology of the skull roof of Indosuchus and Indosaurus is more conservative, and looks similar to Abelisaurus in being dorsoventrally thick but without prominences above the skull roof.

Having demonstrated the abelisaurid affiliation of Indosuchus and Indosaurus, we must 
A K20/350

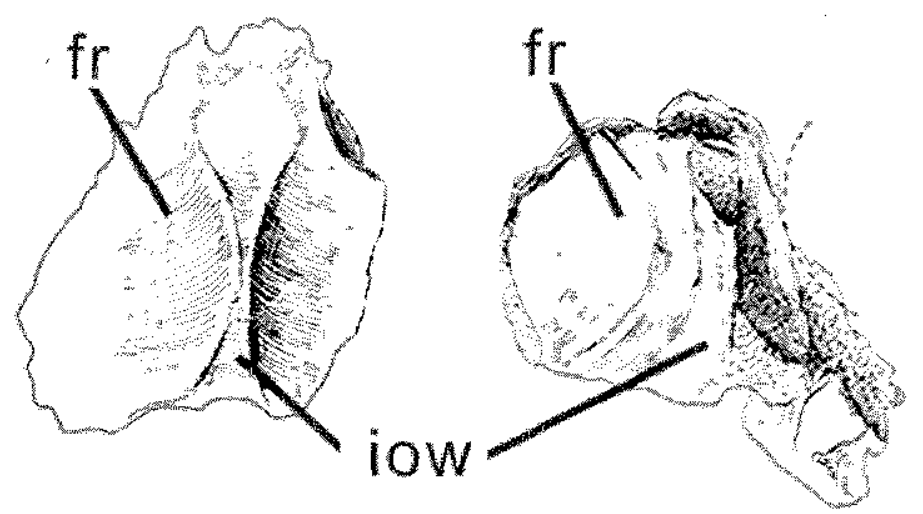

B K27/565

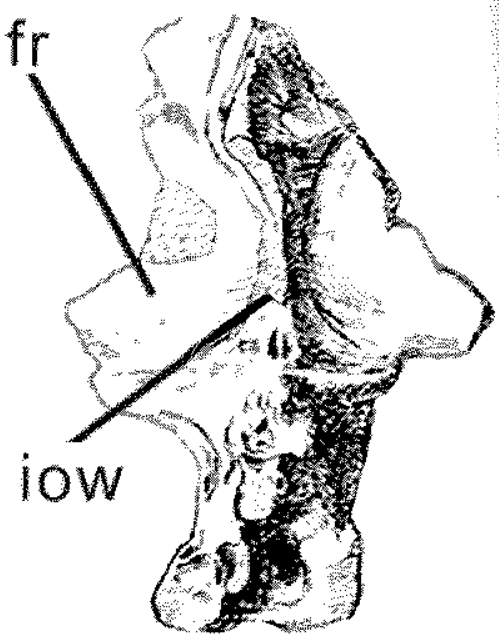

Fig. 3. Ventral view of basicrania of A, Indosuchus raptorius (K20/350), B, Indosaurus matleyi (K27/ 565), and C, Indosuchus raptorius (K 27/685). Figures taken from Huene and Matley (1933). Not to scale. Abbreviations: fr, frontal; iow, interorbital wall.

ask whether they are valid species. Since Huene's description, many authors have accepted the anatomical distinctions between Indosuchus and Indosaurus, supporting them as valid taxa. Moreover, they were interpreted as belonging to quite different theropod clades: while Indosuchus was considered as a tyrannosaurid, Indosaurus was interpreted as representative of a lineage that inherited primitive features from Jurassic forms such as "megalosaurs" (Chatterjee, 1978; Walker, 1964). Huene and Matley (1933), and later Chatterjee (1978) and Chatterjee and Rudra (1996), offered a list of anatomical distinctions between the basicrania of both taxa, including differences in the transverse width of the parietal sagital crest, the presence or absence of a "transverse crest" on the dorsal surface of the skull, the dorsoventral thickness of the frontals, and the contour of the supratemporal fossa. However, it is difficult to evaluate such distinctions, not only because most of the basicrania were unavailable for the present study, but also because the preservation of the skulls is far from optimal. For example, in the available specimen of Indosaurus (GSI K27/565) the dorsal surface of the braincase is eroded, thus no features of the frontal bones or sagital parietal crest are preserved; the purported presence of a «transverse crest above and behind the orbit» in Indosaurus was not identified in our inspection of the specimen, and thus the validity of this feature is here dismissed; preservation of the braincases does not prove the presence of horn-like tuberosities in Indosaurus, nor a dorsally smooth postorbital in Indosuchus. Other possible distinctions recognized by previous authors between Indosuchus and Indosaurus concerning the thickness of the skull roof, the anteroposterior extension of supratemporal fossa, the fusion of sutures, and the degree of development of rugosities on the skull bones, may reflect individual variations. In those regards, the frontal dome of Majungatholus shows a variety of shapes, from being inflated in some specimens (Sues \& Taquet, 1979), to slightly developed in others (Sampson et al., 1998). Such development of the frontal dome also affects the width and shape of the sagital parietal crest of Majungatholus. This possible case of individual variation in the Malagasy abelisaur serves as an alert when distinctions between the poorly preserved skulls of Indosuchus and Indosaurus are evaluated. In sum, anatomical distinctions between Indosuchus and Indosaurus are doubtful, at least.

\section{Skull bones originally described as «carnosaurian»}

Basioccipital. Huene and Matley (1933, pl. $\mathrm{X}, \mathrm{XI}$ ) identified two different types of 
basioccipitals. In GSI K27/687 the exoccipitals presumably form the floor of the foramen magnum, the neck is anteroposteriorly elongate and has a median ventral groove, the posterior surface of the basioccipital bears a double tubercle, and the basioccipital tubera seem to be ventrally bifurcated. Instead, in GSI K27/628, the exoccipitals are excluded from the floor of the foramen magnum, ard the neck is anteroposteriorly short. Unfortunately, most of the ventral portion of the basioccipital is broken, so the peculiar traits enumerated above for GSI K27/687 (e.g., posterior surface of the basioccipital with a pair of tubercles, basioccipital tubera ventrally bifurcated) remain unknown in GSI K27/628. Chatterjee (1978) considered that basioccipital GSI K27/687 belongs to Indosaurus, and GSI K27/ 628 to Indosuchus, but such referal is untenable on the basis of current knowledge of these genera. However, it seems correct that two kinds of basioccipitals are present in the "Carnosaur bed". Besides, it is difficult to discern abelisaurid traits in each of the basioccipitals. In Abelisaurus, Ilokelesia, Majungatholus and Carnotaurus the basioccipital condyle is rounded, robust and with a short neck, thus resembling GSI K27/576. However, in Ilokelesia the ventral surface of the neck is grooved, whereas in Majungatholus it is keeled. However, because other cranial bones belong to Abelisauridae, we tentatively assign the occipital condyles to this group as well.

Premaxilla. The description of this cranial element will be primarily based on specimens GSI K27/710 (a left premaxilla) and GSI K20/619 (a right premaxilla), and a pair of premaxillae (AMNH 1753; Fig. 4) that Chatterjee (1978) interpreted as presumably corresponding to a sin" gle individual. This author referred to AMNH 1753 as Indosuchus, although there is no firm bases for such assumption, because the holotype of this species does not preserve premaxillary bones. Accordingly, we refer to these bones as Abelisauridae indet. The premaxilla is higher than rostrocaudally long (for example, in GSI K27/710, the anteroposterior width is $6.2 \mathrm{~cm}$, while its dorsoventral height is $8.5 \mathrm{~cm}$ ), as characteristic of abelisaurids (Novas, 1997). The anterior surface of the ascending process is sharply defined. The lateral surface is decorated by numerous small foramina, which are particularly abundant on the ascending ramus. However, larger foramina exist along the alveolar margin. The medial symphysis for articulation with the opposite premaxilla is extended. Behind the nasal depression are two distinct, hook-like processes, which articulate with a pair of excavations on the medial premaxillary process of the maxilla. The

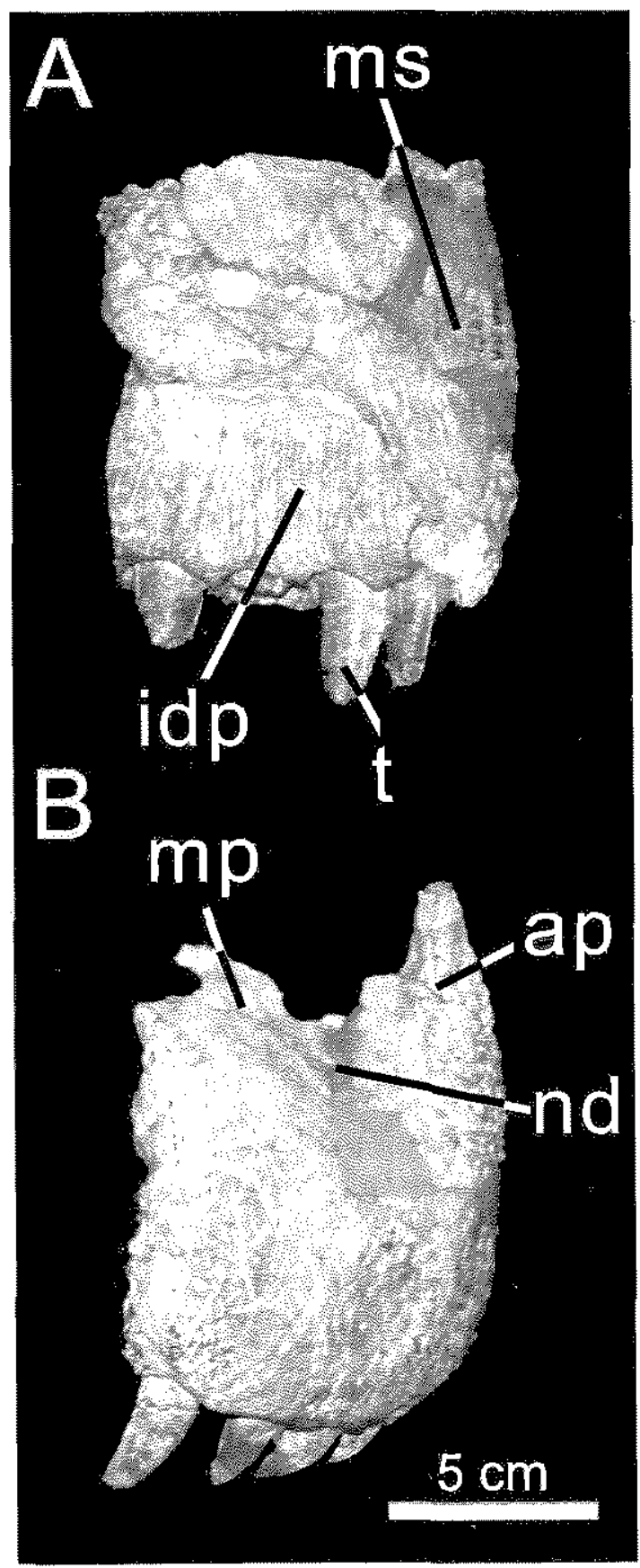

Fig. 4. Right premaxilla of Indosuchus raptorius (AMNH 1753), in A, medial and B, lateral views. Abbreviations: ap, ascending process; idp, interdental plates; mp, maxillary process; ms, medial symphysis; nd, nasal depression; $t$, tooth.

rear margin of the premaxilla is transversely wide and convex, its pitted surface suggesting a lose or somewhat movable contact with the maxilla. In 


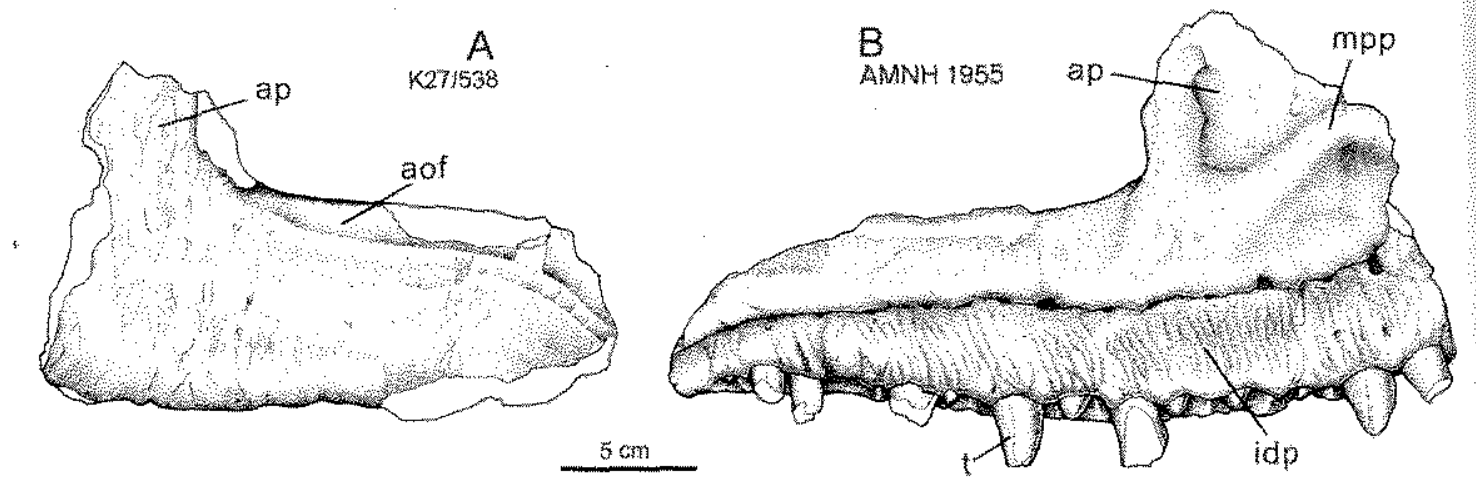

Fig. 5. Abelisaurid maxilla. A, left maxilla of specimen GSI K27/538 in lateral view; B, left maxilla of Abelisauridae indet (AMNH 1955) in medial aspect. Abbreviations: aof, antorbital fossa; ap, ascending process; idp, interdental plates; mpp, medial premaxillary process.

AMNH 1753 a shallow but distinct notch is identified on the posterior border of the premaxilla, corresponding with the subnarial foramen. The narial fossa is deep and well delimited, in contrast with Carnotaurus sastrei and Abelisaurus comahuensis. The external surface of the right premaxilla (K20/619) is not decorated with the foramina and tuberosities present in the remaining abelisaurids, and the ascending ramus looks more robust and complex than in AMNH 1753.

Maxilla. Chatterjee (1978), following Huene and Matley (1933), referred a fairly complete maxilla (K27/548) to Indosuchus, on the basis of its considerable thickness. Moreover, Chatterjee (1978) took this bone as a "Rosetta stone", allowing further reference of a left maxilla (AMNH 1955, Fig. 5B) to that species. Because no means exist to compare with Indosaurus matleyi (for which no maxillary bone has been preserved or identified), we follow Lammana et al. (2002) in considering specimen AMNH 1955 as belonging to Abelisauridae gen. et $\mathrm{sp}$. indet.

The following description of the abelisaurid maxillae from India is based on observations made on AMNH 1955, AMNH 1753, GSI K27/538, and GSI K27/544 (it must be noted that at the collections of the GSI, specimen GSI K27/538 is mistakenly labeled as GSI K27/548, while specimen GSI K27/544, not illustrated by Huene and Matley, is incorrectly labeled as GSI K27/538; specimen GSI K27/548 is missing). The maxilla GST K27/ 538 (Fig. 5) is characteristically triangular, anteroposteriorly short, and has a proportionally low ascending process, characters also present in Abelisaurus, Carnotaurus and Majungatholus. The articulation with the premaxilla is made through a strong medial premaxillary process, which is located high on the medial aspect of the bone, constituting another abelisaurid character. The lateral surface of the maxilla exhibits strong decoration that include foramina and grooves. The grooves, which are predominantly oriented dorsoventrally, split and join in a complex pattern as occurs in other abelisaurids. The grooves are more marked on the ascending ramus than in other regions of the maxilla, specially in larger specimens (e.g., GSI K27/538). The maxillary ascending ramus is almost vertically oriented, with the rostral margin slightly convex in lateral view. The caudal margin of the ascending ramus is transversely wide and deeply excavated, and provided with a presumed promaxillary fenestra (hidden in side view). A maxillary fenestra is lacking. The dorsal margin of the maxilla is transversely convex and affected by deep, presumably pneumatic, excavations. On the internal side is seen a row of dental foramina along the contact between the dental plates and the remainder of the medial surface of the maxilla.

Two conspicuous abelisaurid synapomorphies are identified on the available Indian maxillae: a minute antorbital fossa, and dental plates dorsoventrally deep, strongly fused, and decorated by obliquely oriented striations.

AMNH 1955 was referred to the subfamily Carnotaurinae by Lamanna et $a l$. (2002), because it shares a promaxillary fenestra obscured by the lamina lateralis of the ascending ramus. Additionally, these authors suggested that an anteroposteriorly short maxillary body with parallel dorsal and ventral margins is synapomorphic of this subfamily. However, the 


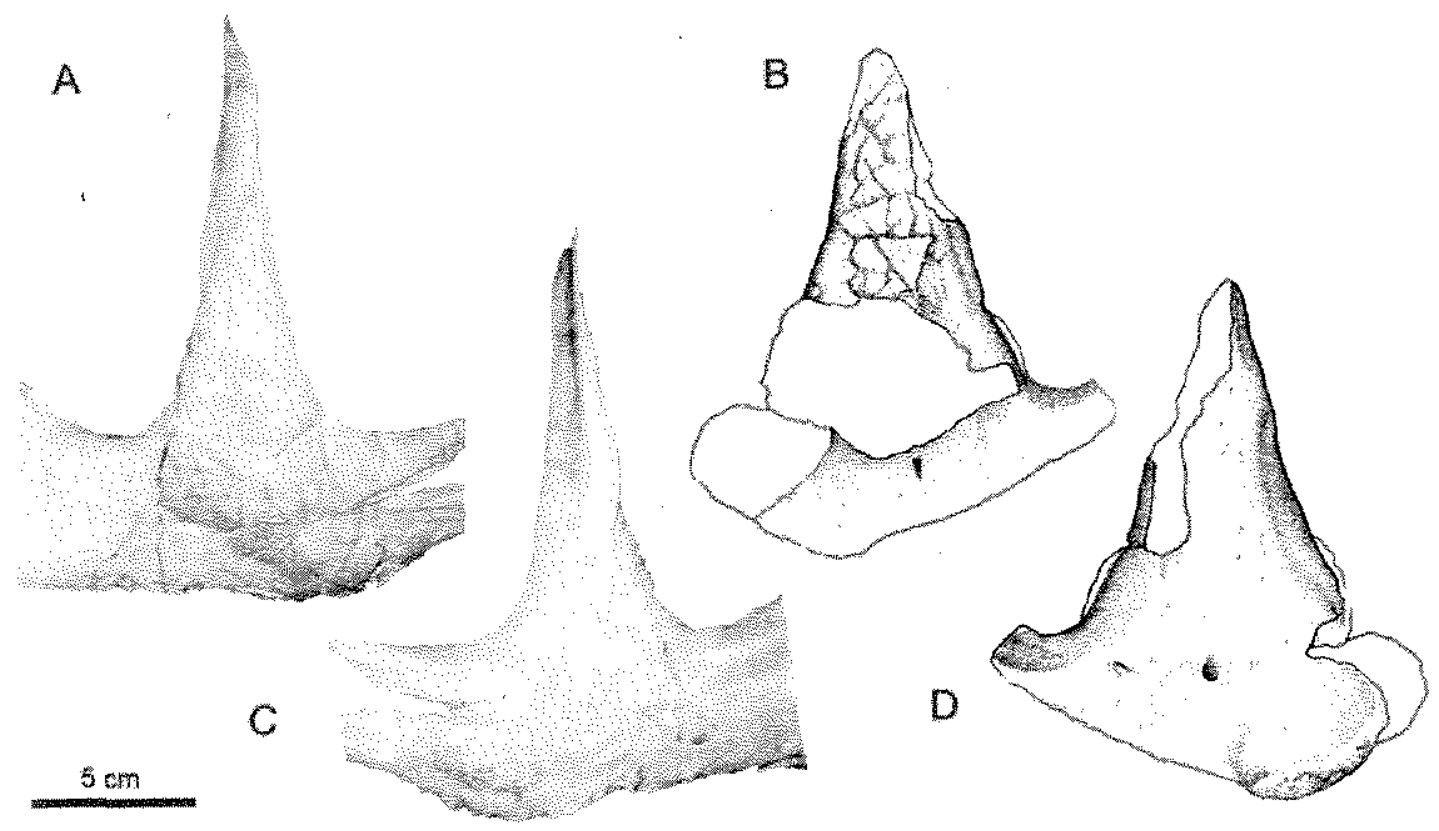

Fig. 6. Left jugals of Abelisauridae in lateral (A,B) and medial (C,D) views. A, C, Majungatholus atopus (FMNH PR 2100); B,D, Abelisauridae indet. (K27/577).

diagnostic value of such characters is debatable, because the maxilla is unknown in other abelisauroids (e.g. Ilokelesia) or it is incompletely preserved in others (e.g. Abeliscurus). In other words, such features may exhibit a wider distribution among abelisaurids.

Several isolated teeth were recovered from the quarry. However, they are lost in the GSI collection, and the figures given by Huene (pl. XIII, fig.1-10) are not detailed enough. However, many of these dental pieces agree in general shape with the teeth of other abelisaurids (e.g., Abelisaurus, Majungatholus) in the great transverse compression and degree of backward curvature.

Jugal. The following description of this bone is based on specimens GSI K27/577 and GSI K27/ 580 . We could not access another two specimens (K27/535 and GSI K27/581) that were described (but not illustrated) by Huene and Matley (1933) as portions of right and left jugals. Specimen GSI $\mathrm{K} 27 / 577$ was originally described as a right lacrimal, but it matches well with the ascending ramus of the left jugal of Carnotaurus and Majungatholus (Fig. 6). Besides, specimen GSI K27/580 (Fig. 7), originally was interpreted by Huene and Matley as a right postorbital, interpretation accepted by Chatterjee (1978) who referred to the presumed postorbital (K27/580) as Indosuchus. GSI K27/580 is here reidentified as a portion of a right jugal (Fig. 7).

Specimen GSI K27/580 has a triangular aspect in lateral view, with a slender and rod-like dorsal extremity. The ventral half of the bone is transversely narrow, and exhibits a concave lateral surface. Towards the dorsal end the bone becomes transversely thicker, constituting the most laterally projected portion of the jugal. Its lateral surface is decorated by grooves, being intensely sculptured on the posterior and ventral orbital portions. A distinct oblique groove is present on its lateral surface. The medial surface of the lacrimal is smooth, with a caudal depression surrounding the infratemporal opening. The medial surface of the ascending process of jugal forms a longitudinal prominence (Fig. 7).

Jugals GSI K27/580 differs from Carnotaurus, Abelisaurus and Majungatholus mainly in the presence of a deep, rounded notch on the caudal margin of the ascending ramus. Specimen GSI K27/577 exhibits rugosities with a different pattern than these seen in Carnotaurus and Majungatholus.

«Lacrimal». Specimen GSI K27/708 was interpreted by Huene and Matley (1933 pl. XI, fig, 5) and later by Chatterjee (1978) as 

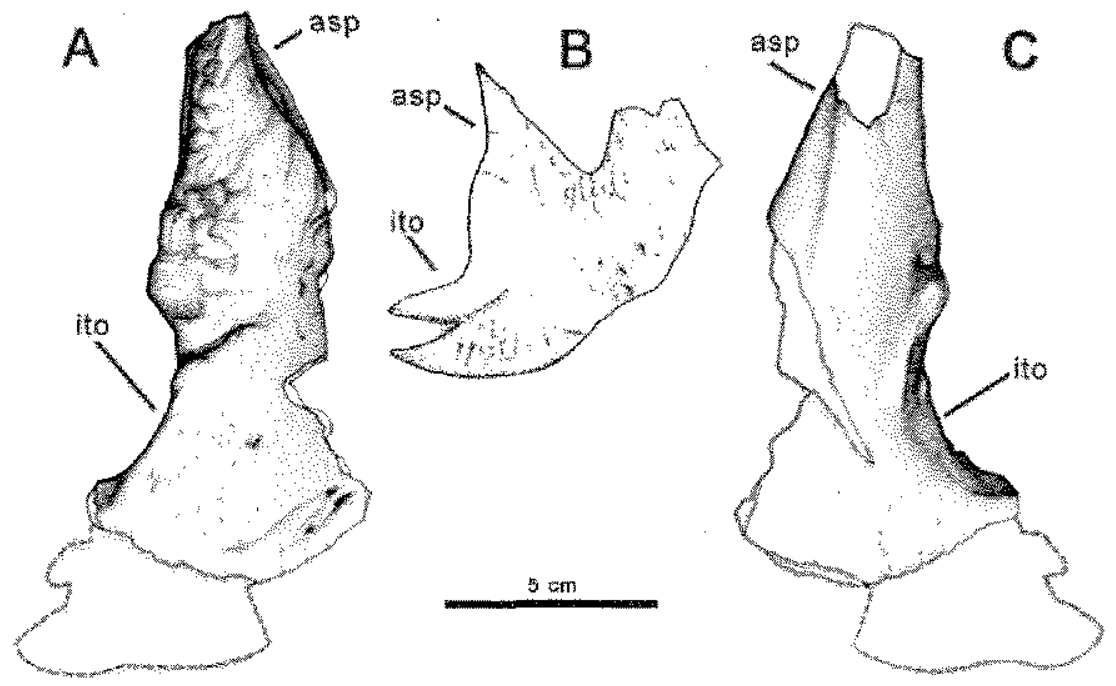

Fig. 7. Right jugal of Abelisauridae in lateral (A,B) and medial (C) views. A,C, Abelisauridae indet. (K27/580); B, Carnotaurus sastrei (from Bonaparte et al., 1990). Not to scale. Abbreviations: asp, ascending process; ito, infratemporal opening.

corresponding to the upper portion of a right lacrimal. However, the bone lacks the pattern of rugosities and the wide contact for the postorbital as seen in the lacrimal of Carnotaurus and Majungatholus. We are unable to identify specimen GSI K27/708.

Quadrate. This bone was originally described as a right astragalus (Huene \& Matley, 1933, pl.XIX, fig. 1; GSI K27/684), but it corresponds in fact to a left quadrate. The specimen preserves the distal articular condyles, the base of the pterigoid ramus, and a rugose lateral surface for the attachment of quadratojugal. The anterior facet of the distal condyles is nearly flat, as it occurs in the abelisaurids Ilokelesia, Majungatholus and Carnotaurus (see Wilson $e t$ al. 2003, character 53).

Dentary bones. The following specimens were studied: GSI K27/550, GSI K27/709, GSI $\mathrm{K} 27 / 529$ (incorrectly catalogued as GSI K27/527 in the GSI collections, a number corresponding to a left articular), and AMNH 1960 (a number that also applies to a caudal vertebrae). Huene and Matley (1933) listed, although did not describe, one more dentary (K27/573), which was not located at the GSI collections. Dentaries GSI K27/ 550 (Figs. 8, 9), GSI K27/709 (Fig. 9), and GSI K27/529 exhibit on the ventral half of their external surface a distinct pattern of ornamentations made up by foramina, grooves and prominences, resembling those of Carnotaurus and Majungatholus. As in the latter two taxa, a clear separation exists between the strongly decorated ventral half relative to the smooth dorsal (or "labial") half of the dentary. The line defined by these two surfaces describes a dorsally concave curvature, which in Carnotaurus and Majungatholus is lined by a number of large foramina. The abovementioned resemblances clearly support the hypothesis that all of the theropod dentaries recovered in the "Carnosaur bed" belong to Abelisauridae.

Huene and Matley (1933:50) and later Chatterjee (1978) cited some distinctions among these dentaries, but because of the fragmentary nature of the material, plus the impossibility of comparing them directly, we prefer do not address this aspect.

Surangular. Specimen GSI K27/693 was originally described as a left articular (Huene \& Matley, 1933, pl. XII, fig. 3), but it is identified here as a left surangular. The dorsal surface of this bone is almost flat and transversely wide, whereas the external surface is strongly convex transversely. Below the more laterally projected portion of the surangular, there are two large foramina (nearly $5 \mathrm{~mm}$ in diameter), separated each other by nearly $20 \mathrm{~mm}$. Both foramina 

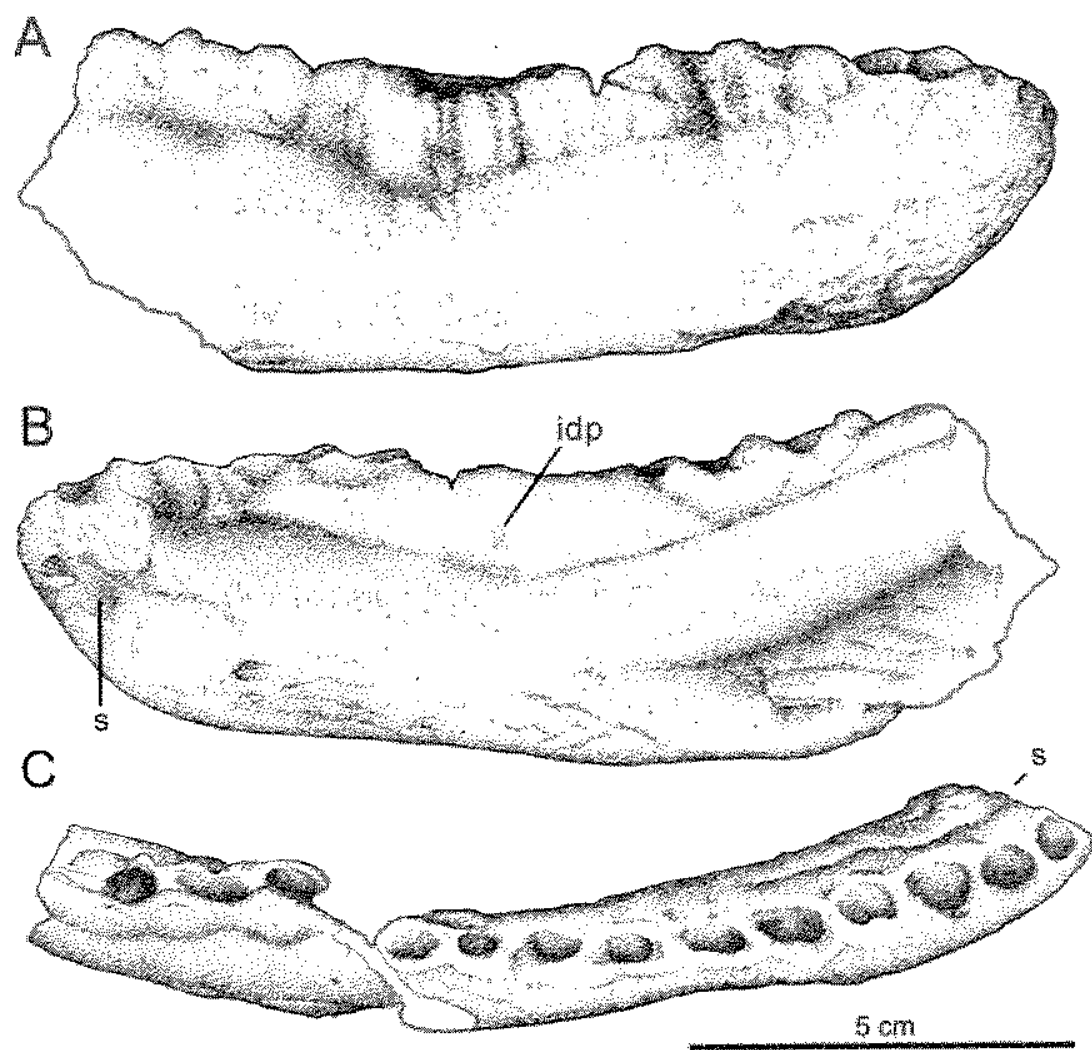

Fig. 8. Right dentary of Abelisauridae indet. (K27/550) in A, lateral, B, medial, and C, dorsal views. Abbreviations: idp, interdental plates; $s$, symphysis.

A

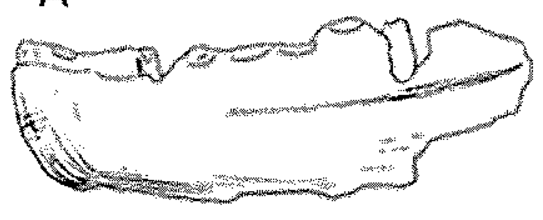

B

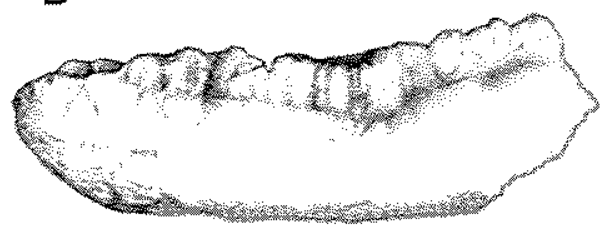

C
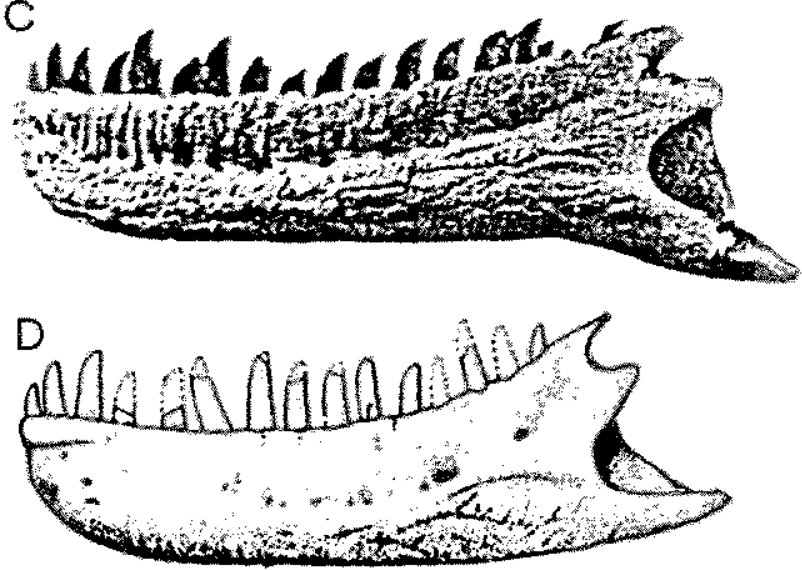

Fig. 9. Dentaries of abelisaurid theropods in left lateral view. A, Abelisauridae indet. (K27/709) (from Huene \& Matley, 1933); B, Abelisauridae indet. (K27/550); C, Majungatholus atopus (from Sampson et al. 1998); and D, Carnotaurus sastrei (from Bonaparte et al., 1990). Not to scale. 
continue forward and inward, perforating the anterior surface of the articular bone. The surangular resembles that of Carnotaurus sastrei (Bonaparte et $a l ., 1990$ ) in the presence and position of the pair of foramina near the glenoid cavity.

\section{Theropod taxa based on vertebral elements}

Seven theropod species were coined by Huene and Matley on the sole basis of vertebrae: Compsosuchus solus, Laevisuchus indicus, Jubbulpuria tenuis, Coeluroides largus, Dryptosauroides grandis, Ornithomimoides mobilis, and Ornithomimoides (?) barasimlensis. Also, some isolated vertebrae were described as corresponding to "allosauroids" or "coelurosaurs". These specimens are reviewed as follows:

Compsosuchus solus. This taxon was described on the basis of a single axis with fused atlantal intercentrum (GSI K27/578; Fig. 10). Most of this vertebra is preserved, except for the the upper portion of its neural arch, which is broken. The axial centrum bears one large pleurocoel, and a pneumatic opening posteroventrally to the diapophysis. The anterior articular surface of the intercentrum is slightly convex and kidney-shaped, while the posterior one is slightly concave. The diapophyses are small and blunt. A sharp lamina extends obliquely from the diapophysis to the postzygapophysis. The neural arch is wide and low.

Molnar et al. (1990) found that the axis of Compsosuchus resembles that of Allosaurus in the similar position of the upper pleurocoel, the cylindrical aspect of the axial intercentrum in ventral view, the axial pleurocentrum less than twice the length of the axial intercentrum, and the broad condition of the neural canal. This lead Molnar et al. (1990) to include Compsosuchus within Allosauridae. However, GSI K27/578 exhibits the following resemblances with Carnotaurus: presence of a pneumatic pore posteroventrally to the diapophysis, and at least one large pleurocoel on the axial centrum, proportionally small and rod-like diapophyses, presence of a sharp lamina extending obliquely from the diapophysis to the postzygapophysis, and a neural arch laterally expanded and triangularshaped in dorsal view. The axis that served as basis to create Compsosuchus closely resembles that of ISI R91/1, referred to Indosaurus by Chatterjee and Rudra (1996). In sum, the general morphology of this cervical vertebra indicates that it pertains to an abelisaurid theropod. Since there are no substantial differences with the axis of Indosuchus

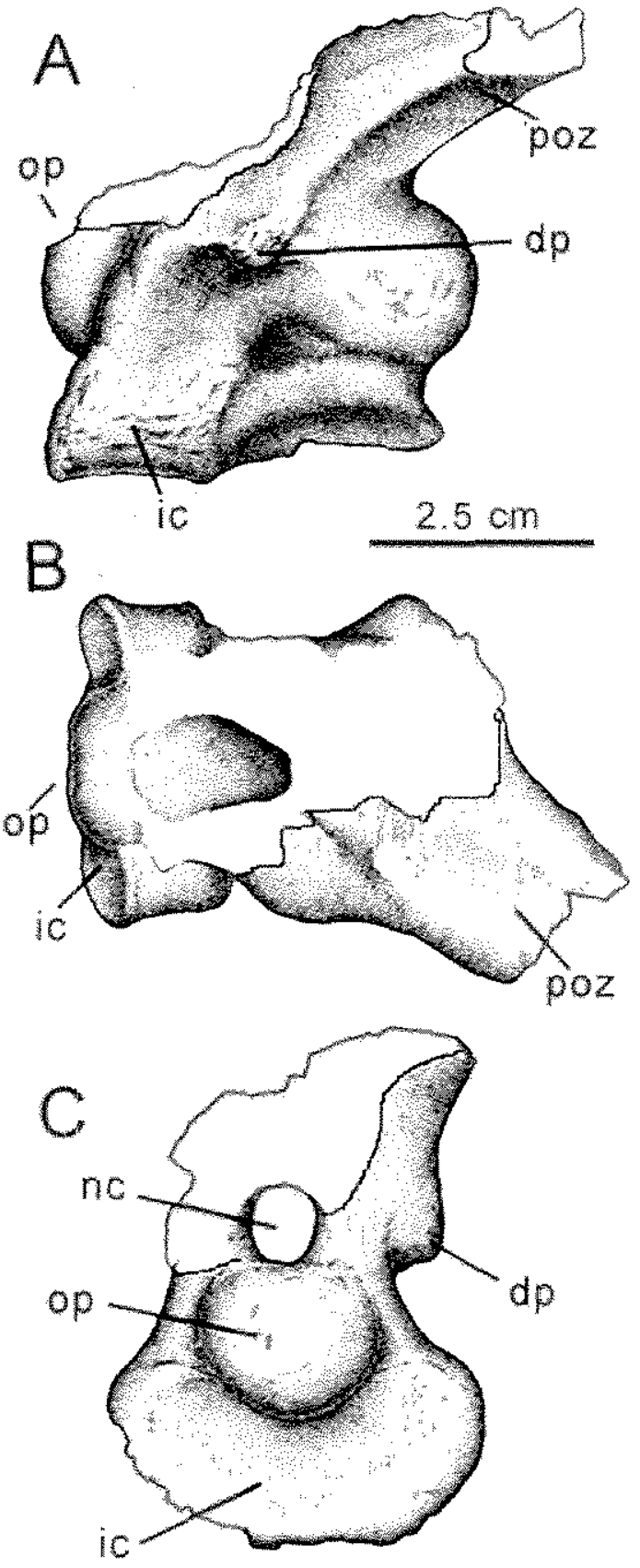

Fig. 10. Compsosuchus solus (K27/578), axis in A, left lateral, $\mathrm{B}$, dorsal, and $\mathrm{C}$, anterior views. Abbreviations: dp, diapophysis; ic, intercentrum; nc, neural canal; op, odontoid process; poz, postzigapophysis.

(ISI R 91/1) and no evident autapomorphies are recognized, we conclude that Compsosuchus is a nomen dubium. 
A

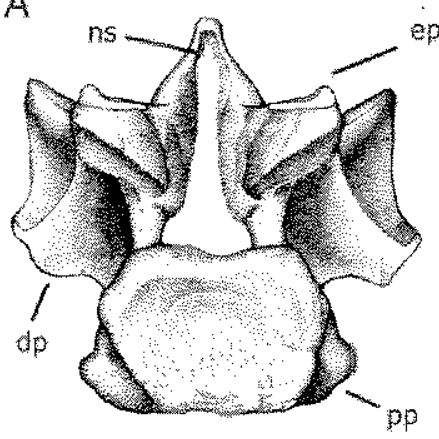

$\mathrm{C}$

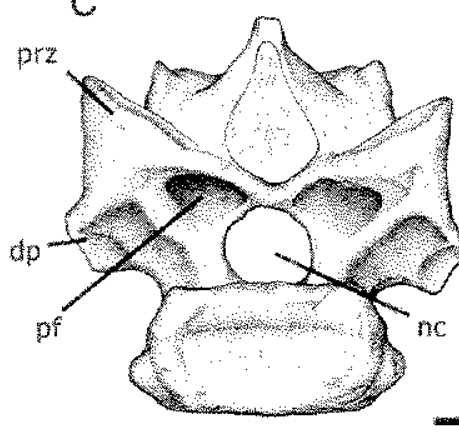

B

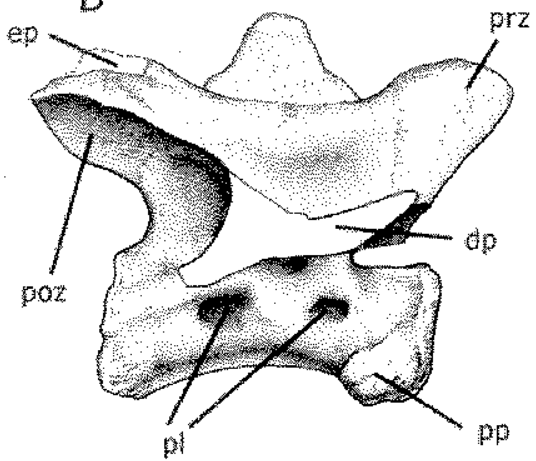

$\mathrm{D}$

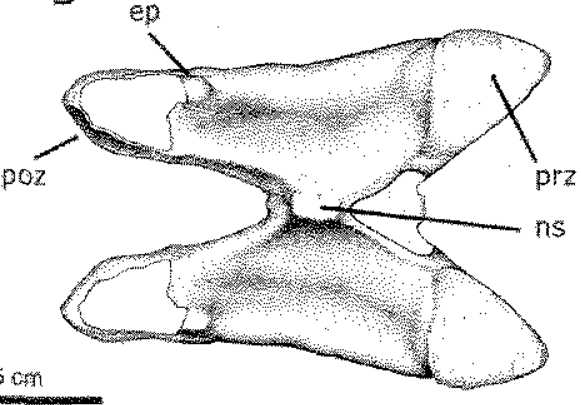

Fig. 11. Laevisuchus indicus (K20/613), cervical vertebra in A, posterior, B, right lateral, C, anterior, and $\mathrm{D}$, dorsal views. Abbreviations: dp, diapophysis; ep, epipophysis; nc, neural canal; ns, neural spine; pf, pneumatic fossa; pl, pleurocoel; poz, postzygapophysis; pp, parapophysis; prz, prezygapophysis.

Laevisuchus indicus. This taxon was described (Huene 1932; Huene \& Matley 1933:6061, pl.XX, figs. 2-5) on the basis of three cervicals (GSI K20/613, GSI K20/614, and GSI K27/696) and one dorsal vertebra (K27/588). Unfortunately, from these elements only a mid-cervical vertebra was located at the GSI collections (GSI K27/696; Fig. 11). The vertebra presumably corresponds with cervical 5 . The centrum is dorsoventrally low (the cranial surface is $19 \mathrm{~mm}$ high), and long (nearly $42 \mathrm{~mm}$ ), with an almost flat and transversely wide ventral surface. The cranial articular surface of the centrum is kidney-shaped, slightly concave, and with rised borders. The caudal articular surface is also concave. A pair of pleurocoels are present on the sides of the centrum, and a pneumatic depression exists more dorsally on the right side (this may correspond to the "third" pleurocoel cited by Huene \& Matley, 1933). The parapophyses are prominent. The neural arch is low and transversely wide (the distance between external margins of the prezygapophyses is $43 \mathrm{~mm}$ ). A sharp dorsal margin connects the prezygapophyses with the epipophyses, thus bounding laterally the dorsal surface of the neural arch. The dorsal surface of the neural arch is concave between the lateral margin and the neural spine. The latter is pyramidal, low ( $7 \mathrm{~mm}$ height) and craniocaudally short $(9 \mathrm{~mm})$. It cranial surface is damaged, but on the caudal surface exist ligament scars that do not reach to the top of the spine. On the cranial surface of the neural arch, and ventromedial to the prezygapophyses, exist a pair of deep and elliptical pneumatic fossae. The articular surface of the prezygapophysis is smooth and slightly convex (transversely and craniocaudally). The caudal surface of the neural arch is deeply excavated between the postzygapophyses and diapophyses. The postzygapophyses are broken dorsally, and consequently their respective epipophyses are incomplete. However, some information about their morphology is still available: the epipophyses are projected dorsally and laterally (as seen from behind; Fig. 11A). They are craniocaudally extended, roughly representing 

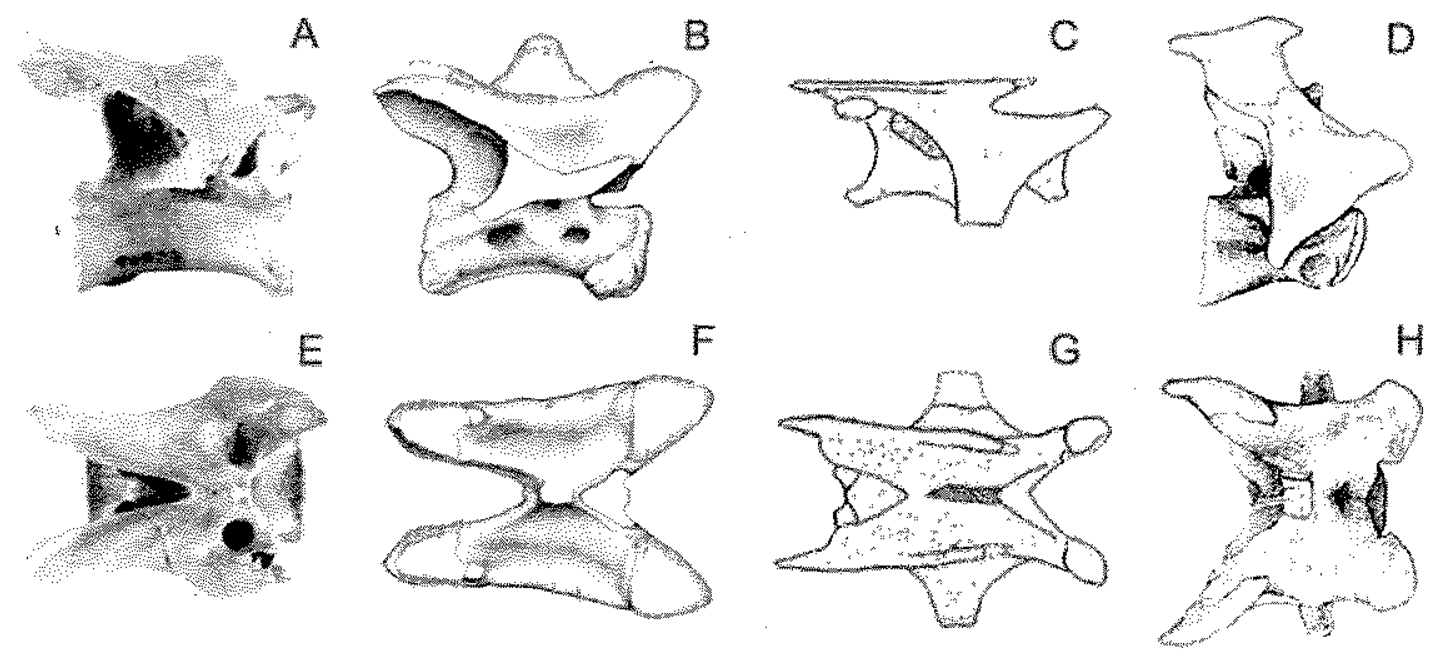

Fig. 12. Cervical vertebrae of abelisauroid theropods in right lateral (A-D) and dorsal (E-H) views. A, E, Masiakasaurus knopfleri (from Carrano et al. 2002); B, F, Laevisuchus indicus; C, G, Noasaurus leali (from Bonaparte and Powell, 1980); D, H, Carnotaurus sastrei (from Bonaparte et al, 1990), Not to scale.

$75 \%$ of the maximum diameter of the postzygapophyseal articular surface. The caudal portions of the epipophyses have not been preserved. However, the epipophyses lack the slender and conical cranial projections present in Noasaurus (Bonaparte \& Powell, 1981), for example.

Huene and Matley (1933, pl,XX, figs. 2 and 4) illustrated another two cervicals of Laevisuchus (GSI K20/613 and GSI K20/614), Cervical GSI $\mathrm{K} 20 / 613$ is remarkable for the extensive, tableshaped dorsal surface of the neural arch, closely resembling that of Noasaurus, Majungatholus and Carnotaurus. Cervical GSI K20/613 is here interpreted as more cranial in position than the previously described cervical GSI K27/696. Reassons supporting this include a centrum with differently inclined cranial and caudal articular surfaces, a proportionally smaller centrum diameter with respect to the neural arch (proportions that are also noticed in cranial cervical vertebrae of Carnotaurus, for example), the dorsal surface of the neural arch is wide, the lateral margin of the dorsal surface is straight in side view, the neural spine seems to be absent, and the epipophysis seems to be well developed and dorsally projected.

Norman (1990: 302), following Huene and Matley (1933: 60-61), pointed out that the vertebra of Laevisuchus resembles that of "Aristosuchus" (junior synonym of Calamospondylus Fox, 1866). However, the vertebra of Calamospondylus differs from Laevisuchus in that only one pleurocoel is present, the cranial articular surface is convex, and the dorsal surface of the neural arch is not transversally wide and well defined as in Laevisuchus. In sum, there are no coelurosaurian features in Laevisuchus. On the contrary Laevisuchus shows the following abelisauroid features: elongate epipophysis, pair of foramina on centrum, pyramid-shaped, low and transversely thick neural spines (Fig.12).

Laevisuchus has cervicals that are proportionally longer than in Carnotaurus and Majungatholus. Also, in Laevisuchus the anterior articular surface is slightly concave, instead of being convex as in Carnotaurus. The articular surfaces of the prezygapophyses are anteroposteriorly wide in Laevisuchus, opposite to the transversally expanded ones of Carnotaurus and Majungatholus. Laevisuchus has large pneumatic cavities below the prezygapophysis, whereas in Carnotaurus and Majungatholus the cavities are smaller in diameter.

Within abelisaturoids, Laevisuchus more closely resembles Noasaurus and Masiakasaurus. Carrano et al. (2002) suggested that these three taxa could be included within Noasauridae because they shares cervical vertebrae with anteriorly placed neural spines and cervical epipophysis that are reduced posteriorly. Laevisuchus and Noasaurus 


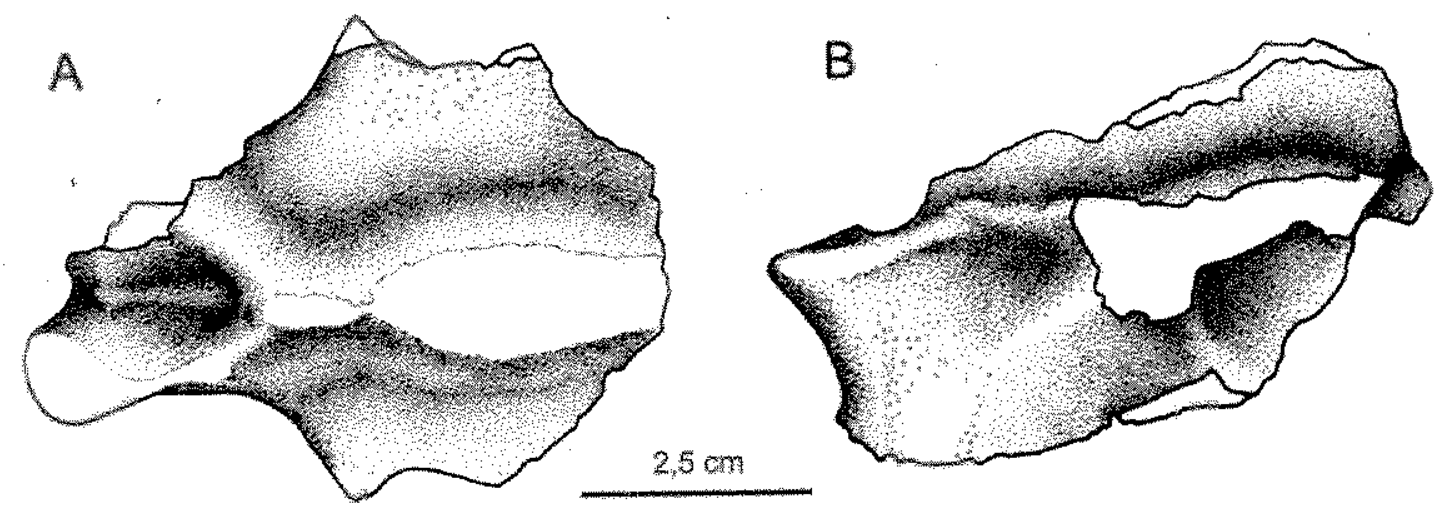

Fig. 13. Ornithomimoides mobilis (K20/614B), dorsal vertebra in A, dorsal, and B, left lateral views.

are similar in the development pneumatic cavities, the presumed absence of neural spines on cranial cervicals, and in the position of the both pre- and postzygapophyses.

Laevisuchus differs from Noasaurus in having the antediapophysial, postdiapophyisial and diapophysial cavities shallower, the diapophysis are wider and less ventrally directed, and the neural spine is less extended anteroposteriorly. In dorsal view Laevisuchus has shorter prezygapophyses and the postzygapophyses are caudally rounded (not acute as in Noasaurus). Laevisuchus differs from Masiakasaurus in having the space between the postzygapophyses less excavated, the prezygapophyses are thinner, and the infrapostzygapophysial and infraprezygapophysial cavities shallower.

Ornithomimoides. Huene \& Mattey (1933, pl. XX, fig. 8-10) created this genus (with a pair of species, $O$. mobilis and $O$.? barasimlensis) on the basis of several vertebrae that this author interpreted as dorsals similar to those of the ornithomimids Ornithomimus and Struthiomimus. One of the species ( $O$. mobilis) is represented by five large and elongate vertebrae (GSI K20/610, GSI K20/614B, GSI K27/586, GSI K27/597, and GSI $\mathrm{K} 27 / 600$ ), and the second species (O.? barasimlensis) by a set of smaller vertebrae (GSI K27/531, GSI K27/541, GSI K27/604, and GSI K27/ 682). Review of these specimens indicate that they are not dorsals but caudal vertebrae (Fig.13), their morphology corresponding to those of Majungatholus (pers. obs.). As it occurs in the latter abelisaurid, the prezygapophyses are close each other, they lack of the ventral projections present in dorsal vertebrae of neoceratosaurs (see Fig. 18 for an illustration of such projections), the prespinal depression is deep and divided by a tiny sagital crest, the neural spine is anteroposteriorly extended, the base of the transverse processes is ventrally buttressed and excavated, and the apneumatic centrum is longer than deep. We did not recognize autapomorphic features diagnostic of Ornithomimoides. On the contrary, the caudal vertebrae referred to this taxon look closely similar to caudals of other abelisauroids. In sum, we follow previous authors (Norman, 1990) in considering Ornithomimoides as a nomen dubium, the set of vertebrae representing proximal caudals of an Abelisauroidea gen. et sp. indet.

Dryptosauroides grandis. Dryptosauroides was recognized by Huene and Matley, (1933; pl. XXII, figs. 1, 2, 3 and 4) on the basis of six dorsal vertebrae (K20/334, GSI K20/609, GSI K27/549, GSI K27/601, GSI K27/626, and GSI K27/602), but they also referred to this taxon a cervical vertebra (K27/555) and several dorsal ribs (GSI K20/615, GSI K27/547, GSI K27/623, GSI K27/624, and GSI $\mathrm{K} 27 / 625$ ). This set of vertebrae does not belong, in fact, to the dorsal, but to the caudal region. Among them we have only accessed specimen GSI K20/609 (Fig.14) which exhibits almost the same morphology as caudal vertebra GSI K20/610 of Ornithomimoides mobilis (Fig. 14). Caudal vertebrae of Dryptosauroides match well with the proximal caudals of Majungatholus (pers.obs.). As is the case for Ornithomimoides the vertebrae of Dryptosauroides correspond to the proximal caudals of an indeterminate abelisauroid. Consequently, Dryptosauroides grandis is considered as a nomen dubium, following previous authors (Molnar, 1990). The size of the caudals indicate the presence of a very large animal, surpassing the size of Carnotaurus (MACN-CH 894), for example. 


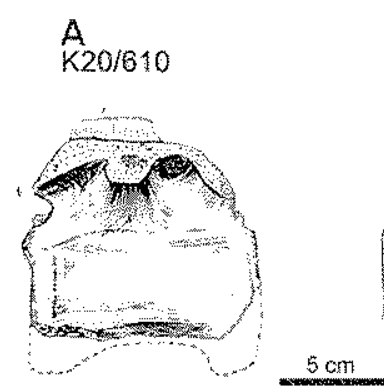

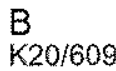

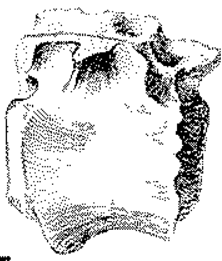

$\mathrm{C}$ K27/519

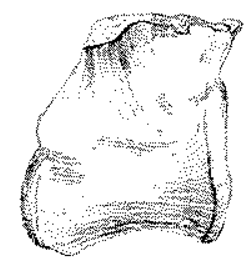

D

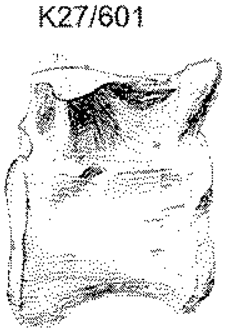

E $\mathrm{K} 20 / 334$

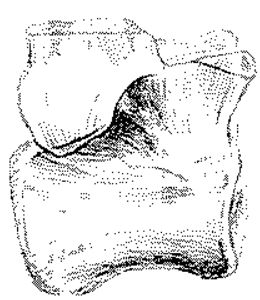

Fig. 14. Left lateral views of dorsal vertebrae of Ornithomimoides mobilis (A) and Dryptosauroides grandis (B-E). From Huene and Matley (1933).

Jubbulpuria tenuis. This taxon was erected on the basis of two small vertebrae (K20/612 and GSI K27/614), identified by Huene and Matley (1933, pl. XX, figs. 6 and 7) as corresponding to the dorsal region. Review of available specimen GSI K20/612 indicates that it is not a dorsal but a distal caudal vertebra (Fig. 15). The centrum is low and elongate, the transverse processes are expanded and dorsally excavated (as in Coeluroides largus GSI K27/562), and the neural spine is anteroposteriorly extended. The spine is represented by a tiny axial crest between the prezygapophyses, but towards the rear it becomes transversely stouter and was probably dorsoventrally higher. The postzygapophyses (Huene \& Matley, 1933, pl.XX, fig. 6a,b) were laterally facing, as it occurs in mid to distal caudals of other theropods (e.g., Majungatholus, Allosaurus, Tyrannosaurus).

The caudal vertebra described as Jubbulpuria has wing whaped transverse processes, which look well developed for such a distal caudal. Distal caudals of abelisaurids (e.g., Majungatholus, pers.obs.) lack well developed transverse processes. Also, its dorsal surface is excavated, different from the dorsally flattened of abelisaurids. However, the Neocomian basal abelisauroid Ligabueino andesi (Bonaparte, 1996) shows similarly developed transverse processes on distal caudals, supporting referal of vertebrae of Jubbulpuria as to Abelisauroidea.

Romer (1956) agreed with Huene and Matley (1933) in that Jubbulpuria is a member of "Coelurosauria", but Norman (1990) considered Jubbulpuria tenuis as a nomen dubium. We follow this last interpretation.

Coeluroides largus. This taxon was coined on the basis several isolated vertebrae (K 27/562, GSI K27/574, GSI K27/595) that Huene and
Matley (1933) erroneously interpreted as corresponding to the dorsal region. They all belong to the caudal region, as already recognized by Welles (1984) and Molnar (1990). Specimen GSI K27/595 (Huene \& Matley, 1933, pl.XXI fig.5) is a neural arch that closely resembles proximal caudals of Majungatholus (pers.obs.) and "Ornithomimoides" (Fig. 13). However, specimens GSI K 27/562 and GSI K27/574 of Coeluroides largus show distinctive features that merit more detailed consideration. Caudal GSI K $27 / 562$ (Fig. 16) is distinguished by its wide, almost horizontally oriented and well separated pre- and postzygapophyses; also, the transverse processes are notably expanded and triangular-shaped in dorsal view, with their dorsal surface deeply excavated, thus resulting the anterior margins of the transverse processes being raised. The neural spine is broken, but its base is axially extended and transversely robust. Zygapophyseal morphology of GSI K27/562 suggests that it is a mid-caudal vertebra. The peculiar morphology described above is also seen in AMNH 1957 (Fig. 17), a caudal vertebra catalogued as Indosuchus raptorius, which also has an elongate and low, apneumatic centrum. Moreover, specimens GSI K27/562 and AMNH 1957 are similar to the fragmentary caudal vertebra GSI K20/612 referred to Jubbulpuria (Fig. 15) in the morphology of the transverse processes (e.g., extensive, triangular shaped, and dorsally excavated). Interestingly, GSI K 27/562 (Coeluroides largus), AMNH 1957 (catalogued as Indosuchus raptorius) and GSI K20/612 (Jubbulpuria tenuis) share a similar set of features that contrasts with the caudal morphology of Majungatholus, Carnotaurus, Ilokelesia, Aucasaurus, as well as other abelisaurid caudal vertebrae of the Indian collections (e.g., GSI K27/ 


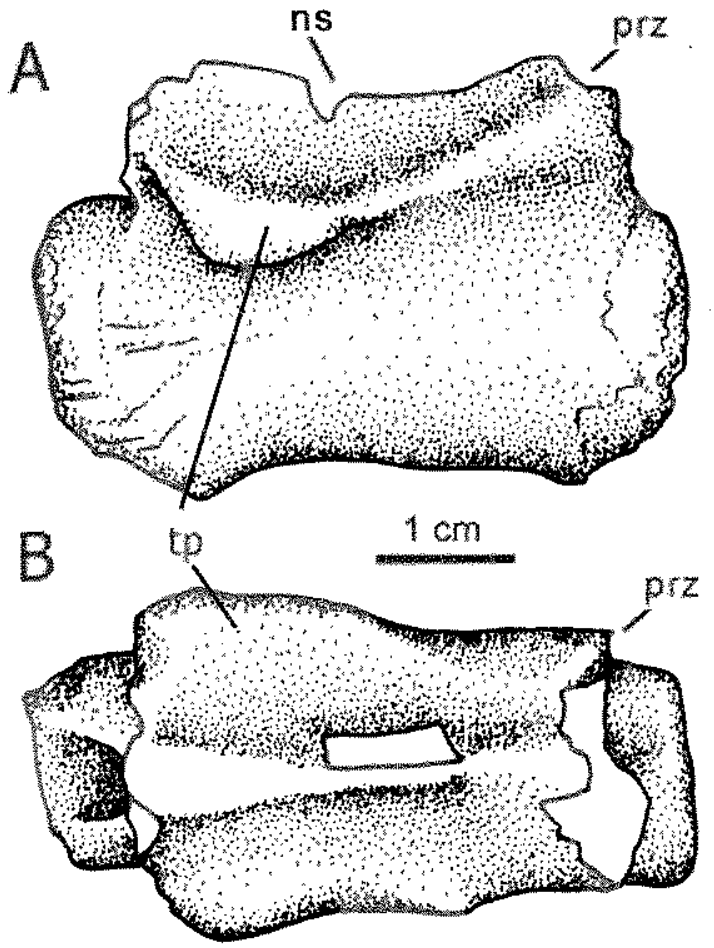

Fig. 15. Jubbulpuria tenuis (K20/612), distal caudal vertebra, in $\mathrm{A}$, right lateral, and $\mathrm{B}$, dorsal views. Abbreviations: ns, neural spine; prz, prezygapophysis; tp, transverse process.

595, GSI K20/610, GSI K20/614B, GSI K27/614, GSI K27/586, GSI K27/597, GSI K27/600). It is important to note that mid-caudal AMNH 1957 is not only different in morphology from proximal caudal AMNH 1960 (also catalogued as Indosuchus raptorius), but it is larger than the latter, thus indicating that they do not belong to a same individual (and presumably pertain to different species).

Possibly Coeluroides largus may represent a valid taxon of an incleterminate abelisauroid theropod. Mid and distal caudals of Coeluroides retained notably developed neural spines. Comparing AMNH 1957 with the similarly elongated and low caudal centra of caudals of Majungatholus, it becomes evident that in AMNH 1957 the transverse processes are well developed, aliform structures, whereas in Majungatholus they are absent or represented by a faint longitudinal ridge. The evidence is not enough to evaluate whether Coeluroides largus and Jubbulpuria tenuis are synonyms, but their caudal vertebrae may represent theropod lineages different from Abelisauroidea. Similarities noted above between distal caudals of Jubbulpuria tenuis and Ligabuieno andesi (Bonaparte, 1996) argues in favor that other caudals with deltashaped transverse processes (e.g., Coeturoides largus, AMNH 1957) also belong to Abelisauroidea.

\section{Axial skeleton remains originally referred to as "allosaurid" and "coelurosaurid"}

"Allosaurid cervical vertebra" (K 27/590). This was described as a cervical vertebra (Huene \& Matley, 1933, pl. XIV, fig. 1), but it is here reinterpreted as a dorsal vertebra because the prezygapophyses are close each other, and the parapophyses are projected outwards occupying a high position on the neural arch (Fig. 18). GSI K. 27/590 is similar to dorsal 9 of Sinraptor (Currie \& Zhao, 1993) in the morphology of the prezygapophyses, with pendant ventral processes, and the pattern of laminae connecting the diapophysis with the parapophysis. Also, the prezygapophysis and diapophysis are connected by a ridge that is dorsally convex in lateral view, a deep pneumatic cavity is located between prezygapophysis and parapophysis, and an "Y"shaped crest connects the parapophysis with the diapophysis. The same description also applies to dorsal 5 of Carnotaurus and dorsal 7 of Ceratosaurus (Welles \& Madsen, 2000), but in these two taxa and GSI K 27/590 the parapophyses are more laterally prominent than in Sinraptor. Also, the prespinal cavity is large and deep, a synapomorphic trait shared by all neoceratosaurs (Holtz, 2000). In sum, dorsal GSI K 27/590 exhibits neoceratosaurian features, and because its morphology is congruent with that of abelisaurids and it was found in association with abelisaurid bones, we refer this specimen to Abelisauroidea indet.

"Allosaurid cervical vertebra" (K 27/572). This is a large vertebra (16 cm height), with an opisthocoelous centrum, albeit the cranial articu* lar surface is almost flat (Huene \& Matley, 1933, lám. XIV fig. 2). Huene cites that a single pleurocoel is present below the diapophysis. This cervical does not resemble that of Abelisauridae in the shape of the neural spine (which is axially extented and transversely narrow, instead of craniocaudally short and transversely wide as in abelisaurids), and the apparently poor development of the epipophyses (in contrast with the high and craniocaudally extended epipophyses of abelisauroids). Unfortunately, specimen GSI $\mathrm{K} 27 / 572$ is lost at the GSI collections, and first 

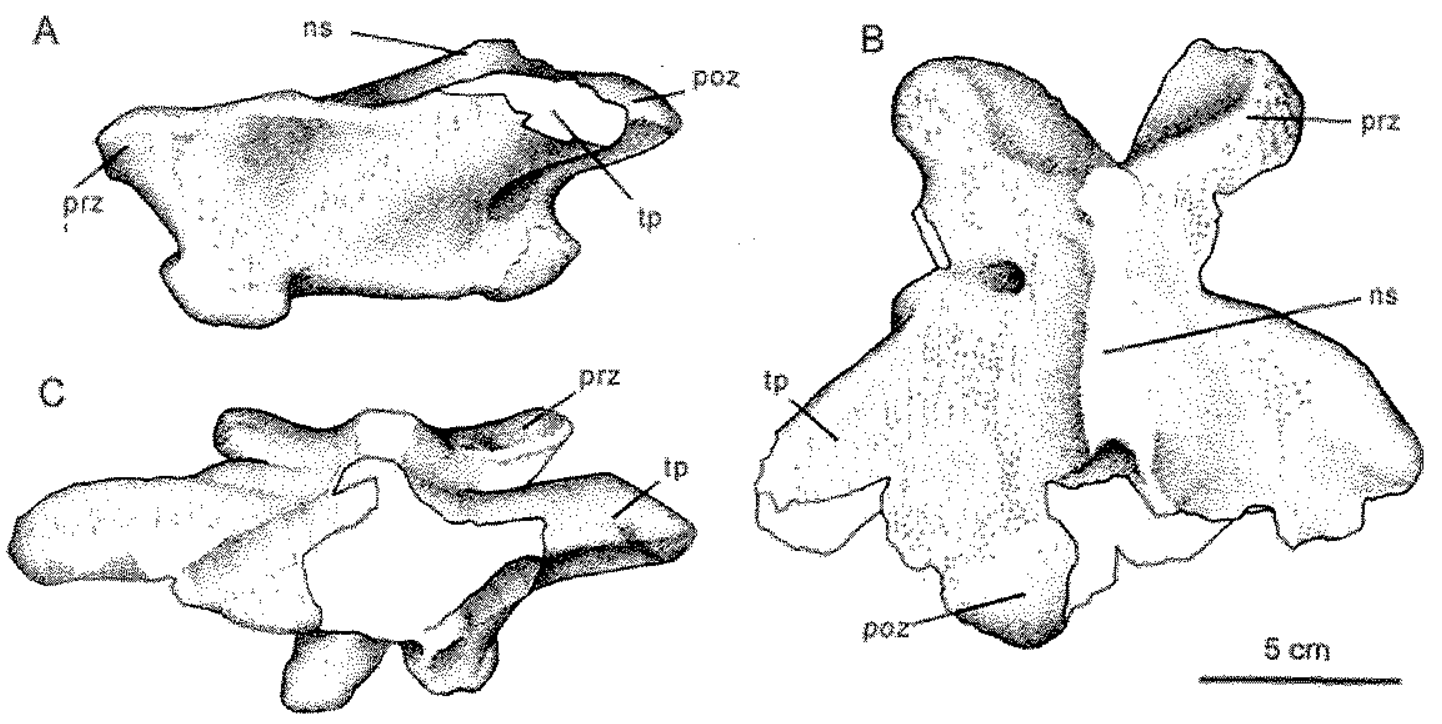

Figy. 16. Coeluroides largus (K.27/562), mid caudal vertebra, in A, left lateral, B, dorsal, and C, posterior views. Abbreviations: ns, neural spine; poz, postzygapophysis; prz, prezygapophysis; tp, transverse process.
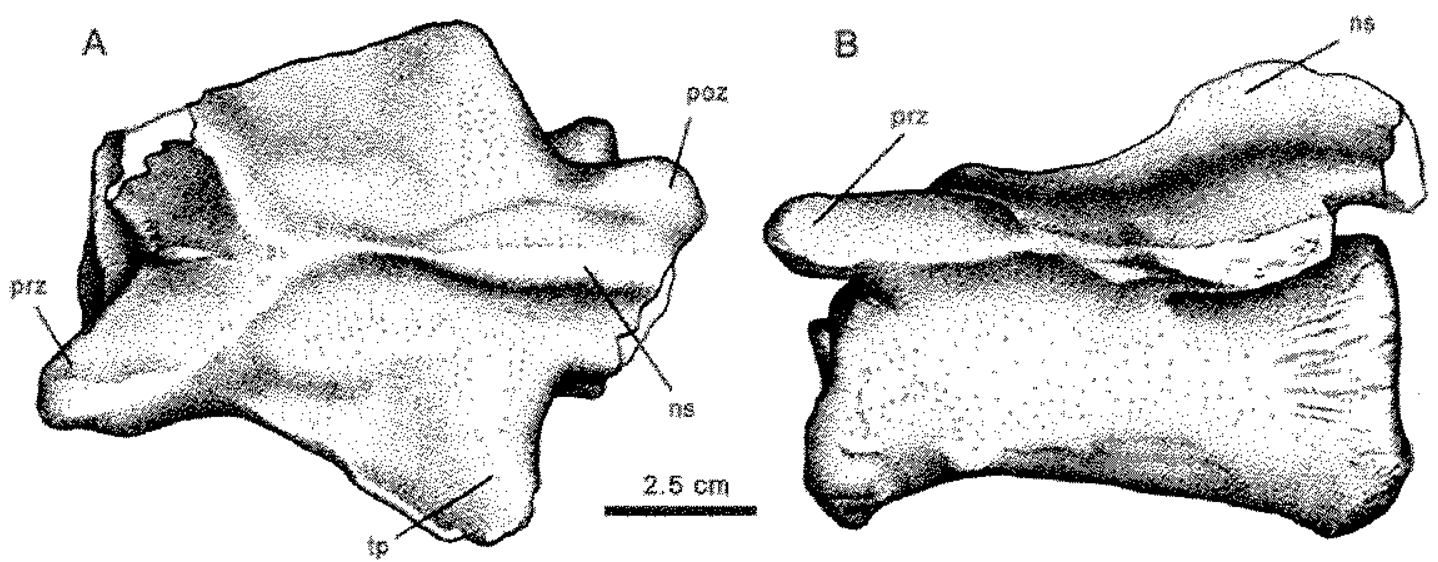

Fig. 17. Mid-caudal vertebra of an indeterminated abelisauroid (AMNH 1957) in A, dorsal, and B, left lateral views. Abbreviations: ns, neural spine; poz, postzygapophysis; prz, prezygapophysis; tp, transverse process.

hand observations are needed to test whether this represents clade of theropod other than Abelisauroidea in the "Carnosaur bed".

Sacral vertebrae. Huene and Matley illustrated some portions of fused sacral vertebrae under the numbers GSI K27/554 (two pieces), GSI K27/533 (two pieces) and GSI K27/571 (Fig. 19). More recently, Bonaparte (1991b) referred specimens GSI K27/533 and GSI K27/554 to Abelisauridae because they are fused into a sin- gle, rod-like structure similar to that of Carnotaurus. Although we do not dismiss that specimens GSI K27/533 and GSI K27/554 belong to Abelisauridae, their morphology more closely resembles that of Lametasaurus (Matley, 1923), Rajasaurus (Wilson et al., 2003) and Masiakasaurus (Cârraro et al., 2002) in that each sacral element is transversely broad and the contact between succesive vertebra is well marked. In Carnotaurus, instead, the sacral cen- 

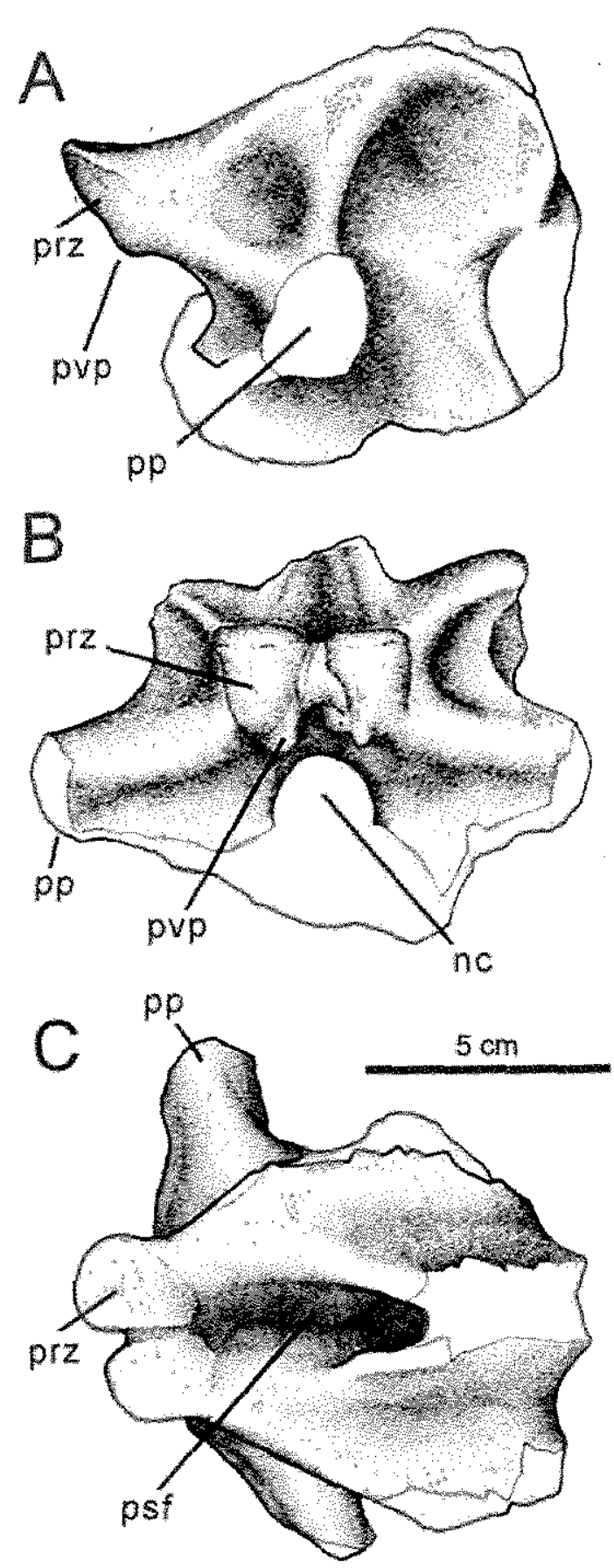

Fig. 18. Dorsal vertebra of an indeterminated abelisaurid (K27/590) in A, lateral, B, anterior, and $C$, dorsal views. Abbreviations: nc, neural canal; pp, parapophysis; prz, prezygapophysis; psf, prespinal fossa; pvp, pendant ventral process. tra are strongly reduced in transverse diameter and the contacts among succesive sacrals are slightly marked. Notably, specimen GSI K27/571 (firstly interpreted by Huene and Matley as coelurosaurian) responds to the Carnotaurus morphotype, thus suggesting the presence of two different large abelisauroids in the fossil assemblange.

There is a large isolated centrum (GSI K27/ $598 ; 19 \mathrm{C}, \mathrm{E})$ with a strong constriction at midlenght, but with highly expanded articular facets. This morphology remember that of sacral 1 of Rajasaurus (Wilson et al., 2003), thus we interpret specimen GSI K27/598 as a probable sacral 1 .

Proximal caudal vertebra (AMNH 1960). This proximal caudal is represented by a neural arch with elongate transverse processes, which are not entirely preserved at their extremities (Fig. 20). General morphology of AMNH 1960 is congruent with that of the proximal caudals of Majungatholus, Carnotaurus and Abelisauridae indet. MPM 99. However, derived traits of Abelisauridae (e.g., distally fanshaped transverse processes, and presence of a slender anterior projection on the transverse processes that contacts with the transverse process of the contiguous anterior caudal; Martínez et al., in press) are not identified in AMNH 1960. AMNH 1960 lacks well developed hyposphene-hypantrum articulations, thus differing from Aucasaurus and Carnotaurus in which hyposphene-hypantrum are present in the proximal and middle sections of the caudal series (Coria et al., 2002). Also, in AMNH 1960 the transverse processes are laterally oriented, instead of dorsolaterally as in the abovementioned Patagonian abelisaurids. Although this orientation may depend on the position of the vertebra in the caudal series, Majungatholus and a new abelisaurid specimen from Patagonia (Abelisauridae indet. MPM 99; Martínez et al., in press) also exhibit laterally projected transverse processes.

Medium and distal caudals. Some distal caudals (Fig. 22) are characterized by a polygonal centrum in cross-section, transverse processes represented by thick ridges overlapping both sides of the centrum, flat ventral surface of the centrum, rounded and short prezygapophyses, and $" \mathrm{Y} »-$ shaped neural arch in dorsal view (being cranially bifurcated towards the prezygapophyses). Distal caudals with these features are: AMNH 1958, GSI K27/596 (Fig. 22), K27/532, and GSI K27/594 (Huene \& Matley, 1933, pl. XXIII, fig. 2, and pl. 


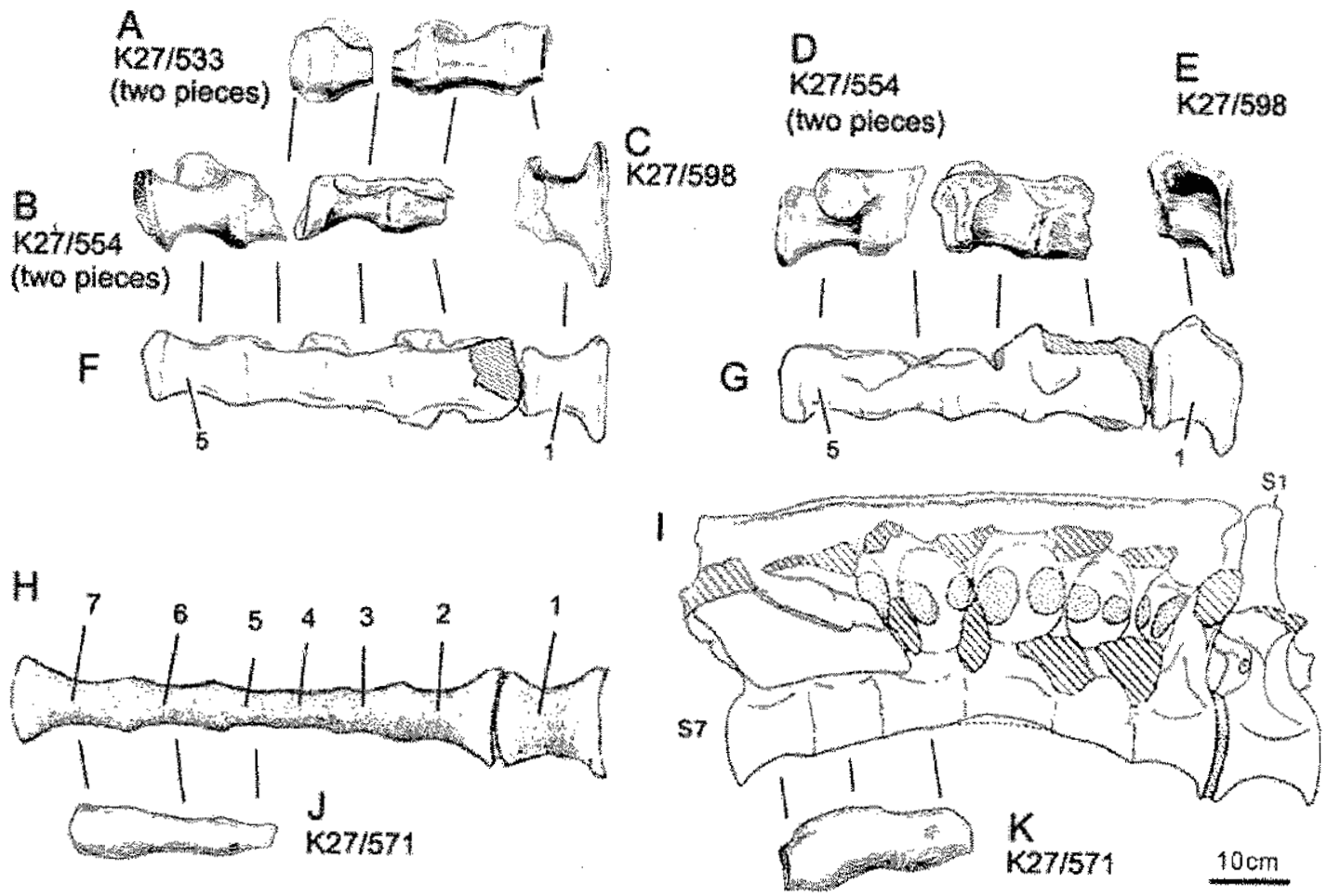

Fig. 19. Abelisauroid sacral vertebrae in ventral (A, B, F, H, J) and lateral (D, E, G, 1, K) views. A, specimen GSI K27/533 (from Huene \& Matley, 1933); B, D, specimen GSI K27/554 (from Huene \& Matley, 1933); C, E, specimen GSI K27/598 (from Huene \& Matley, 1933); F, G, Rajasaurus narmadensis (from Wilson et al., 2003); H, I, Carnotaurus sastrei (from Bonaparte et al., 1990); J,K, specimen GSI K27/571 (from Huene \& Matley, 1933). Not to scale.

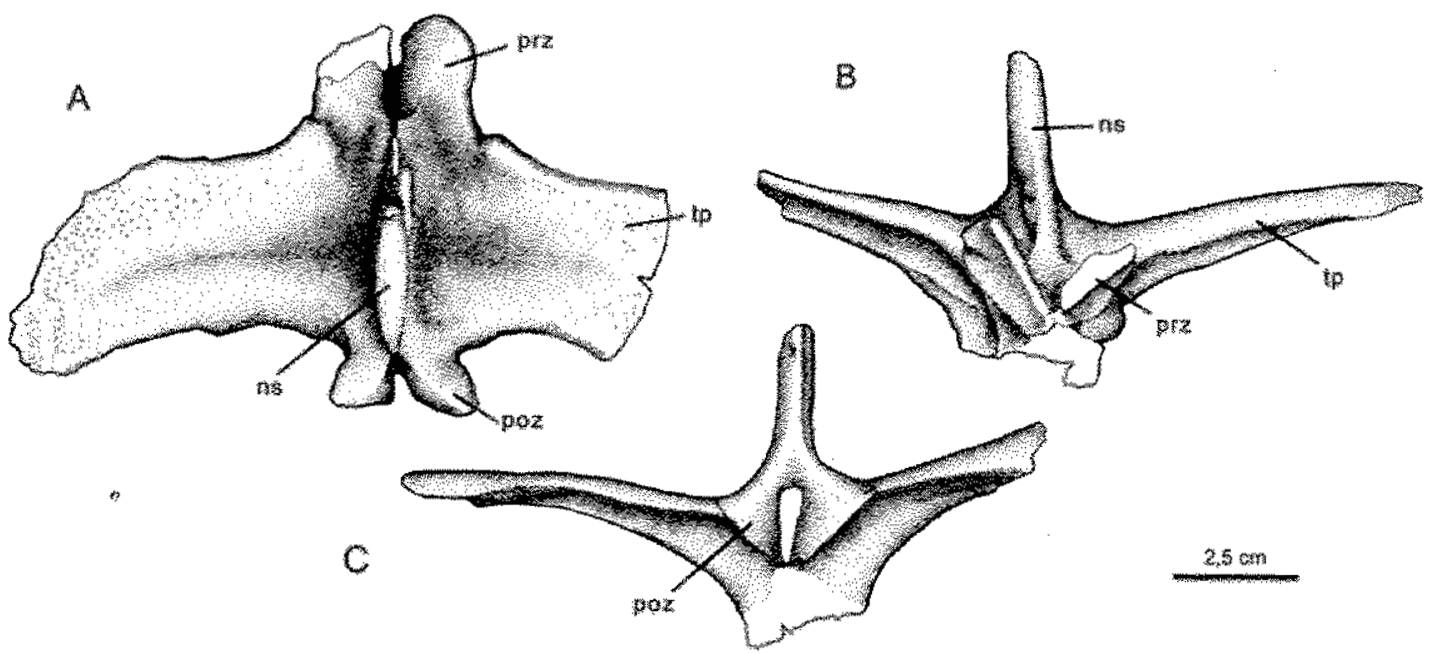

Fig. 20. Proximal caudal vertebra of an indeterminate abelisaurid (AMNH 1960) in A, dorsal, B, anterior, and $\mathrm{C}$, posterior views. 

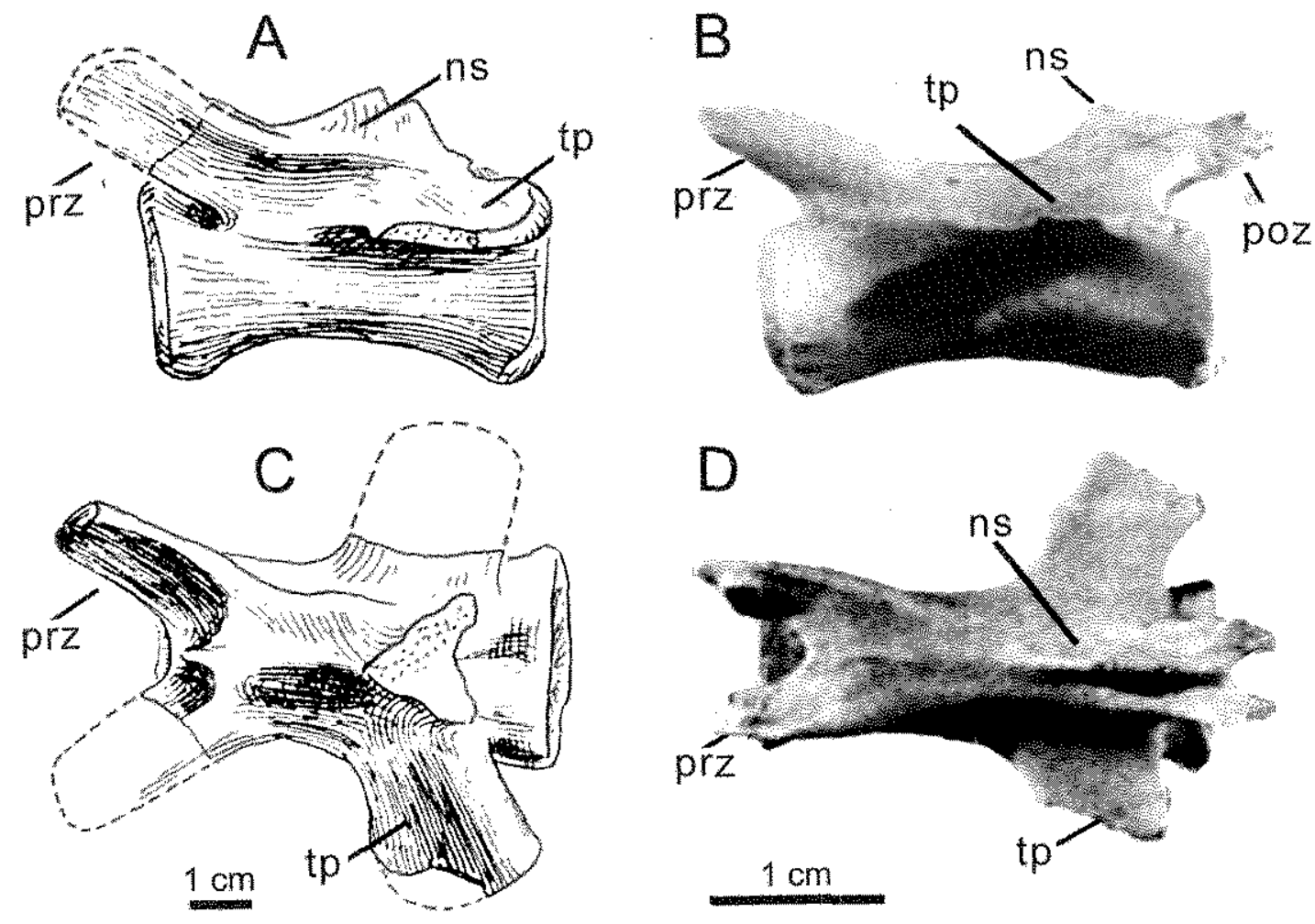

Fig. 21. Distal caudal vertebra of abelisauroids in lateral $(A, B)$ and dorsal $(C, D)$ views. A, C, indeterminated abelisauroid (K27/599), and B,D, Masiakasaurus knopfleri (from Carrano et al. 2002). Abbreviations: ns, neural spine; poz, postzygapophysis; prz, prezygapophysis; tp, transverse process.

XV, fig. 6, respectively). Caudals GSI K27/589 ("coelurosaurid", Huene \& Matley, 1933, pl. XXIII, fig. 3) and GSI K27/705 exhibit a similar pattern, although their prezygapophyses and centra are longer and thus they correspond to the distal end of the tail.

The kind of caudals described previously contrasts with another group in which the transverse processes are well developed, deltashaped (i.e., caudolaterally expanded), and have elongate centra and prezygapophyses. This group of vertebrae includes caudals of Jubbulpuria. An isolated caudal vertebra GSI K27/599 (Fig. 21), assigned by Huene and Matley (1933) to a coelurosaurid, resembles Masiakasaurus (Carrano et al., 2002) in the general shape and principaily in the shape of the transverse processes and elongate prezygapophyses. The latter suggests this is a mid- to distal caudal which retained well developed transverse processes. This combination of features sharply differs from the condition seen in other caudals with equally long centra (Fig. 22), but with short prezygapophyses and nearly absent transverse processes. This suggests the presence of abelisauroids with different kinds of caudal processes.

Obviously, more work needs to be done on the caudal anatomy of abelisauroids in order to resolve the allocation of isolated vertebrae, recognize the morphological variations along the tail series, and evaluate the taxonomic significance.

Haemal arches. Several isolated haemal arches (K27/672, GSI K27/566, GSI K27/676, GSI K20/362, GSI K27/674, GSI K27/680) have been described. Except for GSI K27/680, the haemal arches are elongate and rod-like, and lack a distal expansion, resembling the condition seen in other abelisaurids and Ceratosaurus (Wilson et al. 2003). In contrast with Carnotaurus, at least, the Indian chewrons posses a haemal canal that is proximally open.

\section{Pelvic and hind limb bones originally referred to as "allosaurid" and "coeluro" saurid"}

With the exception of two fragmentary ischia, no other pelvic bone was described from the 

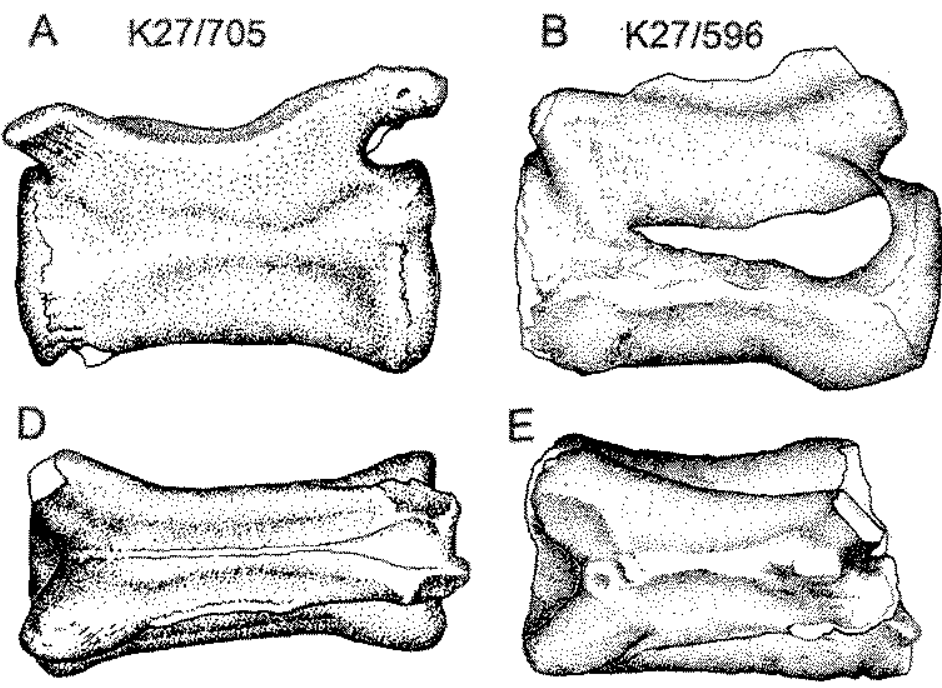

$5 \mathrm{~cm}$
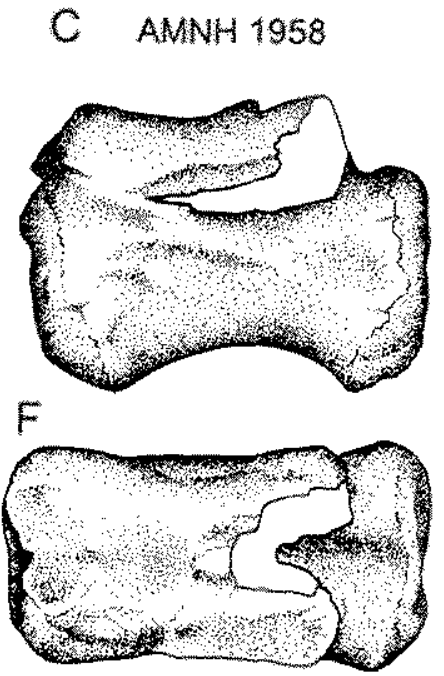

$5 \mathrm{~cm}$

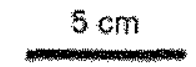

$5 \mathrm{~cm}$

Fig. 22. Distal caudal vertebra of indeterminated abelisauroids in left lateral (A-C) and dorsal (D-F), views. A, D, specimen GSI K27/705; B,E, specimen GSI K27/596; C,F, specimen AMNH 1958 (reversed). Cranial is to the left.

"Carnosaur bed". However, several hind limb elements (femora, tibia, metatarsals, and phalanges) have been recovered and they offer a good source of anatomical information. Huene and Matley (1933) distinguished two types of femora, one of a robust animal and another more slender one. Huene associated the robust kind of femora with a single, equally stout tibia, and referred them to the «allosaurids». Walker (1964) considered the slender kind of femora as belonging to Indosaurus and the stouter type to Indosuchus.

Ischium. Two fragmentary proximal ischia were described by Huene (K27/686 and GSI K27/ 546 ; pl. XVI, figs. 7,8 ). They are poorly informative, and their morphology matches with most basal theropods. The distance between the distal extremity of the obturator process and the iliac pedicle (lost), is approximately $10 \mathrm{~cm}$ and the craniocaudal diameter of the ischiac shaft is less than $4 \mathrm{~cm}$. This is in contrast to the holotype of Carnotaurus, for example, in which the distal tip of the obturator process is $30 \mathrm{~cm}$ from the iliac pedicle, and the craniocaudal diameter of the shaft (immediately distal to the obturator process) is 7 $\mathrm{cm}$. This indicates that ischia GSI K27/686 and GSI K27/546 belonged to animals smaller than
Carnotaurus, and that both bones would not have belonged to the larger forms found in the "Carnosaur bed".

Femur. Most of the femora described by Huene and Matley (1933) are between $60 \mathrm{~cm}$ and $74 \mathrm{~cm}$ in length (Fig. 23), thus belonging to animals of large size. We did not locate the great majority of the femora at the GSI collections, and our comments will mostly rely on Huene and Matley's illustrations. The exception is a proximal portion of a left femoral shaft newly cataloged with number GSI 296 which lost the corresponding numbers of the GSI K series (Fig. 24A). We presume that it may belong to any of the left femora (either GSI K27/564 or GSI K27/563) cited, but not figured, by Huene and Matley (1933:55).

As mentioned before, Huene and Matley sorted out the available 9 theropod femora from the quarry, into two subsets: stout femora (GSI K27/558, GSI K27/570, GSI K27/618) and slender femora (GSI K27/560, GSI K27/563, GSI K27/564, GSI K27/569, GSI K27/621, GSI K27/627). The robust femora are characterized by their relatively short and robust shafts, thus looking sharply different from the remaining non-avian theropods. They may belong to a single taxon (e.g., species) characterized by stout hindlimbs, 

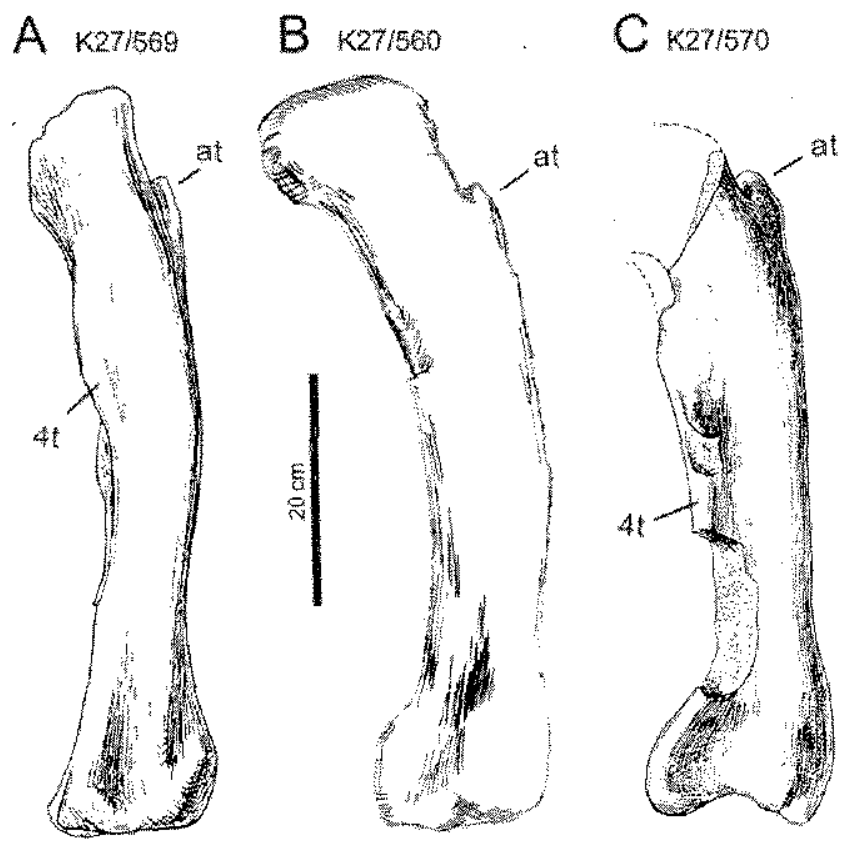

D א27/558

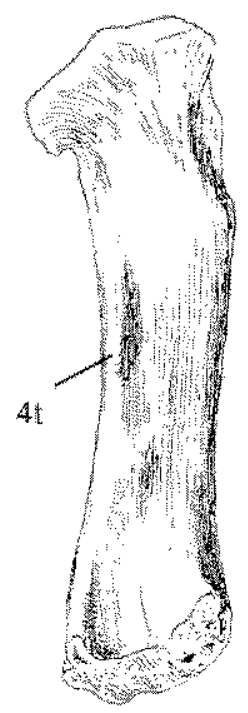

Fig. 23. Abelisaurid femora in caudal view. A, specimen GSI K27/569; B, specimen GSI K27/560; C, specimen GSI K27/570; D, specimen GSI K27/558, Abbreviations: at, anterior trochanter; $4 t$, fourth trochanter.

although some distinctions are observed among them, for example GSI K27/570 appears to exhibit a well developed (i.e., proximally projected) anterior trochanter, whereas in GSI K27/558 this trochanter is smaller. This last specimen, at least, exhibits features resembling Xenotarsosaurus (UNPSJB-PV 184-612) and Indosuchus (ISI R91/ 1), including: rounded femoral head, anterior trochanter low with respect to the femoral head, $4^{\text {th }}$ trochanter convex in side view, and presence of a prominent mediodistal crest. The slender specimen GSI 296 (Fig. 24A) exhibits the following resemblances with Xenotorsosaurus and Carnotaurus: the anterior trochanter is cranially convex in lateral view, the trochanteric shelf is prominent and located at level of the distal end of the anterior trochanter, the $4^{\text {th }}$ trochanter is also convex in side view, and a conspicuous pit for attachment of the $M$. caudofemoralis is present on the medial surface of femur, cranial to the $4^{\text {th }}$ trochanter.

All of the 9 femora discovered in the "Carnosaur bed" are morphologically congruent with the femora of other abelisaurids (e.g. Xenotarsosaurus, Carnotaurus, and ISI specimens of Indosuchus). Our interpretation is that the femora described by Huene and Matley belong to Abelisaurotdea, a conclusion that is in agreement with the whole bone assemblage, mostly (if not entirely made up by abelisauroid bones.

Tibia. Huene and Matley (1933) described three theropod tibiae corresponding to large theropods, none of which was available for the present study at the GSI collection. Only GSI K27/568 was illustrated by Huene and Matley (Fig. 25A). As earlier suggested by Bonaparte (1991b), this specimen resembles Abelisauridae in having a welldeveloped cnemial crest, and a poorly differentiated outer condyle on the proximal end, which is located at almost the same level as the inner condyle. The tibia bears an elongate cnemial crest as usual in neoceratosaturs, but the shaft is remarkably short and stout, being clearly different from other theropods, including most abelisauroids (e.g., Aucasaurus, Xenotarsosaurus, Majungatholus, Masiakasaurus). The only exceptions are the Indian Lametasaurus (Matley, 1923; Fig. 25B) and the Brazilian Pycnonemosaurus (Kellner \& Campos, 2002 ), in which the tibia is proportionally short. This peculiar condition of the tibia is not due to deformation, loss of its distal portion, or a pathological case, and therefore it constitutes a 


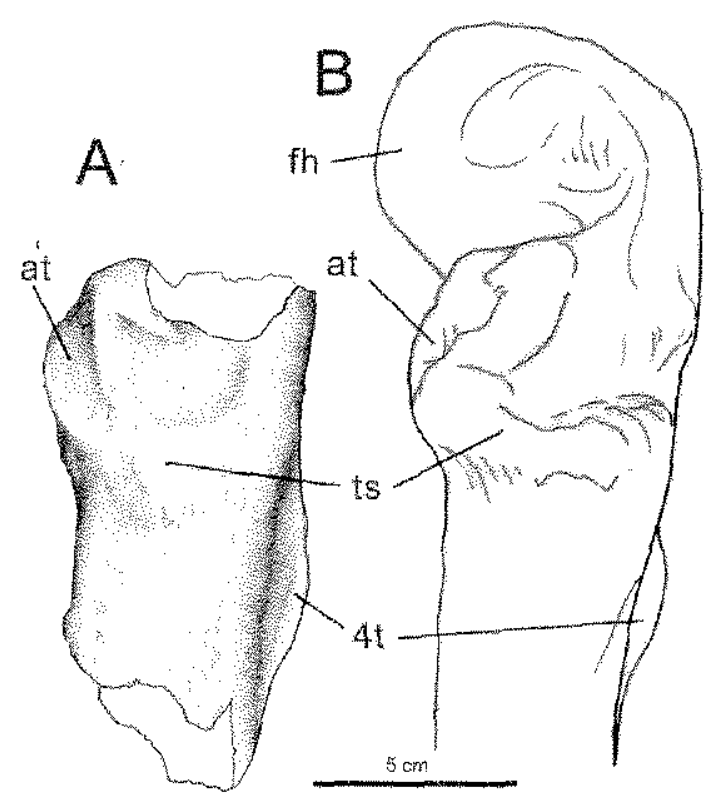

Fig. 24. Abelisaurid femora in lateral view. A, specimen GSI 296; B, Xenotarsosaurus bonapartei (UNPSJB-PV 184 and 612). Abbreviations: at, anterior trochanter; fh, femoral head; ts, trochanteric shelf; $4 \mathrm{t}$, fourth trochanter.

derived trait only documented in GSI K27/568 and Lametasaurus.

Huene and Matley (1933) also described some other tibiae interpreted as belonging to "Coelurosauria» (GSI K27/526, GSI K27/670, GSI K27/552, GSI K27/556, GSI K27/662, and GSI $\mathrm{K} 27 / 669$ ), but none of them could be located at the GSI collections, with the exception of GSI K27/ 669. We doubt that specimens GST K27/526 and GSI K27/669 were correctly identified as tibiae, and we prefer identify them as indeterminate limb bones.

Fibula. An incomplete left fibula ( $\mathrm{K} 27 / 620$; Fig. 26A) resembles that of abelisaurids (e.g. Xenotarsosaurus, Rajasaurus) in having a prominent iliofibularis tubercle and a well excavated fossa on the medial surface of the proximal end. Resemblances between GSI K27/ 620 and the fibula of Rajasaurus (Wilson et al., 2003) include the subtriangular contour of the proximal fossa, which is bounded by strong cranial and caudal ridges. Distal to the fossa, both ridges join to form a single, prominent longitudinal ridge extending along the fibular shaft. GSI K27/620 and Rajasaurus appear to lack the longitudinal groove present in the allosauroids Sinraptor and
Allosaurus (Madsen, 1976). The fibula GSI K27/ 620 and that of Rajasaurus differ from that of the abelisauroid Deltadromeus (Wilson et al., 2003), because in the latter taxon the fossa, albeit deep, is not subtriangular but proximodistally elongate. In sum, GSI K27/620 is recognized as an abelisauroid fibula.

Astragalus and calcaneum. As mentioned in previous pages, the purported astragalus (K27/ 684; Huene \& Matley, 1933, pl. XIX, fig.1) is in fact a left quadrate. Besides, the purported calcaneum (K20/396; Huene \& Matley, 1933, pl. XIX, fig. 2) is considered here to be an indeterminate bone.

Metatarsals. Several isolated metatarsals were recovered in the "Camosaur-bed". Review of these elements (either in the GSI collection or on the basis of Huene \& Matley's illustrations) indicate that: 1) the elements originally thought as belonging to the manus correspond in fact to the pes; 2) available metatarsals correspond to metatarsal II, III or IV; and 3) all these pieces exhibit abelisauroid features.

Metatarsal II (Fig. 27) is represented by specimen GSI K27/671 (Huene \& Matley's "allosauroid, distal extremity of mtt II") and presumably GSI K27/667 (Huene \& Matley's "coelurosaurid, distal end of metacarpal"), both of which exhibit resemblances to metatarsal II of Masiakasaurus (Carrano et al., 2002). They bear a double-flanged distal condyle of which the lateral flange is substantially larger than the medial one, as in Masiakasaurus.

Bones recognized here as metatarsal III (Fig. 28) include specimen GSI K27/665 (Huene \& Matley's "coelurosaurid, probably mtt III"), GSI K27/658 (Huene \& Matley"s "allosaurid, left mtt III"), and GSI K27/697+ GSI K27/681 (Huene \& Matley's "coelurosaurid, probably mtt II"). In them, the ginglymus is dorsoventrally low, as in the metatarsal III of basal ceratosaurians and abelisaurids (Valais et al., 2002). It is interesting to note the differences in size, proportions and shape of metatarsal III of specimens GSI K27/658 (a large abelisauroid with a metatarsal $25.4 \mathrm{~cm}$ long and with a distal ginglymus $5.2 \mathrm{~cm}$ thick; Fig. 28A-D), and specimens GSI K27/665 and GSI K27/ $697+681$ representing slender forms with a distal ginglymus $2.8 \mathrm{~cm}$ wide.

Finally, metatarsals interpreted here as metatarsal IV (Fig. 29) include the following specimens: GSI K27/539 (Huene \& Matley's "allosaurid, right metatarsal IV"; $25 \mathrm{~cm}$ long), GSI K27/659 (Huene \& Matley's "allosaurid, right metatarsal IV"), GSI K27/666 (Huene \& Matley"s "coelurosaurid, distal half of metacarpal"), and GSI K20/337C (Huene \& Matley's "coelurosaurid, 

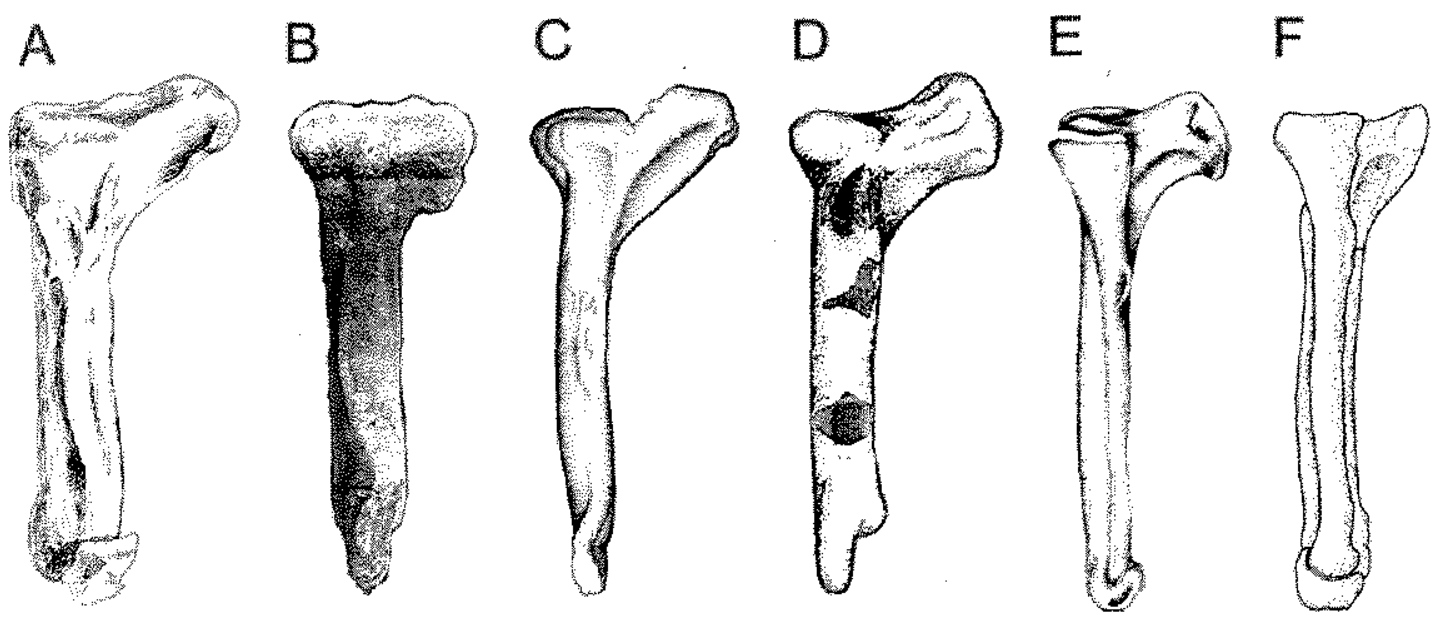

Fig. 25. Tibiae of several abelisauroid in right lateral view. A, specimen GSI K27/568 (from Huene \& Matley, 1933); B, Lametasaurus (from Matley, 1924); C, Indosuchus (ISI R91/1); D, Pycnonemosaurus (from Kellner and Campos, 2001); E, Aucasaurus (from Coria et al., 2001); Xenotarsosaurus (Martínez et al., 1986).
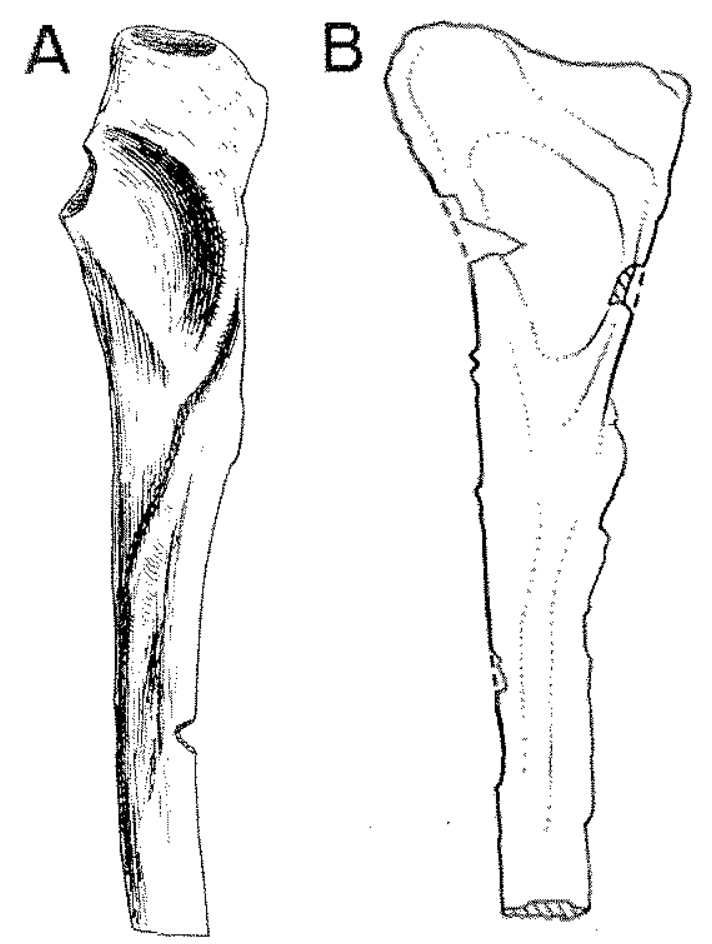

Fig. 26. Fibulae of abelisaurids in medial view. A, specimen GSI K27/620 (from Huene \& Matley, 1933); B, Rajasaurus narmadensis (right fibula, reversed; from Wilson et al. 2003). probably left metatarsal I"). All these bones exhibit deep and transversely compressed distal ends, with asymmetrically developed articular condyles (i.e., the inner condyle is more developed than the outer one), features that also apply to metatarsal IV of the abelisauroids Masiakasaurus (Carrano et al. 2002), Deltadromeus (Sereno et al. 1996), Aucasaurus (Coria et al., 2002), and Abelisauridae indet (MCA 56). As far as Huene \& Matley's figures suggest (pl. XIX, figs. 5 and 6 , and pl. XXIV, fig. 4), two kinds of metatarsal IV may be recognized: one in which the distal ginglymus is relatively robust (K27/539) and others with a transversely narrower ginglymus (K27/659 and GSI K27/666). Also, the shaft exhibits a different contour in transverse section: in GSI K27/539 it is trapezoidal-shaped with the longest side dorsal, instead in GSI K27/659 the transverse section is subtriangular, with the longest side ventral (Fig. 29). Such differences may correspond to two kinds of pes within Abelisauroidea, one in which metatarsals and their respective phalanges are robust, and another kind in which side metatarsals (II and especially IV) are more slender, as well as their respective phalanges, as it occurs in Velocisaurus (Bonaparte, 1991a).

Pedal phalanges. Huene and Matley (1933:57) noted that "there are more than 40 phalangeal bones", but they described three phalanges (e.g, GSI K27/651, GSI K27/652, GSI 


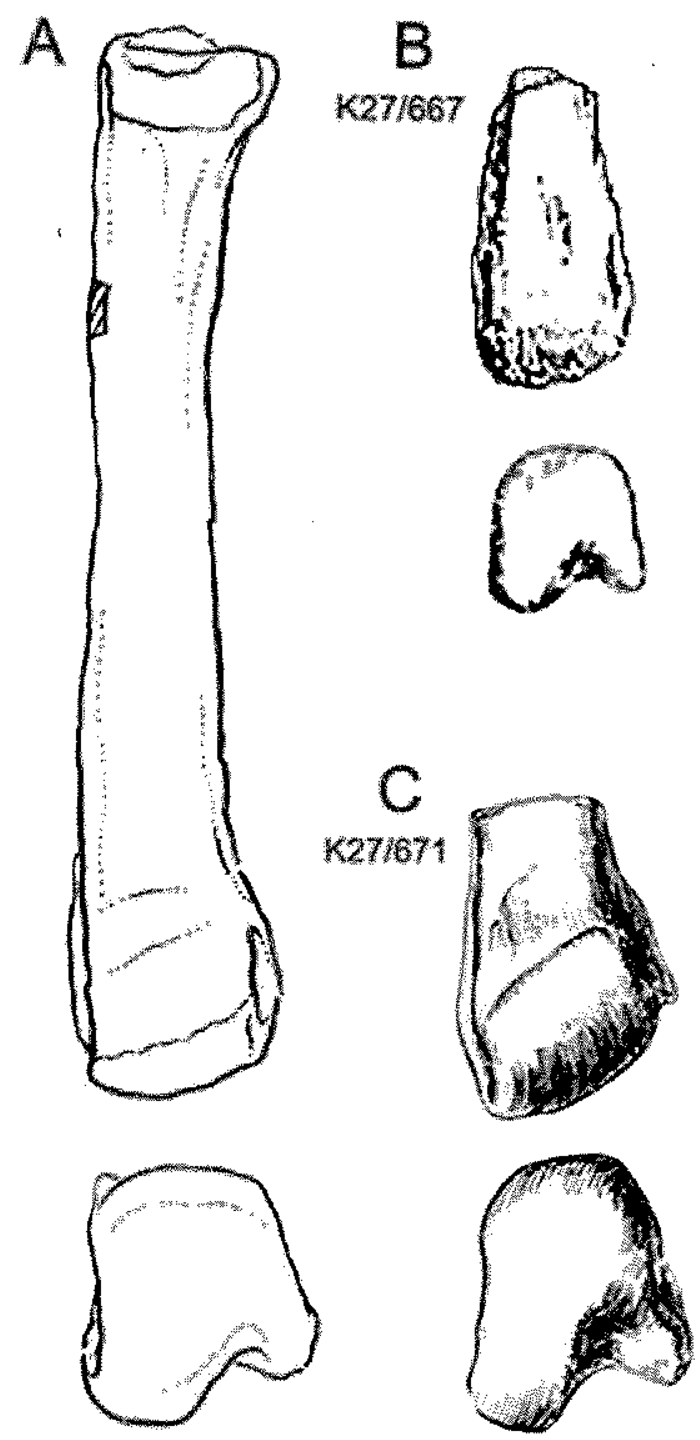

Fig. 27. Metatarsal II of abelisaurids in dorsal and distal views. A, Rajasaurus narmadensis (from Wilson et al. 2003); B, specimen GSI K27/667 (from Huene \& Matley, 1933); C, specimen GSI K27/671 (from Huene \& Matley, 1933).

K27/654), of which only GSI K27/654 has been illustrated (Huene \& Matley, 1933, pl.XIX, fig. 7). They are relatively large, measuring between 8 and $7 \mathrm{~cm}$ long. Specimen GSI K27/654 was originally interpreted as belonging to digit $I$, but we interpret it as corresponding to phalanx II-1. In addition, 18 non-unguals phalanges were also listed by the same authors as belonging to smaller theropods ("coelurosaurids"). From this set of phalanges, we have only accessed GSI K20/626B, GSI K27/648, GSI K27/524 (this last number has been also applied to a pedal ungual; Huene \& Matley, 1933, pl.XIX, fig. 13).

With the aim of determining their tentative positions in the pes, we have sorted out the phalanges illustated by Huene and Matley (1933, pls. XIX and XXIV) on the basis of their morphology, size, and relative proportions, identifying them as belonging to digits II, III and IV. This task was also supported by comparing this set of pedal elements with phalanges of other theropods (e.g., Allosaurus, Sinraptor, Velocisaurus, Aucasaurus). It is clear that the phalanges correspond to animals of different size and robustness.

The phalanges of digit II are represented by specimens GSI K27/654 (Huene \& Matley's "allosaurid pedal digit I") and GSI K27/524 (Huene \& Matley's "coelurosaurid manual digit I"). The morphology of these phalanges matches well with that of pedal phalanx 1 of digit II of Velocisaurus (Bonaparte, 1991a) in being elongate, strongly asymmetrical, with a dorsoventrally deep proximal end, and a pair of well developed proximoventral longitudinal ridges (Fig. 30, A,B). However, specimens GSI K27/654 ( $8 \mathrm{~cm}$ long) and GSI K27/524 $(6 \mathrm{~cm}$ long) correspond to an animal considerably larger than Velocisaurus, in which phalanx III-1 reaches 2.3 cm long.

The phalanges of digit III are represented by the following GSI specimens (Fig. 30, C-F): GSI K27/653 (Huene \& Matley"s "allosaurid foot phalanx"), GSI K27/646 (Huene \& Matley's "coelurosaurid pedal phalanx of digit IV"), GSI K27/525 (Huene \& Matley's "allosaurid pedal phalanx"), and GSI K27/644 (Huene \& Matley's "coelurosaurid pedal phalanx"). They are symmetrical and dorsoventrally depressed phalanges, which are more robust than the remaining phalanges. Their proximal ends are laterally and medially flared for articulation with the corresponding metatarsal III or the preceeding phalanx. In proximal aspect they are crescent-shaped. Available phalanges of digit III are characterized by the presence of a low and wide proximal articular surface, in congruence with the subrectangular distal condyle of metatarsal III. In lateral view, the dorsal margin of these phalanges is more or less straight, and the ginglymus lacks a dorsally expanded articular facet, being slightly more depressed than the rest of the dorsal margin of the bone, a condition contrasting with most other theropods (e.g., Allosaurus and Sinraptor). Specimen GSI K271 653 (Fig. 30, D) is interpreted here as a pedal 

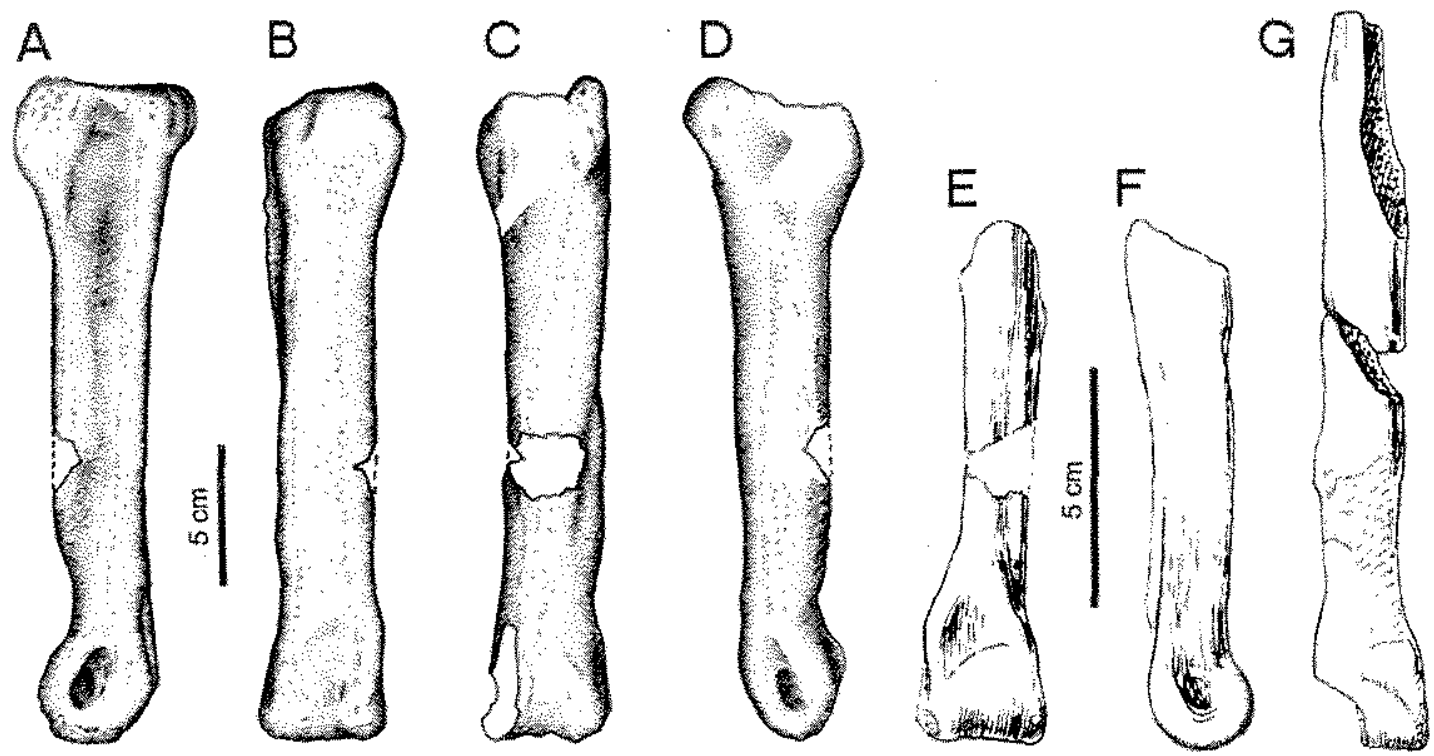

Fig. 28. Metatarsal III of abelisauroids. A-D, specimen GSI K27/658 (left metatarsal III) in medial (A), dorsal (B), ventral (C), and lateral (D) views; E,F, specimen GSI K27/665 in dorsal (E), and side (F) views (from Huene \& Matley, 1933); G, specimens GSI K27/697+681 in dorsal view (from Huene \& Matley, 1933).

phalanx III-2 and GSI K27/646 (Fig. 30, E) probably corresponds to pedal phalanx III-1. The latter one resembles Aucasaurus in its robust proportions, albeit its size $(3.6 \mathrm{~cm}$ long and $2.6 \mathrm{~cm}$ wide proximally) indicates that it probably corresponds to a juvenite individual of a robust abelisauroid. In addition, GSI K27/525 is considered to be pedal phalanx III-1 (it measures $7.6 \mathrm{~cm}$ long and $5 \mathrm{~cm}$ wide proximally), and GSI $\mathrm{K} 27 / 644$ as pedal phalanx III-2 $(4.6 \mathrm{~cm}$ long and approximately $2.3 \mathrm{~cm}$ wide proximally). In sum, two subsets of digit III phalanges seem to be distinguished by their relative proportions: GSI K27/653 and GSI K27/646 are proportionally robust, whereas GSI K27/525 and GSI K27/644 are of more slender proportions, in particular the latter specimen which resembles Velocisaurus (Bonaparte, 1991a).

The phalanges of digit IV are represented by the following specimens (Fig. 30, G-M): GSI K20/ 337B (Huene \& Matley's "coelurosaurid foot phalanx"), GSI K27/637 (Huene \& Matley”s "coelurosaurid foot phalanx"), GSI K27/638 (Huene \& Matley's "coelurosaurid foot phalanx"), GSI K27/647 (Huene \& Matley"s "coelurosaurid foot phalanx of digit IV"), GSI K20/626 (Huene \& Matley"s "coelurosaurid manual phalanx"),
GSI K27/642 (Huene \& Matley's "coelurosaurid manual phalanx"), and GSI K27/648 (Huene \& Matley"s "coelurosaurid manual phalanx"). In agreement with the distal condyle of metatarsal IV described above (K27/659), phalanges of this digit are transversely narrow and dorsoventrally deep, in sharp contrast with those of nonabelisauroid theropods such as Sinraptor, Allosaurus and Deinonychus, in which the phalanges of digit IV are proportionally lower and wider. This is a notable character not described before for abelisauroids, except for Masiakasaurus (Carrano et al., 2002). In contrast with the above described phalanges of digit III, those from digit IV have deep dorsoventral grooves on their distal ginglymoids.

Specimen GSI K20/626B was interpreted by Huene and Matley (1933, pl. XXIV, fig. 7) as a "coelurosaurid manual phalanx". However, this is a pedal element that closely resembles pedal phalanx IV-1 of Velocisaurus (Bonaparte, 1991a). As in the latter taxon, GSI K20/626B is proximodistally short but transversely compressed (Fig. 30, G-I). GSI K20/626B is pedal phalanx IV-1, and GSI K27/648 (Fig, 30, I) is interpreted as IV.3. These last two specimens resemble the phalanges of digit IV of Velocisaurus 


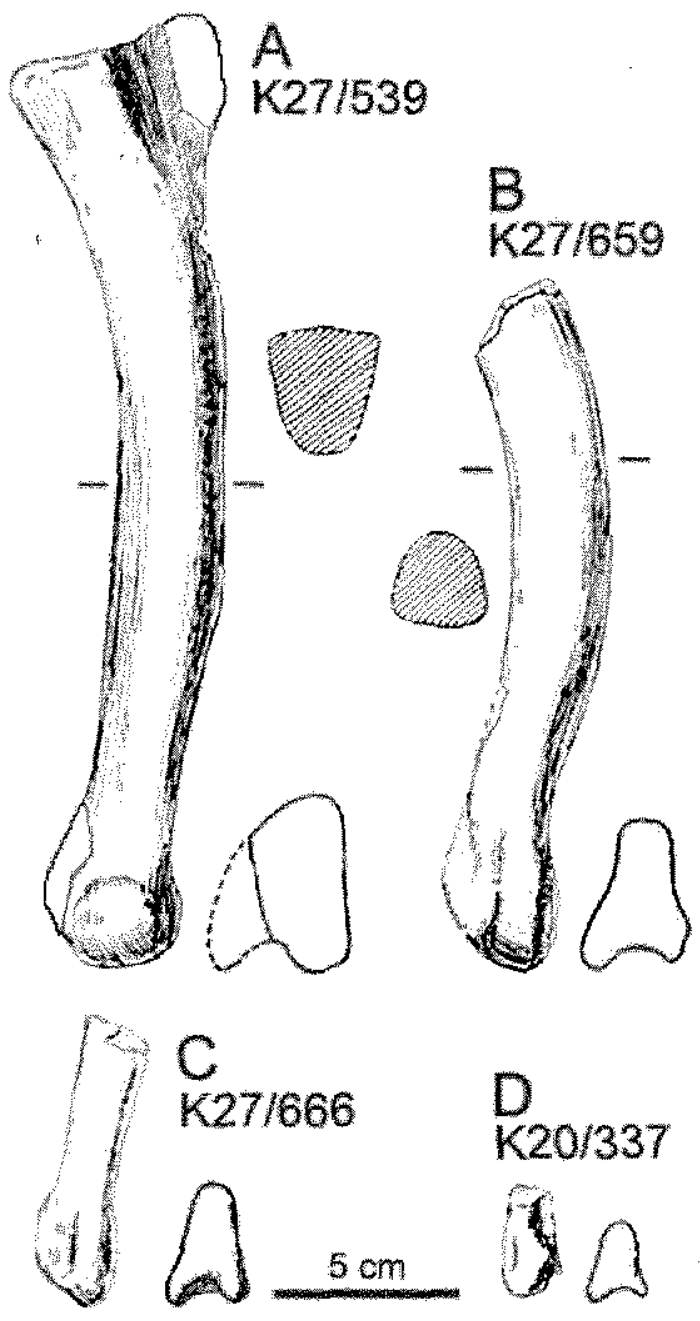

Fig. 29. Metatarsal IV of abelisauroids in dorsal and distal views. A, specimen GSI K27/539 (midshaft cross-section indicated on its right); B, specimen GSI K27/659 (mid-shaft cross-section indicated on its left); C, specimen GSI K27/666; $\mathrm{D}$, specimen GSI K20/337 (all figures taken from Huene \& Matley, 1933).

in being transversely compressed, with a distal ginglymus asymmetrically developed (i.e., the inner condyle is wider and deeper than the outer one), and with a deep dorsoventral groove on distal ginglymus. They also exhibit well excavated collateral and extensor ligament pits. The proximal end of both phalanges is triangular, with the long axis oriented dorsoventrally. This condition resembles the proximal phalanx of digit II, and may lead to confusion regarding the identification of such pedal elements, but the phalanges of digit IV lack of the proximoventral ridges characteristic of the proximal phalanges of digit II. Also, the medial surface of digit IV phalanges is high and almost flat, and exists on its proximoventral corner a deep excavation. Although specimens GSI K20/626B and GSI K27/ 648 exhibit a similar morphology, they appear to belong to different individuals: GSI K20/626B is $5 \mathrm{~cm}$ long and $2.2 \mathrm{~cm}$ wide, but GSI K27/648 is $2.6 \mathrm{~cm}$ long and $1.2 \mathrm{~cm}$ wide, suggesting that individuals in different growth stages, and presumably belonging to a same species (e,g, a gracile abelisauroid), are represented in the "Carnosaur bed".

Huene and Matley say (1933:67) that phalanx GSI K20/626B perfectly articulates with the distal half of a bone that they thought as a "metacarpal of a coelurosaur" (K27/666, here reindentified as distal end of metatarsal IV).

There is another group of phalanges of digit IV (Fig. 30, J-M) which are very short, deep and transversely wide, showing a more conservative morphology similar to that present in other theropods (e.g., Sinraptor, Allosaurus, ornithomimids). Digit IV phalanges of the robust kind are similar to those of the abelisaurid Aucasaurus (Coria et al., 2002), and they can be sorted out on the basis of their size: GSI K20/337B (probably a pedal phalanx IV-2; it is $2.4 \mathrm{~cm}$ long and $1.2 \mathrm{~cm}$ wide proximally) and GST K27/647 (interpreted as a pedal phalanx IV-4) may correspond to a single specimen of small size. Instead, GSI K27/638 (identified here as phalanx IV-3, being $3.8 \mathrm{~cm}$ long and $2.6 \mathrm{~cm}$ wide proximally), and GSI K27/637(interpreted as phalanx IV-4; it is $2.8 \mathrm{~cm}$ long and $2.4 \mathrm{~cm}$ wide proximally), are short, wide and deep pedal digit IV phalanges, responding to an Aucasaurus kind of foot but belonging to a larger specimen.

Summing up, available pedal digits indicate that: 1) they are congruent with abelisauroid anatomy; 2) differences with the set of transversely narrow digit III and IV phalanges described before may reveal the presence of more than one type of abelisauroid species in the quarry, i.e., an Aucasaurus-like foot with more robust phalanges on digits III and especially IV (Figs. 29,32 ), and a Velocisaurus-like foot with slender phalanges (Fig. 31).

There were many more phalanges (Huene \& Matley, 1933:67), originally described as belonging to a single foot, but such pedal elements were not illustrated with the exception of GSI K27/646, GSI K27/647 and GSI K29/337B (see Figs. 30 and 32 ), so there are no possibilities to evaluate such an association. 
A $K 27 / 524$
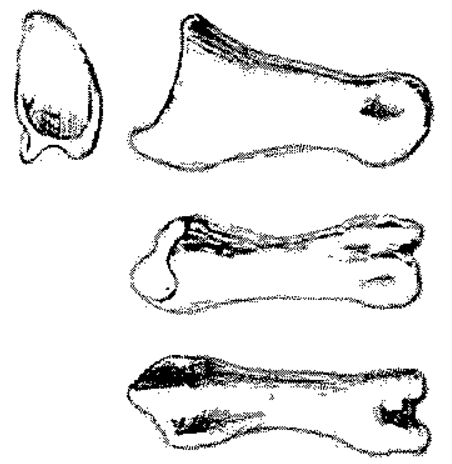

B K27/654
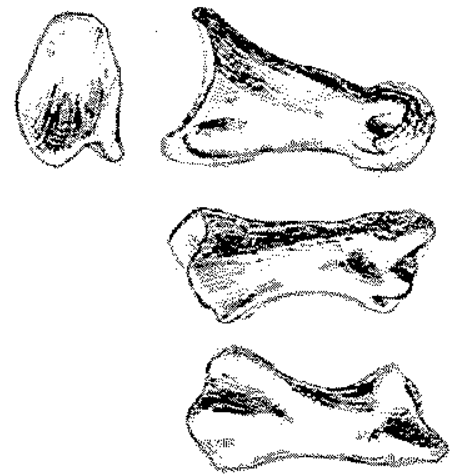

\section{K27/525}
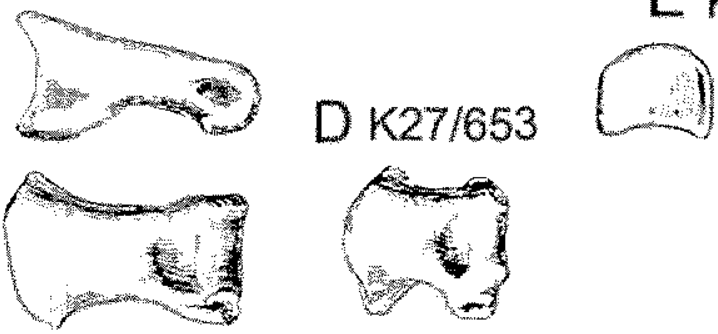

E K27/646

F K27/644
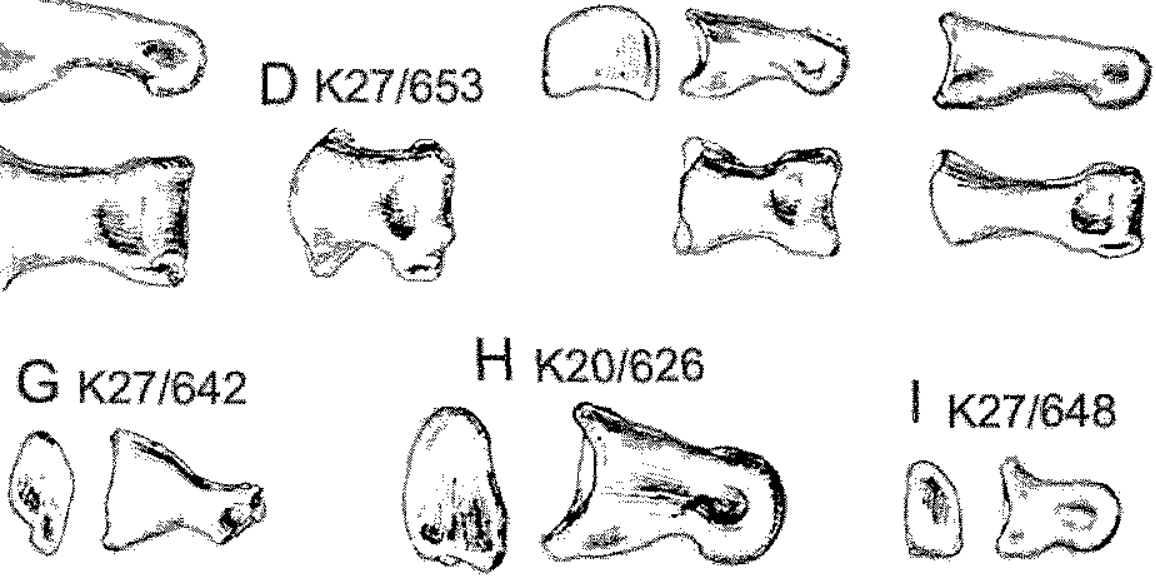

K27/648
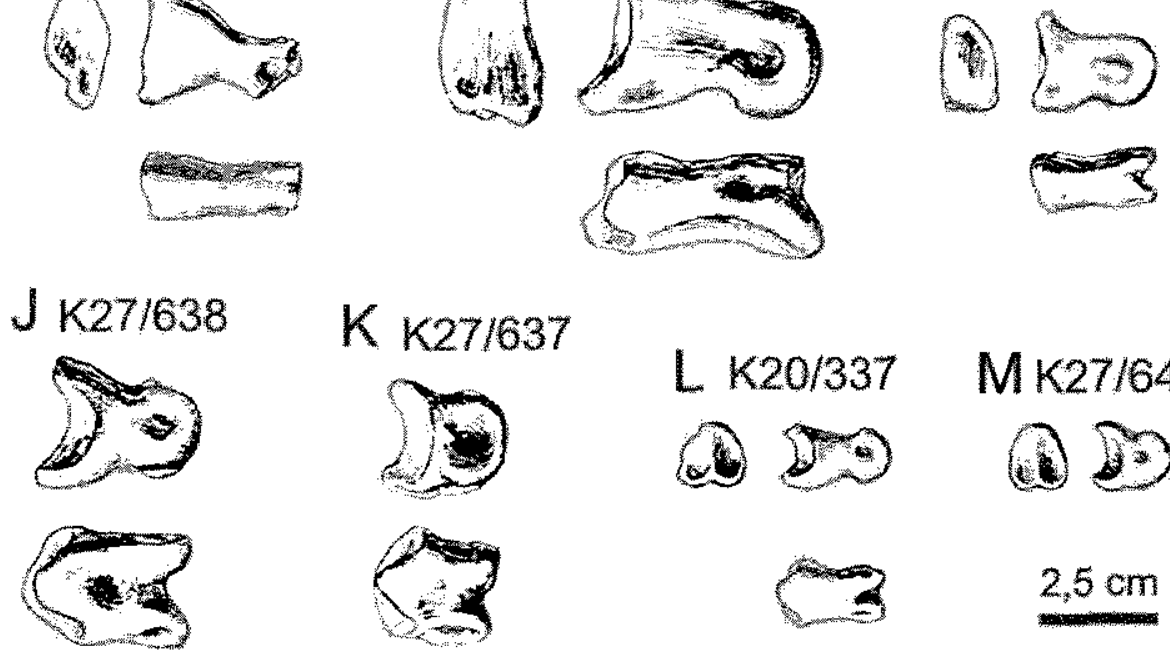

\section{K20/337}

M K27/647
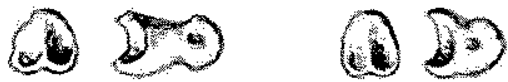

$2,5 \mathrm{~cm}$

Fig. 30. Pedal phalanges of abelisauroids. A, phalanx 1.II (K27/524), in proximal, lateral, dorsal and ventral views; $B$, phalanx $1 . I I$ (K27/654), in proximal, lateral, dorsal and ventral views; C, phalanx 1.III (K27/525) in lateral and dorsal views; D, phalanx 2.III (K27/653) in dorsal view; E, phalanx 1?.III (K27/646) in proximal, lateral and dorsal views; F, phalanx 2.III (K27/644) in lateral and dorsal views; $\mathrm{G}$, phalanx 1.IV? (K27/642) in proximal, lateral and dorsal views; H, phalanx 1.IV (K20/626B) in proximal, lateral and dorsal views; I, phalanx $3 . \mathrm{IV}(\mathrm{K} 27 / 648)$ in proximal, lateral and dorsal views; $J$, phalanx 3.IV (K27/638) in lateral and dorsal views; K, phalanx 4.IV (K27/637) in lateral and dorsal views; L, phalanx 2?.IV (K20/337B) in proximal, lateral and dorsal views; M, phalanx 4.IV (K27/647) in proximal and lateral views. All figures taken from Huene and Matley, 1933. 
A

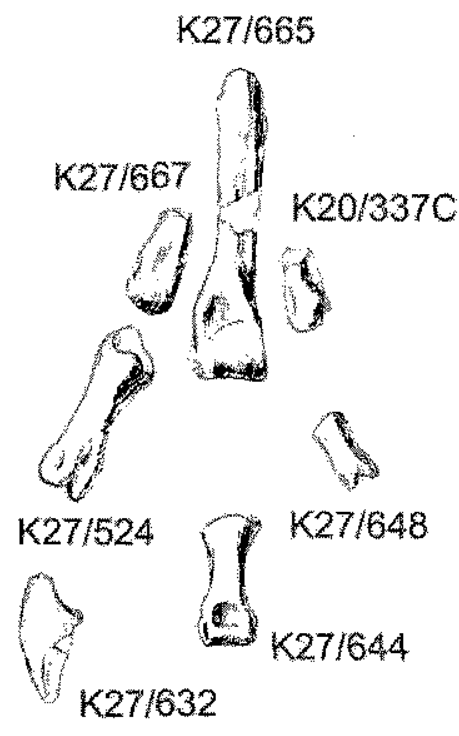

$5 \mathrm{~cm}$

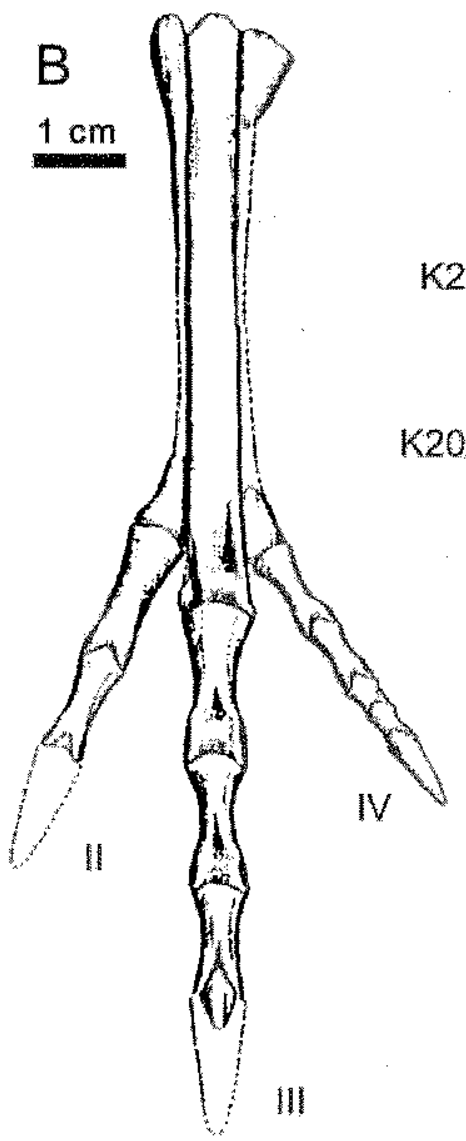

Fig. 31. Abelisauroid foot. A, composite reconstruction based on different pedal elements (indicated on the figure). B, articulated metatarsals and phalanges of the left foot of Velocisaurus (from Bonaparte, 1991a), in dorsal view. C-E, metatarsal IV (K27/666) articulated with phalanx 1.IV (K20/626B), in dorsal (C), distal, proximal, and side views; $F$, composite reconstruction of pedal digit IV in side view, based on different pedal elements (indicated on the figure), and compared with same digit of Velocisaurus (from Bonaparte, 1991a).

Unguals. As analyzed elsewhere (Novas \& Bandyopadhyay, 2001) the set of ungual phalanges figured by Huene and Matley (1933) correspond to the pes, thus dissmising interpretations of these authors that at least some unguals belong to the hand. Also, these pedal unguals exhibit the same morphological pattern (e.g., presence of proximally bifurcated grooves, rounded bump on the lateral side of pedal unguals, and ventral surface excavated or with a narrow deep furrow), described for other abelisauroids (Abelisauridae indet. MCA 56, Masiahasaurus; Novas \& Bandyopadhyay, 2001; Carrano et al., 2002). For a more exhaustive review of the pedal unguals, see Novas and Bandyopadhyay (2001).

\section{CONCLUSIONS}

The review of the theropod bones collected at the "Carnosaur bed" demonstrates that differences in shape, size and proportions of postcranial and cranial bones support the presence of individuals at different growth stages. Cranial and posteranial elements exhibit ceratosaurian, abelisauroid or abelisaurid traits, or they are morphologically congruent with abelisauroids. In other words, most, if not all, of the theropod specimens documented in the quarry correspond to Abelisauroidea. The only possible exception may be a large cervical vertebra (K27) 


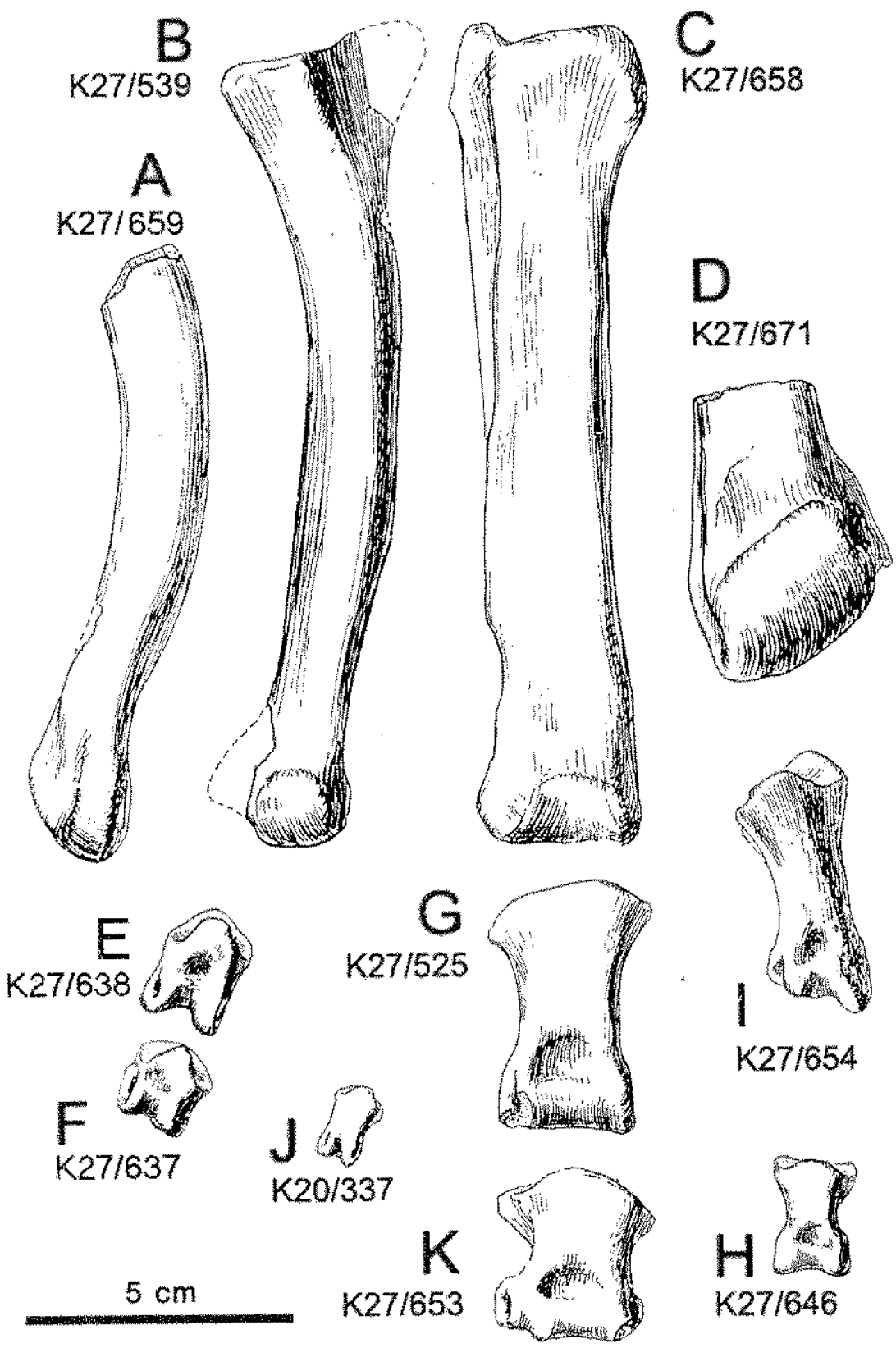

Fig. 32. Abelisaurid foot. Different pedal elements corresponding to individuals of different sizes, eventually referable to as Abelisauridae. A, metatarsal IV (K27/659); B, metatarsal IV (K27/539); C, metatarsal III (K27/658); D, metatarsal II (K27/671); E, phalanx 3 IV (K27/638), F, phalanx 4 IV (K27/ 637); G phalanx 1 III (K27/525); H, phalanx 1 III (K27/646); I, phalanx 2 II (K27/654); J, phalanx 4 IV (K20/337); K, phalanx 2 III (K27/653). All figures taken from Huene and Matley, 1933.

572) which does not exhibit features consistent with this clade.

Most of the taxa originally described by Huene and Matley (1933) on the basis of vertebral remains (Compsosuchus solus, Dryptosauroides grandis, Ornithomimoides barasimlensis, and Jubbulpuria tenuis, Coeluroides largus) are here considered nomina dubia, in agreement with previous authors (Molnar, 1990; Norman, 1990; Welles, 1984). The axis of Compsosuchus solus 
may belong to an abelisauroid the size of Carnotaurus, and it is not illogical to refer this vertebra to Indosuchus raptorius because of its similarities with this taxon. Besides, the proximal caudals of Dryptosauroides grandis and Ornithomimoides barasimlensis are morphologically congruent with the proximal caudals of abelisaurids (e.g., Majungatholus). The caudals of Jubbulpuria tenuis and Coeluroides largus may also belong to Abelisauroidea (because of their resemblance with the Patagonian Ligabueino), albeit they seem different from the caudals of abelisaurids, thus suggesting that the fossil assemblange at the "Carnosaur bed" includes the remains of individuals corresponding to different abelisauroid species.

Sorting out the available cranial and postcranial materials into discrete individuals and taxa is currently not possible, but some postcranial bones (sacral and caudal vertebrae and pedal bones) show contrasting morphological patterns. Among equally elongate distal caudals, some bear short prezygapophyses and almost absent transverse processes, instead other caudals bear elongate prezygapophyses and well developed, triangular-shaped transverse processes. We also recognize two different pedal types (i.e., transversely wide vs. transversely narrow pedal digit IV) and two types of sacrum (i.e., a conservative one in which sacral centra -although fused- remain distinct from each other, vs. a Carnotaurus-like sacrum in which the centra are rod-like, with smooth intervertebral contacts). Such distinctions in sacral, caudal, and pedal morphologies probably reflect the presence of two main abelisauroid clades, informally large abelisaurids (represented in the quarry by Indosuchus and Indosaurus) and smaller noasaurids (represented in the quarry at least by Laevisuchus). Because Laevisuchus is referred to as the Noasauridae, and since some metatarsals and pedal phalanges resemble these of the noasaurids Velocisaurus and Masiakasaurus, we tentatively associate the slender foot bones with Noasauridae or Laevisuchus. Caudals with well developed transverse processes are also tentatively referred to Noasauridae. Instead, distal caudals devoid of transverse processes and having short prezygapophyses, and short and robust pedal digits, more probably belong to abelisaurids. To this list of robust abelisaurid bones, we add all the hindlimb bones (femora, tibiae, metatarsals, phalanges) of large size as well as those of small size but with robust proportions. With respect to the sacral vertebrae, the slender and rod-like kind is documented so far in
Carnotaurus among abelisauroids, but the more conservative type (in which each sacral element is transversely broad and the contact between succesive vertebrae is well marked) are documented among abelisauroids both in Abelisauridae (e.g., Rajasaurus) and Noasauridae (e.g., Masiakasaurus). For this reason, it is probable that the "Carnosaur bed" includes remains of different forms of Abelisauridae. In this regard, we concur with Huene and Matley about the distinctions in femoral proportions ("slender" vs "robust") seen in the femora of large abelisaurids. However, referral of this set of hindlimb bones either to Indosuchus or Indosaurus is not warranted at the moment.

As already mentioned in the Introduction, the abelisaurid Lametasaurus indicus was found in the "Carnosaur bed". Since this taxon characterizes by a stout and transversely wide tibia, we interpret the short and stout femora (GSI K27/558, GSI K27/570, GSI K27/618) and tibiae (GSI K27/568) discovered in the same quarry as probably belonging to Lametasaurus indicus. Moreover, it would not be dismissed that Lametasaurus indicus may constitutes a senior synomym of the also robust Indosaurus matleyi and Rajasaurus narmadensis.

The fragmentary nature of the Indian abelisaurids, including Lametasaurus, Rajasaurus, Indosaurus and Indosuchus (except specimen ISI R91/1 referred to as Indosuchus raptorius, still awaiting a detailed description), obstructs easy recognition of the taxonomic validity of each of these taxa. Eventual solution of their respective taxonomic validity will need direct comparisons among all specimens as well as new, more complete discoveries. We keep the names Indosuchus, Indosaurus, Rajasaurus and Lametasaurus pending new studies or more discoveries that might clarify whether these taxa can be diagnosed on the basis of autapomorphies.

Although our knowledge on the anatomy and phylogeny of Indian abelisauroids is far from being settled, it seems clear that these theropods were numerically dominant and taxonomically diverse in the Late Cretaceous of India, as documented in different fossil sites of the Lameta Formation (e. g., Bara Simla, Rahioli), a view that is in concert with the information available from other Gondwanan localities of Late Cretaceous age (Madagascar, Patagonia).

\section{ACKNOWLEDGEMENTS}

The senior author received support from Agencia Nacional de Promoción Científica y Técnica, The National Geographic Society, CONICET, 
Fundación Antorchas, and The Jurassic Foundation. Thanks to Ashok Sahni for the support received during the trip of FEN to India. Our gratitude to the personnel of the Geological Survey of India (Kolkata) for allowing us to study the theropod collection, and P. Ghosh for his information on Indian geology. M. Carrano and S. Chatterjee offered valuable observations on the manuscript. We wish to thank also to Catherine Forster, Dave Krause, Sankar Chatterjee, and Rodolfo Coria for access to specimens under their care, and Jorge González for his artwork.

\section{BIBLIOGRAPHY}

Bonaparte, J.F. 1986. History of the terrestrial Cretaceous vertebrates of Gondwana. $N$ Congr. Arg. Paleont. y Biostrat., Actas, Vol. 2, p.63-95.

- 1991a. Los vertebrados fósiles de la Formación Río Colorado, de la ciudad de Neuquén y cercanías, Cretácico Superior, Argentina. Rev. Mus. Arg. Cienc. Nat. "B. Rivadavia", Paleont, 4:17-123.

- 1991b. The Gondwanan theropod families Abelisauridae and Noasauridae. Hist. Biol, 5: 1-25.

- 1996. Cretaceous tetrapods of Argentina. Münch. Geowiss. Abh. (A) 30:73-130.

Bonaparte, J. F. \& F.E. Novas. 1985. Abelisaurus comahuensis, n. g., n. sp., Carnosauria del Cretacio tardio de Patagonia. Ameghiniana 21 (2-4): 259-265.

Bonaparte, J. F, F.E. Novas \& R.A. Coria. 1990. Carnotaurus sastrei Bonaparte, the horned, lightly built carnosaur from the Middle Cretaceous of Patagonia. Nat. Hist. Mus. Los Angeles Count., Contrib. Sci. 416:1-42.

Bonaparte, J. F. \& J.E. Powell. 1980. A continental assemblage of tetrapodsfrom the Upper Cretaceous beds of El Brete, north-western Argentina. Mém. Soc. Géol. France, 139: 19-28.

Carrano, M.T., S.D. Sampson \& C.A. Forster. 2002. The osteology of Masiakasaurus GSI Knopfleri, a small abelisauroid (Dinosauria: Theropoda) from the Late Cretaceous of Madagascar. Jour: Vert. Paleont. 22(3): $510-534$.

Chakravarti, D.K. 1935. Is Lametasaurus indicus an armored dinosaur? Am. Jour. Sci. 5 (30):138-142.

Chatterjee, S. 1978. Indosuchus and Indosaurus, Cretaceous carnosaurs from India. Jour of Paleont. $52(3): 570-580$.

Chatterjee, S. \& D. Rudra. 1996. KT events in India: impact, rifting, volcanism and dinosaur extinction. Mem. Queens. Mus. 39 (3): 489m532.

Coria, R. A. \& L. Salgado. 1998. A basal Abelisauria Novas, 1992 (Theropoda-Ceratosauria) from the Cretraceous of Patagonia, Argentina. GAIA 15: 89102.

Coria, R., L.M. Chiappe \& L. Dingus. 2002. A new close relative of Carnotaurus sastrei Bonaparte, 1985 (Theropoda: Abelisauridae) from the Late Cretaceous of Patagonia. Jour. Vert. Paleont. 22 (2): 460-465.

Currie, P.J. \& X.J. Zhao. 1993. A new carnosaur (Dinosauria, Theropoda) from the Jurassic of Xinjiang, People's Republic of China. Can. Jour.
Earth Sci. 30: 2037-2081.

Holtz, T.R. 2000. A new phylogeny of the carnivorous dinosaurs. GAIA 15: 5-61.

Huene, F. V. 1914. Das natürliche System der Saurischia. Zentr. für Min., Geol. Palaeont., B 1914: 154-158.

- 1920. Stammesgeschichtliche Ergebnisse einiger Untersuchungen an Trias-Reptilien. Zeits. für Induk. Abst. Vererbung. 24:159-163, Berlin.

- 1932. "Die fossile Reptile-Ordnung Saurischia, ihre Entwicklung und Geschichte». Monogr. Geol. Palaeont. 1. (4): 1-361.

- 1956. Paläontologie und Phylogenie der Niederen Tetrapoden. Fischer Jena: $1-716+$ suppl.

Huene, F. V. \& C.A.. Matley. 1933. The Cretaceous Saurischia and Ornithischia of the central provinces of India. Mem. Geol. Surv. India 21 (1):1-74, Delhi.

Kellner, A. W. A. \& D. A. Campos. 2002. On a theropod dinosaur (Abelisauria) from the continental Cretaceous of Brazil. Arq. Mus. Nac. Rio de Janeiro $60(3): 163-170$.

Lamanna, M. C., R.D. Martinez \& J.B. Smith. 2002. A definitive abelisaurid theropod dinosaur from the Early Late Cretaceous of Patagonia. Jour. Vert. Paleont. 22(1): 58-69.

Madsen, JH. 1976. Allosaurus fragilis: a revised osteology. Bull. Utah Geol. and Min. Surv. 109: 1163.

Madsen J.H. \& S.P. Welles. 2000. Ceratosaurus (Dinosauria, Theropoda). A revised osteaology. Utah Geol.l Surv., Misc. Publ., 00-2:1-80.

Martínez, R., O. Giménez, J. Rodríguez \& G. Bochatey. 1986. Xenotarsosaurus bonapartei gen. et. sp. nov. (Carnosauria, Abelisauridae), un nuevo Theropoda de la Formación Bajo Barreal, Chubut, Argentina. $4^{\circ}$ Congr. Arg. Paleont. y Bioestrat. Actas 2: 23-31.

Martinez, R., F. E. Novas, and A. Ambrosio. (in press). Abelisaurid remains (Theropoda, Ceratosauria) from southern Patagonia. Ameghiniana.

Matley, C. A. 1921. On the Stratigraphy, Fossils and Geological Relationships of the Lameta Beds of Jubbulpore. Rec. Geol. Surv. Ind., LIII: 142-164.

- 1923. Note on an armoured dinosaur from the Lameta beds of Jubbulpore. Rec. Geol Surv, India 55: 105 109 .

Molnar, R. E. 1990. Problematic Theropoda: "Carnosaurs": 306-317. In: Weishampel, D. B., P. Dodson \& H. Osmólska (eds.): The Dinosauria. Berkeley, University of California Press.

Molnar, R. E., S.M. Kurzanov \& Dong, Z. 1990. Carnosauria: 169-209. In: Weishampel, D. B., P. Dodson \& H. Osmólska (eds.): The Dinosauria. Berkeley, University of California Press.

Norman, D. B. 1990. Problematic Theropoda: "Coelurosaurs»; 280-305. In: Weishampel, D. B., P. Dodson \& H. Osmólska (eds.): The Dinosauria. Berkeley, University of California Press.

Novas, F. E. 1992. La evolución de los dinosaurios carnívoros: 125-163. In: J. L. Sanz y A. Buscalioni (eds.), Los dinosaurios y su entorno biótico. Actas $2^{\circ}$ Curso de Paleontología en Cuenca, Instituto "Juan de Valdés", Ayuntamiento de Cuenca, España.

- 1997. "Abelisauridae". In: P. Currie and K. Padian (eds.), Encyclopaedia of Dinosaurs, pp. 1-2. Academic Press. 
Novas, FE. \& S. Bandyopadhyay, 1999. New approaches on the Cretaceous theropods from India. Seventh International Symposium on Mesozoic Terrestrial Ecosystems (Buenos Aires), Abstract: 46-47.

- 2001. Abelisaurid pedal unguals from the Late Cretaceous of India. Asociación Paleontológica Argentina, Publ. Espec. 7: 145.149.

Sampson, S. D., L. M. Witmer, C.A. Forster, D.W. Krause, P.M. O'Connor, P. Dodson, \& F. Ravoavy. 1998. Predatory dinosaur remains from Madagascar: implications for the Cretaceous biogeography of Gondwana. Soience 280: 1048-1051.

Stovall, J.W. \& W.L. Langston. 1950. Acrocanthosaurus atokensis, a new genus and species of Lower Cretaceous Theropoda from Oklahoma. Am. Midl. Nat. 43:696-728

Sues, H.D. \& P Taquet. 1979. A pachycephalosaurid dinosaur from Madagascar and a LaurasiaGondwanaland connection in the Cretaceous. Nature 279: 633-635.
Romer, A. S. 1956. Osteology of the Reptiles. University of Chicago Press. p. 772.

Russel1, D.A. 1970. Tyrannosaurs from the Late Cretaceous of western Canada. Nat. Mus. Nat. Sci, Publ. Paleont. 1. 1.-34.

Valais, S. de, FE. Novas and S. Apesteguía. 2002. Morfología del pie de los terópodos abelisaurios: nuevas evidencias del Cretácico de Patagonia. Ameghiniana 39 (4) Supl. 9 R.

Walker, A. D. 1964. Triassic reptiles from the Elgin area: Ornithosuchus and the origin of carnosaurs. Phil. Trans. Royal Soc. London, 248 (744): 53-134.

Welles, S. P. 1884. Dilophosaurus wetherilli (Dinosauria, Theropoda). Osteology and comparisons. Palaeontographica A 185 (4-6): 85-180.

Wilson, J.A., P.C. Sereno, S. Srivastava, D.K. Bhatt, A. Khosla \& A. Sahni. 2003. A new abelisaurid (Dinosauria, Theropoda) from the Lameta Formaiton (Cretaceous, Maastrichtian) of India. Contrib. Mus. Paleont., Univ. Michigan 31(1): 1-42.

Appendix. List of theropod specimens described by Huene and Matley (1933), indicating current determination of bones and their respective taxonomic interpretation.

\begin{tabular}{|c|c|c|c|c|c|}
\hline $\begin{array}{c}\text { Taxa } \\
\text { (original } \\
\text { description) }\end{array}$ & $\begin{array}{c}\text { Collection } \\
\text { number }\end{array}$ & $\begin{array}{l}\text { Original } \\
\text { illustration }\end{array}$ & $\begin{array}{c}\text { Material } \\
\text { (original } \\
\text { interpretation) }\end{array}$ & $\begin{array}{c}\text { Taxonomic } \\
\text { intexpretation } \\
\text { (this paper) }\end{array}$ & $\begin{array}{c}\text { Current } \\
\text { determination } \\
\text { of bones }\end{array}$ \\
\hline $\begin{array}{l}\text { Indosuchus } \\
\text { raptorius }\end{array}$ & $\mathrm{K} 20 / 350$ & Pl. IX, fig. 1 & Skull-roof & Indosuchus raptorius & Skull-roof \\
\hline $\begin{array}{l}\text { Indosuchus } \\
\text { raptorius }\end{array}$ & $\mathrm{K} 27 / 685$ & Pl. IX, fig. 2 & Skull-roof & Indosuchus raptorius & Skull-roof \\
\hline $\begin{array}{l}\text { Indosaurus } \\
\text { matleyi }\end{array}$ & $\mathrm{K} 27 / 565$ & PI. IX, fig. 3 & Cast of braincavity & Indosaurus matleyi & Cast of braincavity \\
\hline $\begin{array}{l}\text { Indosaurus } \\
\text { matleyi }\end{array}$ & $\mathrm{K} 27 / 565$ & Pl. IX, fig. 4 & Middle part of skull & Indosaurus matleyi & Middle part of skull \\
\hline $\begin{array}{l}\text { Indosuchus } \\
\text { raptorius }\end{array}$ & $\mathrm{K} 27 / 690$ & None & Skull & Indosuchus raptorius & Skull \\
\hline $\begin{array}{l}\text { Indosuchus } \\
\text { raptorius }\end{array}$ & $\begin{array}{l}\text { AMNH } \\
1753\end{array}$ & None & Premaxilla & Abelisauridae indet. & Premaxilla \\
\hline $\begin{array}{l}\text { Indosuchus } \\
\text { raptorius }\end{array}$ & $\begin{array}{l}\text { AMNH } \\
1955\end{array}$ & None & Left maxilla & Abelisauridae indet. & Left maxilla \\
\hline $\begin{array}{l}\text { Indosuchus } \\
\text { raptoritus }\end{array}$ & $\begin{array}{l}\text { AMNH } \\
1960\end{array}$ & None & Right dentary & Abelisauridae indet. & Right dentary \\
\hline $\begin{array}{l}\text { Indosuchus } \\
\text { raptorius }\end{array}$ & $\begin{array}{l}\text { AMNH } \\
1960\end{array}$ & None & Caudal vertebra & Abelisauridae indet & Caudal vertebra \\
\hline $\begin{array}{l}\text { Indosuchus } \\
\text { raptorius }\end{array}$ & $\begin{array}{l}\text { AMNH } \\
1957\end{array}$ & None & Caudal vertebra & Abelisauroidea indet & Caudal vertebra \\
\hline $\begin{array}{l}\text { Indosuchus } \\
\text { raptorius }\end{array}$ & $\begin{array}{l}\text { AMNH } \\
1958\end{array}$ & None & Caudal vertebra & Abelisauroidea indet & Caudal vertebra \\
\hline $\begin{array}{l}\text { Indosuchus } \\
\text { raptorius }\end{array}$ & $\begin{array}{l}\text { AMNH } \\
\text { no number }\end{array}$ & None & Proximal caudal & Abelisauroidea indet & $\begin{array}{l}\text { Proximal caudal } \\
\text { vertebrae }\end{array}$ \\
\hline Allosaurid & $\mathrm{K} 27 / 548$ & Pl. X, fig. 2 & Right maxilla & Abelisauridae indet. & Right maxilla \\
\hline Allosaurid & $\mathrm{K} 27 / 628$ & Pl. X, fig. 3 & Basioccipital & Abelisauridae indet. & Basioccipital \\
\hline Allosaurid & $\mathrm{K} 27 / 577$ & P1. X, fig. 4 & "Lacrimal" & Abelisauridae indet. & Left jugal \\
\hline Allosaurid & $\mathrm{K} 20 / 619$ & Pl. XI, fig. 1 & Right premaxilla & Abelisauridae indet. & Premaxilla \\
\hline Allosaurid & $\mathrm{K} 27 / 710$ & PI. XI, fig. 2 & Left premaxilla & Abelisauridae indet. & Premaxilla \\
\hline
\end{tabular}


Allosaurid

Allosaurid

Allosaurid

Allosaurid

Allosaurid

Allosaurid

Allosaurid

Allosaurid

Allosaurid

Allosaurid

Allosaurid

Allosaurid

Allosaurid

Allosaurid

Allosaurid

Allosaurid

Allosaurid

Allosaurid

Allosaurid

Coelurosaurian

Carnosauria

Allosaurid

Allosaurid

Allosaurid

Allosaurid

Coelurosaurid

Allosaurid

Allosaurid

Allosaurid

Allosaurid

Allosaurid

Allosaurid

Allosaurid

Allosaurid

Allosaurid

Allosaurid

Allosaurid

Allosaurid

Allosautrid

Allosaurid

Allosaurid

Allosaurid

Allosaurid

Allosaurid

Allosaurid

Allosaurid

Allosaurid

Allosaturid

Allosaurid

Allosaurid

Allosaturid

Allosaurid

Allosaurid

Allosaurid

Allosaurid

Allosaurid

Allosaurid

Allosaurid

Allosaturid

Compsosuchus

solus
$\mathrm{K} 27 / 544$

K27/538

K27/688

$\mathrm{K} 27 / 708$

K27/687

K27/580

$\mathrm{K} 27 / 550$

K27/709

K27/693

K27/527

$\mathrm{K} 27 / 583$

$\mathrm{K} 27 / 583$

$\mathrm{K} 27 / 584$

K20/670

K20/670

K27/583

K27/585

K27/583

K27/583

K27/579

K27/598

K27/590

K27/572

K27/554

$\mathrm{K} 27 / 533$

$\mathrm{K} 27 / 571$

K27/596

$\mathrm{K} 27 / 530$

$\mathrm{K} 27 / 536$

K27/603

K27/617

K27/594

K27/672

K27/566

K27/676

K20/362

K27/674

$\mathrm{K} 27 / 680$

K27/686

K27/546

K27/569

K27/560

K27/570

K27/558

$\mathrm{K} 27 / 568$

$\mathrm{K} 27 / 620$

K27/684

K20/396

$\mathrm{K} 27 / 671$

$\mathrm{K} 27 / 658$

K27/539

K27/659

K27/654

K27/525

$\mathrm{K27/653}$

K27/635

K27/634

K27/537

$\mathrm{K} 27 / 524$

K27/578
Pl. XI, fig. 3

Pl. XI, fig. 4

PI. XI, fig. 5

Pl. XI, fig. 6

PI. XI, fig. 7

PI. XII, fig. 1

Pl. XII, fig. 2

Pl. XII, fig. 3

PI. XII, fig. 4

Pl. XIII, fig. 1

Pl. XIII, fig. 2

P1. XIII, fig. 3

Pl. XIII, fig. 4

Pl. XIIT, fig. 5

Pl. XIII, fig. 6

PI. XIII, fig. 7

PI. XIII, fig. 8

PI. XIII, fig. 9

PI. XIII, fig. 10

PI. XIII, fig.11

PI. XIV, fig. 1

Pl. XIV, f̌g. 2

Pl. XIV, fig. 3

Pl. XIV, fig. 4

PI.XXIII, fig. 1

Pl. XV, fig. 1

Pl. XV, fig. 2

PI. XV, fig. 3

PI. XV, fig. 4

PI. XV, fig. 5

PI. XV, fig. 6

PI. XVI, fig. 1

PI. XVI, fig. 2

PI. XVI, fig. 3

Pl. XVI, fig. 5

Pl. XVI, fig. 4

Pl. XVI, fig. 6

P1. XVI, fig. 7

P1. XVI, fig. 6

PI. XVI, fig. 9

PI. XVI, fig. 10

PI. XVII, fig.1

Pl. XVII, fig.2

Pl. XVIII, fig.2

P1. XVII, fig.3

Pl. XIX, fig. 1

P1. XIX, fig. 2

Pl. XIX, fig. 3

PI. XIX, fig. 4

PI. XIX, fig. 5

PI. XIX, fig. 6

PI. XIX, fig. 7

Pl. XIX, fig. 8

Pl. XIX, fig. 9 Foot phalanx

Pl. XIX, fig. 10

P1. XIX, fig. 11

Pl. XIX, fig. 12

PI. XIX, fig. 13

PI. XX, fig. 1

Right fermur
Right maxilla

Left maxilla

"Transverse bone"

"Right Lacrimal"

Basioccipital

Right Postorbital

Right Dental

Right Dental

Left Articular

Left Articular

Tooth

Tooth

Tooth

Tooth

Tooth

Tooth

Tooth

Tooth

Tooth

Tooth

Dorsal vertebra

Cervical vertebra

Cervical vertebra

Sacral vertebra

Sacral vertebra

Sacral vertebra

Caudal vertebra

Caudal vertebra

Caudal vertebra

Caudal vertebra

Caudal ventebra

Caudal vertebra

Hemal arches

Hemal arches

Hemal arches

Hemal arches

Hemal arches

Hemal arches

Left ischium

Left ischium

Right femur

Left femur

Right femur

Right tibia

Left fibula

Right astragalus

Calcanetum

Right Mtt 2

Left Mtt 3

Right Mtt 4

Right Mtt 4

Phalanx digit 1

Foot phalanx

Claw of foot

Claw of foot

Claw of foot

Claw of foot

1,2 cervical

vertebrae

Abelisauridae indet.

Abelisauridae indet.

Abelisauridae indet

Abelisauridae indet.

Abelisauridae indet.

Abelisauridae indet.

Abelisauridae indet.

Abelisauridae indet.

Abelisauridae indet.

Abelisauridae indet.

Indet.

Indet.

Indet.

Indet.

Indet.

Indet.

Indet.

Indet.

Indet.

Indet.

Abelisauridae indet.

Abelisauridae indet.

Theropoda indet.

Abelisauridae indet.

Abelisauridae indet.

Abelisauroidea

Abelisauridae indet.

Abelisauridae indet.

Abelisauridae indet.

Abelisauridae indet.

Abelisauridae indet.

Abelisauridae indet.

Abelisauridae indet,

Abelisauridae indet.

Abelisauridae indet.

Abelisauridae indet.

Abelisauridae indet.

Abelisauridae indet.

Abelisauridae indet.

Abelisauridae indet.

Abelisauridae indet.

Abelisauridae indet.

Abelisauridae indet.

Abelisauridae indet.

Abelisauridae indet.

Abelisauridae indet.

Abelisauridae indet

Indet. 


\begin{tabular}{|c|c|c|c|c|c|}
\hline $\begin{array}{l}\text { Laevisuchus } \\
\text { indicus }\end{array}$ & $\mathrm{K} 20 / 613$ & Pl. XX, fig. 2 & Cervical vertebra & Noasauridae & Cervical vertebra \\
\hline $\begin{array}{l}\text { Laevisuchus } \\
\text { indicus }\end{array}$ & $\mathrm{K} 27 / 696$ & Pl. XX, fig. 3 & Cervical vertebra & Noasauridae & Cervical vertebra \\
\hline $\begin{array}{l}\text { Laevisuchus } \\
\text { indicus }\end{array}$ & $\mathrm{K} 20 / 614$ & PI. XX, fig. 4 & Cervical vertebra & Noasauridae & Cervical vertebra \\
\hline $\begin{array}{l}\text { Laevisuchus } \\
\text { indicus }\end{array}$ & $\mathrm{K} 27 / 588$ & Pl. XX, fig. 5 & Dorsal vertebra & Noasauridae & Dorsal vertebra \\
\hline $\begin{array}{l}\text { Jubbulpuria } \\
\text { tenuis }\end{array}$ & $\mathrm{K} 20 / 612$ & Pl. XX, fig. 6 & Dorsal vertebra & Abelisauroidea & Caudal vertebra \\
\hline $\begin{array}{l}\text { Jubbulpuria } \\
\text { tenuis }\end{array}$ & $\mathrm{K} 27 / 614$ & Pl. XX, fig. 7 & Dorsal vertebra & Abelisauroidea & Caudal vertebra \\
\hline $\begin{array}{l}\text { Omithomimoi- } \\
\text { des mobilis }\end{array}$ & $\mathrm{K} 27 / 600$ & P1. XX, fig. 8 & Dorsal vertebra & Abelisauroidea & Caudal vertebra \\
\hline $\begin{array}{l}\text { Ornithomimoi } \\
\text { des mobilis }\end{array}$ & $\mathrm{K} 20 / 610$ & PI. XX, fig. 9 & Dorsal vertebra & Abelisauroidea & Caudal vertebra \\
\hline $\begin{array}{l}\text { Ornithomimoi- } \\
\text { des mobilis }\end{array}$ & $\begin{array}{l}\mathrm{K} 20 / 614 \\
\mathrm{~B}\end{array}$ & Pl. XX, fig. 10 & Dorsal vertebra & Abelisauroidea & Caudal vertebra \\
\hline Coelurosaurian & $\mathrm{K} 27 / 703$ & Pl. XX, fig. 11 & Tooth & Indet. & Tooth \\
\hline $\begin{array}{l}\text { Ornithomimoides? } \\
\text { barasimlensis }\end{array}$ & $\mathrm{K} 27 / 541$ & Pl. XXI, fig. 1 & Dorsal vertebra & Abelisauroidea & Caudal vertebra \\
\hline $\begin{array}{l}\text { Ornithomimoides? } \\
\text { barasimlensis }\end{array}$ & $\mathrm{K} 27 / 531$ & Pl. XXI, fig. 2 & Dorsal vertebra & Abelisauroidea & Caudal vertebra \\
\hline $\begin{array}{l}\text { Ornithomimoides? } \\
\text { barasimlensis }\end{array}$ & $\mathrm{K} 27 / 604$ & Pl. XXI, fig. 3 & Dorsal vertebra & Abelisauroidea & Caudal vertebra \\
\hline $\begin{array}{l}\text { Ornithomimoides? } \\
\text { barasimlensis }\end{array}$ & K27/682 & None & Dorsal vertebra & Abelisauroidea & Caudal vertebra \\
\hline $\begin{array}{l}\text { Coeluroides } \\
\text { largus }\end{array}$ & $\mathrm{K} 27 / 574$ & PI. XXI, fig. 4 & Dorsal vertebra & Abelisauroidea & Caudal vertebra \\
\hline $\begin{array}{l}\text { Coeluroides } \\
\text { largus }\end{array}$ & $\mathrm{K} 27 / 595$ & Pl. XXI, fig. 5 & Dorsal vertebra & Abelisauroidea & Caudal vertebra \\
\hline $\begin{array}{l}\text { Coeluroides } \\
\text { largus }\end{array}$ & $\mathrm{K} 27 / 562$ & Pl. XXI, fig. 6 & Dorsal vertebra & Abelisauroidea & Caudal vertebra \\
\hline $\begin{array}{l}\text { Dryptosauroi } \\
\text { des grandis }\end{array}$ & $\mathrm{K} 20 / 334$ & P1. XXIl, fig. 1 & Dorsal vertebra & Abelisauroidea & Caudal vertebra \\
\hline $\begin{array}{l}\text { Dryptosauroi } \\
\text { des grandis }\end{array}$ & $\mathrm{K} 20 / 609$ & PI. XXII, fig. 2 & Dorsal vertebra & Abelisauroidea & Caudal vertebra \\
\hline $\begin{array}{l}\text { Dryptosauroi } \\
\text { des grandis }\end{array}$ & $\mathrm{K} 27 / 549$ & Pl. XXII, fig. 3 & Dorsal vertebra & Abelisauroidea & Caudal vertebra \\
\hline $\begin{array}{l}\text { Dryptosauroides } \\
\text { grandis. }\end{array}$ & $\mathrm{K} 27 / 601$ & Pl. XXII, fig. 4 & Dorsal vertebra & Abelisauroidea & Caudal vertebra \\
\hline Coelurosaurid & $\mathrm{K} 27 / 571$ & Pl. X & $\mathrm{Sac}$ & Abelisauridae & Sacral vertebra \\
\hline Coelurosaurid & $\mathrm{K} 27 / 532$ & P1. XXIII, fig.2 & Caudal vertebra & Abelisauridae & Caudal vertebra \\
\hline Coelurosaturid & $\mathrm{K} 27 / 589$ & PI. XXIII, fig. 3 & Caudal vertebra & Abe & rtebra \\
\hline Coelurosaurid & $\mathrm{K} 27 / 599$ & PI. XXIII, fig.4 & Caudal vertebra & Abelisauroidea & Caudal vertebra \\
\hline Coelurosaurid & $\mathrm{K} 27 / 587$ & Pl. XXIII, fig.5 & Caudal vertebra & Abelisauroidea & Caudal vertebra \\
\hline Coelurosaurid & $\mathrm{K} 27 / 559$ & P1. XXII, fig. 6 & Right ilium & Indet. & Indet. \\
\hline Coelurosaurid & $\mathrm{K} 27 / 526$ & Pl. XXIII, fig.7 & Right tibia & Indet. & Indet. \\
\hline Coelurosaurid & $\mathrm{K} 27 / 669$ & Pl. XXIV, fig.1 & Distal tibia & Indet. & Indet. \\
\hline Coelurosaurid & $\mathrm{K} 27 / 665$ & Pl. XXIV, fig, 2 & Metatarsal III & Abelisauroidea indet. & Metata \\
\hline Coelurosaurid & $\begin{array}{l}\mathrm{K} 27 / 697+ \\
\mathrm{K} 27 / 681\end{array}$ & Pl. XXIV, fig.3 & Metatarsal II & Abelisaudoidea indet. & Metatarsal III \\
\hline Coelurosaurid & $\mathrm{K} 27 / 666$ & PI. XXIV, fig.4 & Distal metacarpal & Abelisauroidea indet. & Distal metatarsal IV \\
\hline Coelurosaurid & $\mathrm{K} 27 / 667$ & P1. XXIV, fig.5 & Distal metacarpal & Abelisauroidea indet. & Distal metatarsal II \\
\hline Coelurosaurid & $\mathrm{K} 20 / 337 \mathrm{C}$ & Pl. XXIV, fig.6 & Metatarsal I & Abelisauroidea indet. & Distal metatarsal IV \\
\hline Coelurosaurid & $\mathrm{K} 20 / 626 \mathrm{~B}$ & Pl. XXIV, fig.7 & $\begin{array}{l}\text { First manual } \\
\text { phalanx }\end{array}$ & Abelisauroidea indet. & $\begin{array}{l}\text { Pedal phalanx } 1 \\
\text { digit } X V\end{array}$ \\
\hline Coelure & K27/657 & Pl. XXIV, fig. 8 & Phalanx & Indet. & Phalanx \\
\hline Coelurosaurid & $\mathrm{K} 27 / 637$ & Pl. XXIV, fig.9 & Phalanx foot IV toe & Abelisauroidea indet. & $\begin{array}{l}\text { Pedal phalanx } 4 \text { of } \\
\text { digit IV }\end{array}$ \\
\hline Coelurosaurid & $\mathrm{K} 27 / 638$ & PI. XXIV, fig.10 & Phalanx & Abelisauroidea indet. & $\begin{array}{l}\text { Pedal phalanx } 3 \text { of } \\
\text { digit IV }\end{array}$ \\
\hline Coelurosaurid & $\mathrm{K} 27 / 645$ & Pl. XXIV, fig. 11 & Phalanx & Indet. & Indet. \\
\hline
\end{tabular}




\begin{tabular}{|c|c|c|c|c|c|}
\hline Coelurosaurid & $\mathrm{K} 27 / 642$ & Pl. XXIV, fig. 12 & Manual phalanx & Abelisauroidea indet. & $\begin{array}{l}\text { Pedal phalanx } 1 \text { of } \\
\text { digit IV }\end{array}$ \\
\hline Coelurosaurid & $\mathrm{K} 27 / 648$ & Pl. XXIV, fig.13 & Manual phalanx & Abelisauroidea indet. & $\begin{array}{l}\text { Pedal phalanx } 3 \text { of } \\
\text { digit IV }\end{array}$ \\
\hline Coelurosaurid & $\mathrm{K} 27 / 646$ & Pl. XXIV, fig.14 & Phalanx of digit IV & Abelisauridoidea indet. & $\begin{array}{l}\text { Pedal phalanx } 1 \text { ? of } \\
\text { digit III }\end{array}$ \\
\hline Coelurósaurid & $\mathrm{K} 27 / 647$ & PI. XXIV, fig.15 & Phalanx of digit IV & Abelisauroidea indet. & $\begin{array}{l}\text { Pedal phalanx } 4 \text { of } \\
\text { digit IV }\end{array}$ \\
\hline Coelurosaurid & $\mathrm{K} 20 / 337 \mathrm{~B}$ & P1. XXIV, fig.16 & Phalanx & Abelisauroidea indet. & $\begin{array}{l}\text { Pedal phalan } \times 2 \text { ? of } \\
\text { digit II }\end{array}$ \\
\hline Coelurosaurid & $\mathrm{K} 27 / 524$ & Pl. XXIV, fig. 17 & Phalanx & Abelisauroidea indet. & $\begin{array}{l}\text { Pedal phalanx } 1 \text { of } \\
\text { digit II }\end{array}$ \\
\hline Coelurosatrid & $\mathrm{K} 27 / 644$ & PI. XXIV, fig. 18 & Phalanx & Abelisauroidea indet. & $\begin{array}{l}\text { Pedal phalanx } 2 \text { of } \\
\text { digit III, }\end{array}$ \\
\hline Coelurosaurid & $\mathrm{K} 27 / 632$ & Pl. XXIV, fig:19 & $\begin{array}{l}\text { Pedal ungual } \\
\text { phalanx }\end{array}$ & Abelisauroidea indet. & $\begin{array}{l}\text { Pedal ungual } \\
\text { phalanx }\end{array}$ \\
\hline Coelurosaurid & $\mathrm{K} 27 / 629$ & Pl. XXrV, fig. 20 & $\begin{array}{l}\text { Pedal ungual } \\
\text { phalanx }\end{array}$ & Abelisauroidea indet. & $\begin{array}{l}\text { Pedal ungual } \\
\text { phalanx }\end{array}$ \\
\hline Coelurosaurid & $\mathrm{K} 20 / 626$ & PI. XXIV, fig.7. & $\begin{array}{l}\text { Coelurosaurian } \\
\text { manual phalanx }\end{array}$ & Abelisauroidea indet. & $\begin{array}{l}\text { Pedal phalanx } 1 \text { of } \\
\text { digit IV }\end{array}$ \\
\hline
\end{tabular}

